\title{
Summary of California DSM Impact Evaluation Studies
}

\author{
Marilyn A. Brown \\ Oak Ridge National Laboratory \\ and \\ Philip E. Mihlmester \\ Aspen Systems Corporation
}

October 1994

\author{
Sponsored by \\ California DSM Measurement Advisory Committee (CADMAC) \\ c/o Peter Miller \\ Natural Resources Defense Council \\ 71 Stevenson Street, Suite 1825 \\ San Francisco, CA 94105 \\ and \\ Office of Energy Efficiency and Renewable Energy \\ U.S. Department of Energy
}

Prepared by the

Oak Ridge National Laboratory

Oak Ridge, Tennessee 37831

Managed by Martin Marietta Energy Systems, Inc.

for the U.S. Department of Energy

Under Contract No. DE-AC05-84OR21400 



\section{DISCLAIMER}

This report was prepared as an account of work sponsored by an agency of the United States Government. Neither the United States Government nor any agency thereof, nor any of their employees, make any warranty, express or implied, or assumes any legal liability or responsibility for the accuracy, completeness, or usefuiness of any information, apparatus, product, or process disclosed, or represents that its use would not infringe privately owned rights. Reference herein to any specific commercial product, process, or service by trade name, trademark, manufacturer, or otherwise does not necessarily constitute or imply its endorsement, recommendation, or favoring by the United States Government or any agency thereof. The views and opinions of authors expressed herein do not necessarily state or reflect those of the United States Government or any agency thereof. 


\section{DISCLAIMER}

Portions of this document may be illegible in electronic image products. Images are produced from the best available original document. 


\section{TABLE OF CONTENTS}

LIST OF FIGURES............................................................................................................................. v

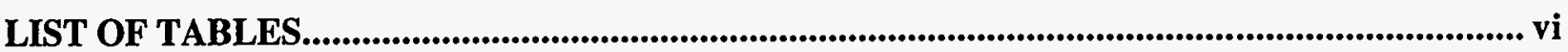

EXECUTIVE SUMMARY .................................................................................................................. vii

ABSTRACT .................................................................................................................................. xiii

ACKNOWLEDGMENTS .................................................................................................................. xiv

1. INTRODUCTION ............................................................................................................. 1

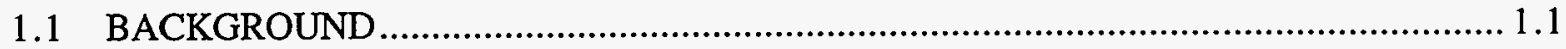

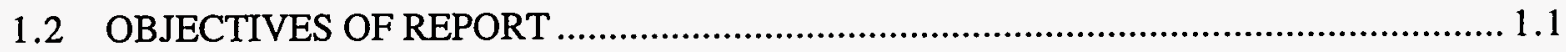

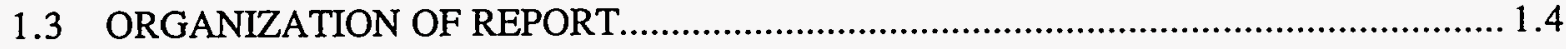

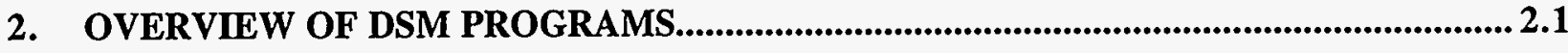

2.1 OVERVIEW OF UTIITIES AND THEIR DSM EXPENDITURES ............................... 2.1

2.2 DSM EXPENDITURES BY SECTOR AND PROGRAM TYPE ...................................... 2.3

2.3 OVERVIEW OF PROGRAM PARTICIPATION LEVELS............................................ 2.5

2.4 INSTALLATION LEVELS FOR SELECTED MEASURES …………........................... 2.9

3. SUMMARY OF EX-POST PROGRAM IMPACT ESTIMATES

3.1 INTRODUCTION

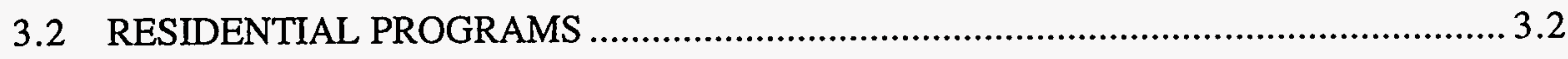

3.3 COMMERCIAL, INDUSTRIAL, AND AGRICULTURAL PROGRAMS ........................ 3.5

4. SUMMARY OF EX-POST PROGRAM IMPACT ESTIMATES

FOR SELECTED MEASURES ................................................................................................ 4.1

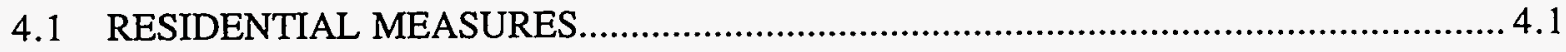

4.2 COMMERCIAL, INDUSTRIAL, AND AGRICULTURAL MEASURES ........................ 4.3

5. COMPARISON OF EX-POST AND EX-ANTE IMPACT ESTIMATES ...............................5.1

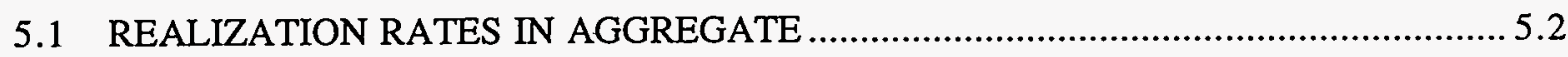

5.2 REALIZATION RATES BY SECTOR ................................................................ 5.4

5.3 REALIZATION RATES BY PROGRAM TYPE ……............................................... 5.8

5.4 REALIZATION RATES OF DIFFERENT EVALUATION METHODS ...........................5.9

5.5 REALIZATION RATES FOR SELECTED MEASURES.............................................. 5.10

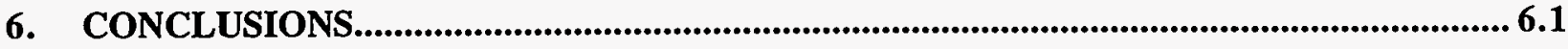

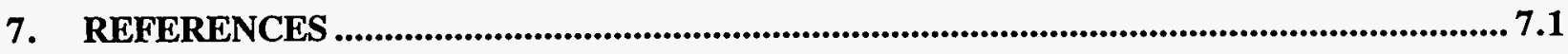

APPENDIX A - BIBLIOGRAPHY ……....................................................................................... A.1

APPENDIX B - OVERVIEW OF EVALUATION METHODOLOGIES ......................................... B.1

APPENDIX C - DETAILED EVALUATION TABLES ....................................................................... 
$\ldots, \cdots, \ldots$ 


\section{LIST OF FIGURES}

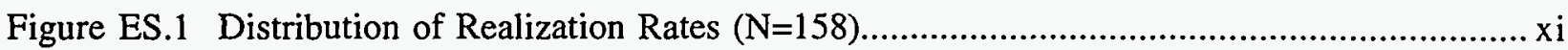

Figure 2.1 Total Energy-Efficiency/Conservation Expenditures

(in Millions of Dollars): 1990-92

Figure 2.2 Total Energy-Efficiency/Conservation Expenditures

(in Millions of Dollars): 1990-92

Figure 2.3 Total Energy-Efficiency/Conservation Expenditures by Program Type

(in Millions of Dollars): 1990-92...

Figure 2.4 Total Energy-Efficiency/Conservation Expenditures by Utility

(in Millions of Dollars): 1990-92

Figure 2.5 Annual Number of Participants in Residential Programs

Covered by Evaluation Studies....

Figure 2.6 Annual Number of Participants in C/I/A Programs Covered by Evaluation Studies..... 2.8

Figure 2.7 Number of Compact Fluorescent Lamps Distributed for

Programs Covered by Evaluation Studies

Figure 2.8 Number of Low-Flow Showerheads Distributed Under

Programs Covered by Evaluation Studies

Figure 2.9 Number of Refrigerator Replacements Under Programs Covered

by Evaluation Studies.

Figure 3.1 Summary of Residential Program Level mWh Savings

Reported in Nine Evaluation Studies

Figure 3.2 Summary of Residential Program Level mWh Savings By End-Use Category

Reported in Nine Evaluation Studies (Excludes New Construction)

Figure 3.3 Summary of Residential Program Level Gas Savings

Reported in Nine Evaluation Studies

Figure 3.4 Summary of Program-Level Non-Residential mWh Savings

Reported in Seven Evaluation Studies.

Figure 3.5 Summary of Program-Level Non-Residential MW Savings

Reported in Six Evaluation Studies.

Figure 4.1 Savings Reported per Refrigerator Replaced................................................... 4.2

Figure 4.2 Savings Reported per Residential CFLB ........................................................ 4.2

Figure 4.3 Annual kWh Savings Reported by C/I/A Measure Class....................................... 4.3

Figure $4.4 \mathrm{~kW}$ Savings Reported by C/I/A Measure Class...................................................... 4.3

Figure 4.5 Annual Gas Savings Reported by C/I/A Measure Class (Therms)........................... 4.4

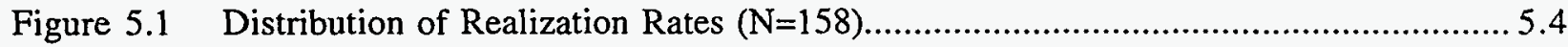

Figure 5.2 Realization Rates for all Residential Programs .................................................... 5.6

Figure 5.3 Realization Rates for all C/I/A Programs ................................................... 5.7 


\section{LIST OF TABLES}

Table ES.1 Summary of Realization Rates by Sector and Program Type.................................. xiii

Table 1.1 Impact Evaluation Studies Summarized in This Report ........................................... 1.2

Table 2.1 DSM Conservation Expenditures as a Percent of Operating Revenues ....................... 2.2

Table 3.1 Summary of Reported Program-Level Savings....................................................... 3.7

Table $5.1 \quad$ Realization Rates by Utility ............................................................................ 5.2

Table 5.2 Mean and Median Realization Rates by Sector ................................................. 5.5

Table 5.3 Realization Rates by Type of Program........................................................... 5.8

Table 5.4 Realization Rates for Seven Evaluation Methods ............................................. 5.9

Table 5.5 Realization Rates by Selected Measure......................................................... 5.10

Table 5.6 Realization Rates for Compact Fluorescent Lamps .............................................. 5.11

Table 5.7 Analysis of Realization Rates for Low-Flow Showerheads ................................ 5.13

Table 5.8 Analysis of Realization Rates for Refrigerator Replacements ............................... 5.14

Table C.1 Numbers of Participants in Residential Programs .....................................................

Table C.2 Numbers of Participants in C/I/A Programs ............................................................

Table C.3 Residential Program Level mWh Savings.............................................................

Table C.4 Residential Program Level Kilotherm Savings.....................................................5

Table C.5 Non-Residential Program Level mWh and MW Savings...........................................5

Table C.6 Non-Residential Program Level Kilotherm Savings..................................................5

Table C.7 Savings per Residential Refrigerator Replaced................................................. 6

Table C.8 Savings per Residential Compact Fluorescent Bulb.............................................. 6

Table C.9 Electrical Savings for Selected Non-Residential Measures .......................................6.

Table C.10 Gas Savings for Selected Non-Residential Measures...............................................7

Table C.11 Realization Rates for all Residential Programs....................................................

Table C.12 Realization Rates for all C/I/A Programs ........................................................ 10 


\section{EXECUTIVE SUMMARY}

Over the past several years, four of the largest California utilities have completed more than 50 evaluation studies designed to measure the energy and demand impacts of their demand-side management (DSM) programs. The four utilities include: Pacific Gas and Electric Company (PG\&E), San Diego Gas and Electric Company (SDG\&E), Southern California Edison (SCE), and Southern California Gas Company (SoCalGas). These utilities, along with eight additional organizations, comprise the California Demand Side Management Measurement Advisory Committee (CADMAC) which was established by the California Public Utilities Commission to oversee the DSM measurement and evaluation activities of these utilities. ${ }^{1}$

The objective of this report is to summarize the results of these DSM evaluation studies in order to describe what DSM has achieved in California, to assess how well these achievements were forecast, and to compare the effectiveness of different types of DSM programs. The CADMAC supported the analysis and the U.S. Department of Energy funded publication of the report.

The studies reviewed for this report represent a major, multi-million dollar undertaking by the four utilities. While the depth and rigor of these evaluations varied tremendously, the studies generally involved state-of-the-art evaluation methods and extensive data collection and analysis. Many of the study reports were multi-volume, with separate sub-studies focusing on particular issues, such as net-to-gross analysis and the validity of various engineering assumptions. In some cases, multiple methodologies were employed to converge on the savings estimates. Overall, the effort expended to evaluate these programs will pay dividends in California and throughout the nation, in terms of advances in evaluation methods and lessons learned about the performance of a wide array of DSM activities.

This report documents the sizable investment made by the California utilities in their 1990-92 DSM programs. Between 1990 and 1992, the four utilities spent $\$ 772$ million on energyefficiency/conservation programs. ${ }^{2}$ The utilities operated two types of programs: (1) resource programs that typically earn the utilities financial incentives based on the savings achieved, and (2) equity/services programs that generally are operated for performance-adder incentives. Resource programs are intended to provide a reliable, cost-effective alternative to supply-side resources. They include a variety of retrofit incentive and new construction programs. Equity/services programs are

1 The remaining members of CADMAC are the California Manufacturers Association, Toward Utility Rate Normalization, California Energy Commission, Natural Resources Defense Council, California Institute for Energy Efficiency, California Public Utilities Commission, National Association of Energy Service Companies, and Residential Energy Services Companies' United Effort.

2 In addition, the four utilities spent $\$ 114$ million on measurement and evaluation activities between 1990 and 1992 and earned shareholder incentives of $\$ 156$ million, neither of which are reflected in the above total. The four utilities also spent additional funds on information, load management, load retention, and load building programs which are not reflected in the above total. 
implemented for equity or educational purposes. They include residential direct assistance programs for low-income households, which are viewed as equity programs, and programs that provide energy management services such as energy audits, for which savings are difficult to estimate. Between 1990 and 1992 , the four utilities spent $51 \%$ of their DSM expenditures on resource programs and $49 \%$ on equity/services programs.

Each utility had a unique profile of investments in different types of programs, with SDG\&E investing the greatest share $(73 \%)$ of its total DSM expenditures in resource programs. In contrast, PG\&E and SCE spent a large proportion of their total DSM budgets delivering energy management services. Another profile is provided by SoCalGas, which dedicated $47 \%$ of its total DSM expenditures to residential direct assistance programs. Altogether, the programs described in the 50 impact studies served more than 800,000 participants annually between 1990 and 1992 . Thus, an impressive number of customers (approximately 2,400,000) benefited from California's DSM programs over the three-year study period.

Based on the measure penetration rates itemized in these impact studies, the four California utilities have had a significant impact on the purchase and installation of energy-efficient equipment and materials in the State. Undoubtedly this has been responsible for generating region-wide consumer demand for DSM products and for strengthening the wholesale and retail infrastructures that promote their distribution beyond the immediate participants in DSM programs. Few of the 50 impact evaluations reviewed in this report attempted to quantify these market transformation benefits.

The evaluation studies summarized in this report do not address the total impacts of all DSM programs implemented during the 1990-92 period, but only those specific programs and years actually addressed by the studies. Therefore, the estimates of DSM participants, measures installed, and savings compiled in this report are substantially less than the total achievements of the four utilities in all years.

Compiling the total savings estimates reported by the individual evaluation studies was complicated by the significant variation in the way savings were estimated and reported across the studies. Specifically, the reported savings:

- varied by time frame

- were aggregated at many different levels

- varied by unit of measurement

- resulted from a variety of estimation and evaluation methodologies.

For these reasons, it was difficult to summarize total savings across all of the evaluation studies. 
This report also summarizes realization rates from the evaluation studies reviewed. Realization rates are defined as ex-post net savings estimates divided by ex-ante net savings estimates where both estimates have been adjusted for free-ridership. ${ }^{3}$ Ex-ante savings estimates are preliminary estimates of program impacts developed by the utilities and based usually on engineering calculations. Ex-post savings estimates are based on formal post-implementation evaluation studies. Realization rates are summarized for 158 programs and program segments.

The distribution of realization rates is shown in Figure ES.1. The median realization rate for all 158 programs and program segments is 0.86 and the mean is 1.12 . Four realization rates (ranging from 5.59 to 14.54) were found to be more than 3 standard deviations above the mean. (No values were more than 3 standard deviations below the mean.) Removal of these four outliers results in the same median of 0.86 but reduces the mean to 0.93 . Overall, these results suggest that the forecasts of energy savings were reasonably accurate, and that most of the DSM programs were cost-effective since they generally were designed to produce benefit-cost ratios of at least 1.2. Further, these results suggest that the California DSM programs operating between 1990 and 1992 have outperformed typical programs from the 1980 's, which often fell short of their expected savings by $30 \%$ to $70 \%$

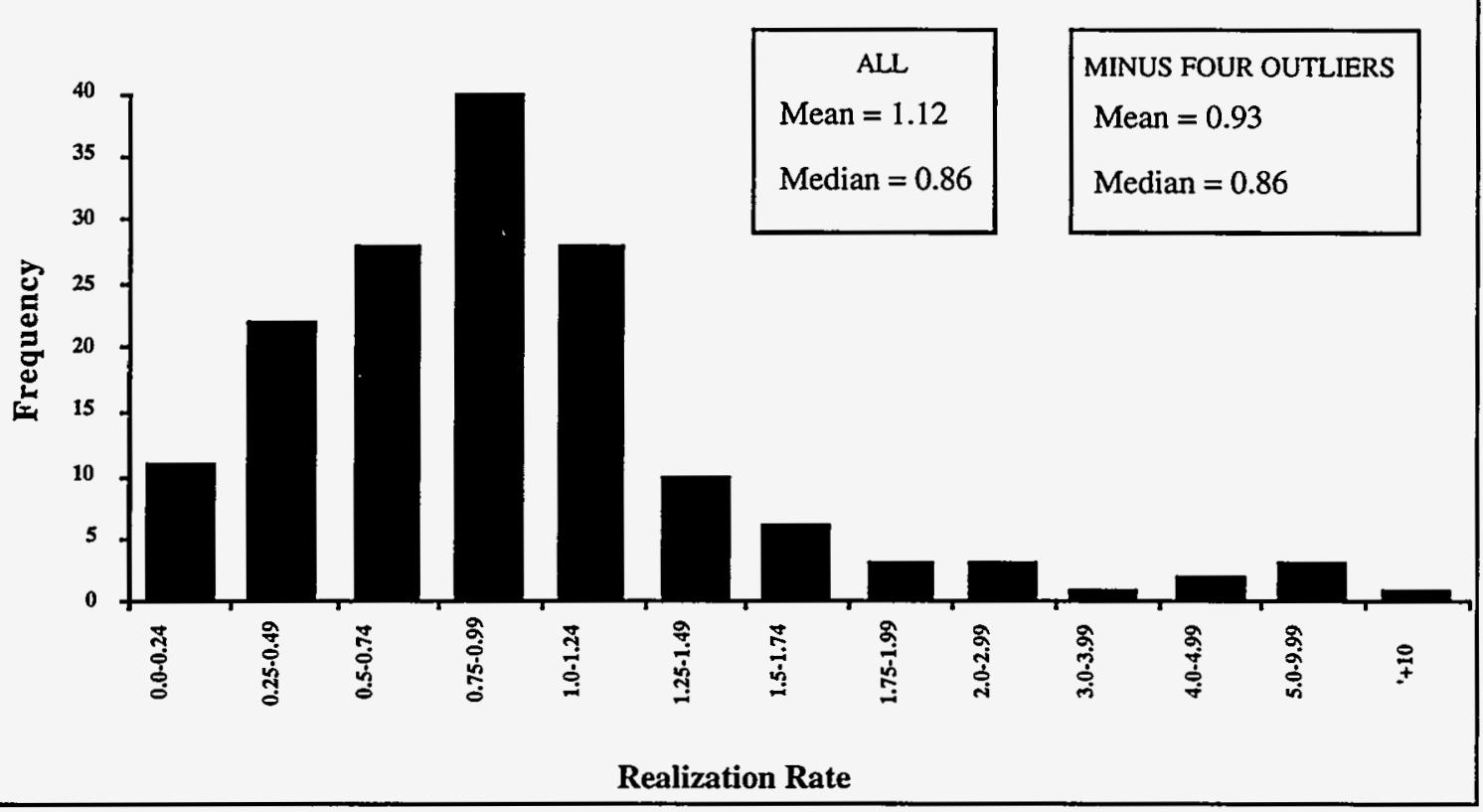

Figure ES.1 Distribution of Realization Rates $(\mathbf{N}=158)$

3 In some cases the numerator is an ex-post estimate of gross savings because the impact study did not present net savings or assumed a net-to-gross ratio of $100 \%$. The ex-ante savings estimates are assumed to be net savings (unless explicitly noted in the studies). However, limited documentation was provided on the calculation of the ex-ante savings estimates. Thus, it cannot be stated with certainty which realization rates are net and which are gross. 
(Hirst, et al., 1989; Sebold and Fox, 1985; Brown and White, 1992). However, it was not possible to discern how much the improved performance resulted from greater actual energy savings versus improved forecasting (i.e., ex-ante estimation of savings).

In general, commercial, industrial, and agricultural (C/I/A) realization rates were higher than residential realization rates. The mean realization rate for all $\mathrm{C} / \mathrm{A}$ programs and program segments is 1.26. Removal of the four highest realization rates (which are all C///A) reduces this mean to 0.96 . The mean realization rate for all residential programs and program segments is 0.88 .

The realization rates presented in this report are unweighted. That is, each program or program segment realization rate (total of 158 ) has the same weight in the calculation of means. If the realization rates were weighted by energy savings, the mean would be expected to be greater. This is because the $\mathrm{C} / \mathrm{T} / \mathrm{A}$ programs have higher realization rates and tend to have higher savings than the residential programs, yet in the unweighted calculation all are counted equally. Thus, the overall mean of 1.12 ( 0.93 without the four highest outliers) could be viewed as a conservative calculation of the ratio of actual savings to anticipated savings.

The difference between the mean and median values reflects the skewed distribution of realization rates. Nearly one quarter $(22 \%)$ of the programs delivered less than $50 \%$ of their ex-ante savings estimates, while $10 \%$ exceeded $150 \%$ of their ex-ante savings estimates. The implementation of initiatives to narrow the range of realization rates should be a major thrust of resource planners and program managers in the four California utilities. The impact of different ex-ante estimation procedures warrants further examination in this regard. The ex-ante estimates of savings for similar DSM measures across utilities and across programs in the same utility were found to be wide ranging and a possible source of systematic bias in the realization rates. In particular, higher-than-average exante estimates of savings for a particular measure generally were associated with lower-than-average realization rates.

Table ES.1 reports mean and median realization rates by sector and by program type. The means, particularly in the C/I/A retrofit incentive area, are affected by a few very high observations (See Figure ES.1). Some studies reported several savings estimates (e.g., by market segment or measure type), rather than an overall program value. Hence, some studies had a greater influence on the statistics reported in Table ES.1 than other studies, because they contributed several realization rate observations.

By comparing the realization rates reported in the various impact studies, it is possible to suggest features of the DSM programs, the ex-ante estimates of savings, and the evaluation methods that may cause realization rates to vary. In the residential sector, higher realization rates were associated with retrofit incentive programs, calibrated engineering models, relatively low ex-ante 
Table ES.1 Summary of Realization Rates by Sector and Program Type

\begin{tabular}{|c|c|c|c|}
\hline & Mean & Median & $\begin{array}{l}\text { Number of } \\
\text { Programs or } \\
\text { Segments }\end{array}$ \\
\hline TOTAL & 1.12 & 0.86 & 158 \\
\hline \multicolumn{4}{|l|}{ Sector: } \\
\hline Residential & 0.88 & 0.69 & 60 \\
\hline Commercial/Industrial/Agricultural (C/VA) & $1.26 *$ & 0.91 & 98 \\
\hline \multicolumn{4}{|l|}{ Resource Programs: } \\
\hline TOTAL & 1.36 & 0.86 & 83 \\
\hline Residential retrofit incentives & 1.18 & 1.06 & 17 \\
\hline C/I/A retrofit incentives & 1.54 & 0.91 & 52 \\
\hline Residential new construction & 0.78 & 0.70 & 8 \\
\hline C/L/A new construction & 1.16 & 0.66 & 6 \\
\hline \multicolumn{4}{|l|}{ Equity/Services Programs: } \\
\hline TOTAL & 0.85 & 0.86 & 75 \\
\hline Residential direct assistance & 0.68 & 0.53 & 26 \\
\hline Residential energy management services & 1.00 & 0.59 & 9 \\
\hline $\mathrm{C} / \mathrm{J} / \mathrm{A}$ energy management services & 0.92 & 0.95 & 40 \\
\hline
\end{tabular}

* This mean becomes 0.96 if the four highest realization rates (ranging from 5.59 to 14.54) are removed from the calculation.

estimates of savings, and evaluations that fail to discount savings for free riders, rebound effects, and imperfect measure retention. Among the non-residential programs, higher realization rates were associated with commercial sector programs and ex-post evaluation methods that involve simplified engineering models and conditional demand analysis.

More information and knowledge would have been gained from this review of California's recent impact evaluations if similar types of programs had been evaluated using similar methodologies and if consistent reporting formats had been employed. The California state-wide measurement protocols will promote more consistent reporting of savings in future evaluation studies and thus facilitate the statewide aggregation of savings and comparative analysis. In general, such greater consistency will result in the following benefits:

- improvement in the transferability of savings estimates across utilities (so that the number and frequency of evaluation might be reduced), 
- greater ability to identify effective program features (so that programs can be redesigned to maximize performance), and

- aggregations of energy savings estimates, participation levels, realization rates, and other key statistics across utilities (to help state level DSM planning and forecasting).

Finally, any future effort to summarize and synthesize lessons learned from California impact studies should involve the analysis of a wider range of data. In particular, it should include (a) calculation of a total energy savings estimate appropriate for weighting each realization rate, ${ }^{4}$ (b) analysis of procedures used to generate ex-ante estimates of energy savings, and (c) compilation of utility statistics such as the numbers of customers by sector which would facilitate comparisons of the relative market penetration of each utility's DSM programs.

Appendix A to this report contains a bibliography of the evaluation and related studies summarized, while Appendix B describes the evaluation methodologies employed in the 50 studies. Appendix $\mathrm{C}$ contains detailed tables of evaluation results.

4 For instance, if a realization rate is calculated by comparing the ex-post and ex-ante savings of a particular retrofit measure, then it would be necessary to know how many of these measures were installed to calculate the total energy savings associated with the realization rate. Alternatively, if a realization rate is calculated for a particular market segment, it would be necessary to know the number of participants in that segment to calculate the total energy savings and thereby weight the realization rate. 


\section{ABSTRACT}

Over the past several years, four of the largest investor-owned California utilities have completed more than 50 evaluation studies designed to measure the energy and demand impacts of their demand-side management (DSM) programs. These four are: Pacific Gas and Electric (PG\&E), Southern California Edison (SCE), Southern California Gas (SoCalGas), and San Diego Gas and Electric (SDG\&E). These studies covered residential, commercial, industrial, and agricultural DSM programs and provided a wealth of information on program impacts. The objective of this report is to summarize the results of these DSM evaluation studies in order to describe what DSM has achieved in California, to assess how well these achievements were forecast, and to compare the effectiveness of different types of DSM programs.

This report documents the sizable investment made by the California utilities in their 1990-92 DSM programs. Between 1990 and 1992, the four utilities spent $\$ 772$ million on energyefficiency/conservation programs. Over this three-year period, the four utilities operated two types of programs: (1) resource programs that typically earned the utilities financial incentives based on the savings achieved, and (2) equity/services programs that generally were operated for performanceadder incentives. Resource programs are intended to provide a reliable, cost-effective alternative to supply-side resources. The four utilities spent $51 \%$ of their DSM expenditures on resource programs and $49 \%$ on equity/services programs.

This report also summarizes the realization rates extimated by the $50+$ evaluation studies. Realization rates are defined as ex-post net savings estimates divided by ex-ante net savings estimates. Realization rates are summarized for 158 programs and program segments. The median realization rate for these 158 programs and program segments is 0.86 and the mean is 1.12. Removal of four positive outliers results in the same median of 0.86 but reduces the mean to 0.93 . Overall, these results suggest that the forecasts of energy savings were reasonably accurate and that most of the DSM programs were cost-effective, since the programs generally were designed to produce benefitcost ratios of at least 1.2. In general, realization rates were higher for commercial, industrial, and agricultural programs than for residential programs. In the residential sector, higher realization rates were associated with retrofit incentive programs, calibrated engineering models, relatively low ex-ante estimates of savings, and evaluations that fail to discount savings for free riders, rebound effects, and imperfect measure retention. Among the non-residential programs, higher realization rates were associated with commercial sector programs and ex-post evaluation methods that involve simplified engineering models and conditional demand analysis. 


\section{ACKNOWLEDGMENTS}

The authors wish to thank Mark Beyer of Aspen Systems Corporation for his assistance with the study database and the analysis of realization rates. Terry Baxter of Aspen provided assistance in abstracting several of the evaluation studies. We would also like to thank Jenny Bozarth, Laura McGavin, and Sherry Surdam for their assistance in the production of the report. The authors would like to thank Eric Hirst and Les Baxter of Oak Ridge National Laboratory, Patrice Ignelzi of Pacific Consulting Services, and Marian Brown of Southern California Edison for their helpful comments on earlier drafts of this report. Finally, we would like to thank Peter Miller of the Natural Resources Defense Council for his comments and patient shepherding of the report through several iterations. 


\section{INTRODUCTION}

\subsection{BACKGROUND}

Since the late 1980's, the four largest California investor-owned utilities have initiated and expanded various demand-side management (DSM) programs designed to produce energy and capacity savings and to provide comprehensive services to their customers. This commitment to energy efficiency was encouraged by the establishment of financial incentives for the utilities to acquire demand-side resources. The four utilities include:

- Pacific Gas and Electric Company (PG\&E),

- San Diego Gas and Electric Company (SDG\&E),

- Southern California Edison (SCE), and

- Southern California Gas Company (SoCalGas).

Over the past several years, each of the four utilities has conducted or sponsored formal evaluation studies designed to retrospectively evaluate the energy (gas and electric) and electrical demand impacts achieved by DSM programs that operated between 1990 and 1992 . This effort yielded more than 50 evaluation studies, which are listed by utility and program in Table 1.1.' Altogether, these studies assess the impacts of a cumulative investment of nearly one billion dollars by the four utilities in DSM programs. This figure does not reflect the total DSM investment by the four utilities since the evaluation studies listed in Table 1.1 do not cover all of the DSM programs undertaken by the utilities over this period.

These four utilities, along with nine additional organizations, comprise the California Demand Side Management Measurement Advisory Committee (CADMAC). ${ }^{2}$ CADMAC was established by the California Public Utilities Commission (CPUC) to oversee the DSM measurement and evaluation activities of these utilities. CADMAC commissioned this report.

\subsection{OBJECTIVES OF REPORT}

The evaluation studies produced by the four utilities contain much detailed information related to the measurement of energy and demand impacts of the utilities' DSM programs. Many of the studies are multi-volume and examine the impact issues from several methodological perspectives. (The individual evaluation studies are listed in Table 1.1). The objective of this report is to

1 These studies are publicly available through the respective utilities.

2 The remaining members of CADMAC are the California Manufacturers Association, Toward Utility Rate Normalization, California Energy Commission, Natural Resources Defense Council, California Institute for Energy Efficiency, California Public Utilities Commission, National Association of Energy Service Companies, and Residential Energy Services Companies' United Effort. 
Table 1.1 Impact Evaluation Studies Summarized in This Report*

\begin{tabular}{|c|c|c|}
\hline Utility & $\operatorname{Year}(\mathrm{s})$ & Program(s) Covered \\
\hline PG\&E & $1991-1992$ & Ceiling Insulation Rebate \\
\hline PG\&E & 1991 & Energy Saver Showerhead Coupon \\
\hline PG\&E & 1992 & Residential Compact Fluorescent Lighting \\
\hline PG\&E & $1991-1992$ & Residential New Construction \\
\hline PG\&E & 1991 & Energy Partner \\
\hline PG\&E & $1991-1992$ & Targeted Customer Appliance \\
\hline PG\&E & 1991 & Residential Energy Savings Plan \\
\hline PG\&E & 1991 & Commercial, Industrial, and Agricultural Direct Rebate--Phase I \\
\hline PG\&E & 1991 & Commercial, Industrial, and Agricultural Direct Rebate--Phase II \\
\hline PG\&E & 1991 & Commercial New Construction \\
\hline PG\&E & 1991 & Commercial, Industrial, and Agricultural Direct Rebate \\
\hline PG\&E & $1991-1992$ & CIA Retrofit Rebate \\
\hline PG\&E & $1990-1992$ & Non-Residential New Construction \\
\hline PG\&E & $1990-1992$ & Non-Residential Energy Management Services \\
\hline PG\&E & $1990-1991$ & Custom Rebates--On-Site Validation \\
\hline SDG\&E & 1991 & Low-Flow Showerhead \\
\hline SDG\&E & 1991 & Appliance Efficiency--Residential Compact Fluorescent Lighting \\
\hline SDG\&E & 1991 & Residential High Efficiency Refrigerator \\
\hline SDG\&E & $1990-1991$ & Appliance Efficiency--Low-Flow Showerheads \\
\hline SDG\&E & 1992 & Appliance Efficiency--Compact Fluorescents \\
\hline SDG\&E & $1991-1992$ & Residential Energy Management Services--Audits \\
\hline SDG\&E & 1992 & Residential Direct Assistance \\
\hline SDG\&E & $1985-1989$ & Non-Residential Audits \\
\hline SDG\&E & $1990-1991$ & Commercial/Industrial Lighting Retrofit \\
\hline SDG\&E & $1991-1992$ & Commercial/Industrial Efficiency Incentives--Lighting Retrofits \\
\hline SDG\&E & $1991-1992$ & Commercial/Industrial Efficiency Incentives--Lighting Retrofit \\
\hline SDG\&E & $1990-1991$ & Agricultural Energy Management Services \\
\hline
\end{tabular}

* See Appendix A for complete citations. 
Table 1.1 Impact Evaluation Studies Summarized in This Report (cont'd)*

\begin{tabular}{|c|c|c|}
\hline Utility & Year(s) & Program(s) Covered \\
\hline SCE & 1990-1992 & Residential Appliance Efficiency Incentives \\
\hline SCE & 1990 & Residential Appliance Efficiency Incentives \\
\hline SCE & 1990 & Residential Energy Management Services \\
\hline SCE & $1990-1991$ & Customer Assistance \\
\hline SCE & 1990 & Welcome Home Appliance Usage \\
\hline SCE & 1991 & Welcome Home Appliance Usage \\
\hline SCE & 1990 & Energy Management Services \& Hardware Rebate \\
\hline SCE & 1990 & Energy Management Services \& Hardware Rebate \\
\hline SCE & 1990 & Energy Management Services \& Hardware Rebate \\
\hline SCE & 1990 & Energy Management Services \& Hardware Rebate \\
\hline SCE & 1990 & Energy Management Services \& Hardware Rebate \\
\hline SCE & 1990 & Energy Management Services \& Hardware Rebate \\
\hline SCE & 1990 & Energy Management Services \& Hardware Rebate \\
\hline SCE & 1990 & Energy Management Services \& Hardware Rebate \\
\hline SCE & 1990 & Energy Management Services \& Hardware Rebate \\
\hline SCE & $1990-1992$ & Commercial New Construction Incentives \\
\hline SoCalGas & $1990-1992$ & Residential Conservation \\
\hline SoCalGas & 1990-1992 & Direct Assistance: Appliance Repair and Replacement \\
\hline SoCalGas & $1990-1991$ & Residential New Construction \\
\hline SoCalGas & $1990-1992$ & Commercial Demand-Side Management \\
\hline SoCalGas & 1990-1992 & Industrial Demand-Side Management \\
\hline SoCalGas & $1990-1992$ & Commercial New Construction \\
\hline SoCalGas & 1990 & Residential Energy Management Services \\
\hline
\end{tabular}

* See Appendix A for complete citations.

summarize the results of these DSM evaluation studies in order to describe what DSM has achieved in California, to assess how well these achievements were forecast, and to compare the effectiveness of different types of DSM programs. The main emphasis is on summarization.

In defining their programs, and in annual reporting of program status, the individual utilities formulated preliminary estimates of program impacts. These estimates are known as ex-ante impact estimates. In most cases, they are based on engineering calculations. The formal evaluation studies, 
summarized in this report, estimate impacts based on post-implementation measurement and/or estimates of key parameters. Thus, the impact evaluation studies summarized in this report produced ex-post impact estimates. A key objective of this report is to compare the ex-ante and ex-post impact estimates of the four utilities' DSM programs. This was accomplished by formulating "realization rates," which are the ratio of the ex-post to the ex-ante estimates.

\subsection{ORGANIZATION OF REPORT}

This report is organized into seven chapters and four appendices. Chapter 2 provides an overview of the California utility DSM programs which are the subject of the evaluation studies. The programs are summarized in terms of extent of DSM investment, program participation, and the installation of DSM measures. Chapter 3 provides a summary of ex-post program impact estimates to the extent they are reported at the programmatic level. Three measures of impact are summarized. These include net electrical savings ( $\mathrm{mWh}$ or $\mathrm{kWh}$ ), net electrical demand savings (MW or $\mathrm{kW}$ ), and net gas savings (therms). Chapter 4 provides a similar summary of impact estimates, but at the participant and/or measure level for selected measure types. Chapter 5 compares ex-post and ex-ante impact estimates based on a summary of realization rates achieved. Finally, Chapter 6 provides brief conclusions. Chapter 7 contains references.

The report includes four appendices. Appendix A contains a bibliography with citations for each of the impact evaluation studies and annual DSM reports reviewed as part of this report. Appendix B provides an abbreviated overview of the impact evaluation methodologies which have been employed in the impact evaluation studies reviewed as part of this report. Appendix $\mathrm{C}$ contains detailed tables of evaluation results. 


\section{OVERVIEW OF DSM PROGRAMS}

\subsection{OVERVIEW OF UTILITIES AND THEIR DSM EXPENDITURES}

Between 1990 and 1992, Pacific Gas and Electric Company, Southern California Edison Company, Southern California Gas Company, and San Diego Gas and Electric Company spent $\$ 772$ million on energy-efficiency/conservation programs (Division of Ratepayer Advocates, California Public Utilities Commission, 1993). ${ }^{1}$ The magnitude of DSM investments varies widely across the four utilities (Figure 2.1). Almost half ( $\$ 358$ million) of this total was expended by PG\&E, the largest of the four investor-owned utilities and the country's leading utility in terms of DSM expenditures in 1992 (Hirst, 1994). Less than 10 percent ( $\$ 70$ million) was spent by SDG\&E, the smallest of the four utilities. However, the magnitude of the SDG\&E investment is still large by national standards. According to Hirst (1994), only twelve electric utilities spent more than SDG\&E on DSM in 1992.

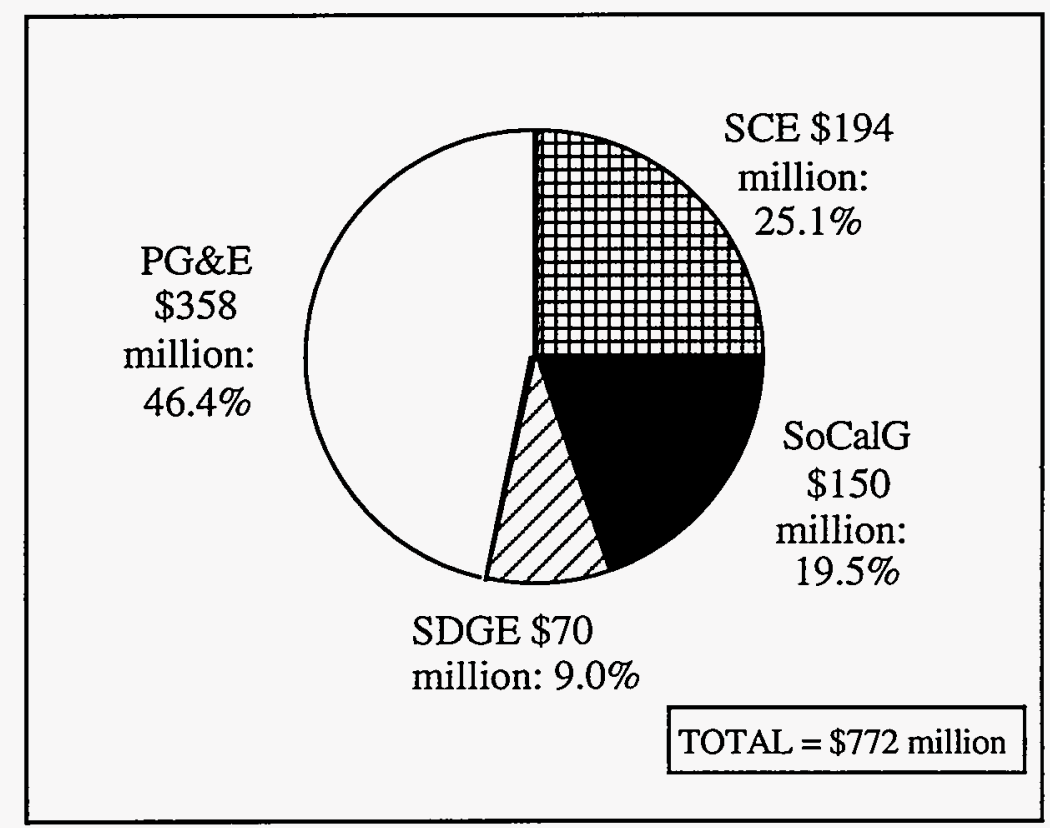

Source: Division of Ratepayer Advocates, California Public Utilities Commission, 1993

Figure 2.1 Total Energy-Efficiency/Conservation Expenditures (in Millions of Dollars): $1990-92$

1 In addition, the four utilities spent $\$ 114$ million on measurement and evaluation activities between 1990 and 1992 and earned shareholder incentives of $\$ 156$ million between 1990 and 1992, neither of which are reflected in the above total. The four utilities also spent additional funds on information, load management, load retention, and load building programs which are not reflected in the above total. 
When calculated as a percent of operating revenues, these conservation expenditures are quite consistent across the four utilities (Table 2.1). Based on the findings of Schlegel, et al. (1993), SCE spent the smallest proportion $(1.1 \%)$ of its operating revenues on DSM conservation expenditures between 1990 and 1992. At the other end of the spectrum, SoCalGas spent $1.7 \%$ of its operating revenues on DSM conservation expenditures.

Table 2.1 DSM Conservation Expenditures as a Percent of Operating Revenues

\begin{tabular}{|c|c|c|c|c|}
\hline & 1990 & 1991 & 1992 & Averages \\
\hline PG\&E & & & & \\
\hline Electric & 0.9 & 1.3 & 1.7 & 1.3 \\
\hline Gas & 1.3 & 1.4 & 1.5 & 1.4 \\
\hline SCE & 0.8 & 1.2 & 1.3 & 1.1 \\
\hline SoCalGas & 1.2 & 2.0 & 1.9 & 1.7 \\
\hline SDG\&E & & & & 1.5 \\
\hline Electric & 0.6 & 1.8 & 2.1 & 1.1 \\
\hline Gas & 0.3 & 1.2 & 1.7 & 1.4 \\
\hline Averages & 0.9 & 1.5 & 1.7 & \\
\hline
\end{tabular}

Source: Schlegel, et al. (1993), Figures 3-15, 3-21, 3-36, and 3-30.

As Table 2.1 and Figure 2.2 show, DSM expenditures grew rapidly between 1990 and 1991 and leveled off somewhat between 1991 and 1992. The establishment of DSM shareholder incentives for each of the four utilities was a major contributor to this observed increase in utility DSM activities. These shareholder incentives resulted in approximately $\$ 100$ million in after-tax earnings for the four utilities over the three-year period (Schlegel, et al., 1993).

The increase in DSM expenditures between 1990 and 1992 represents the second period of growth in DSM activities in California. In the early 1980's, California experienced a significant rise in demand-side investments, spurred by regulatory pressures. This was followed by a period of decline in DSM expenditures between 1985 and 1988, corresponding with decreased regulatory interest in DSM. As a result of the growth between 1989 and 1992, three of the four utilities (PG\&E, SCE, and SDG\&E) have now nearly reached or exceeded the high levels of investment in DSM experienced at the end of the earlier growth period. SoCalGas is the one exception. It has experienced only modest increases in its DSM expenditures in recent years, and by 1992-93, was spending less than half of the amount it had invested annually in DSM between 1983 and 1985. This is due to generally lower gas prices than in the 1980's and the consequent significant reduction in DSM budgets which can be justified by SoCalGas based on benefit-cost criteria. 


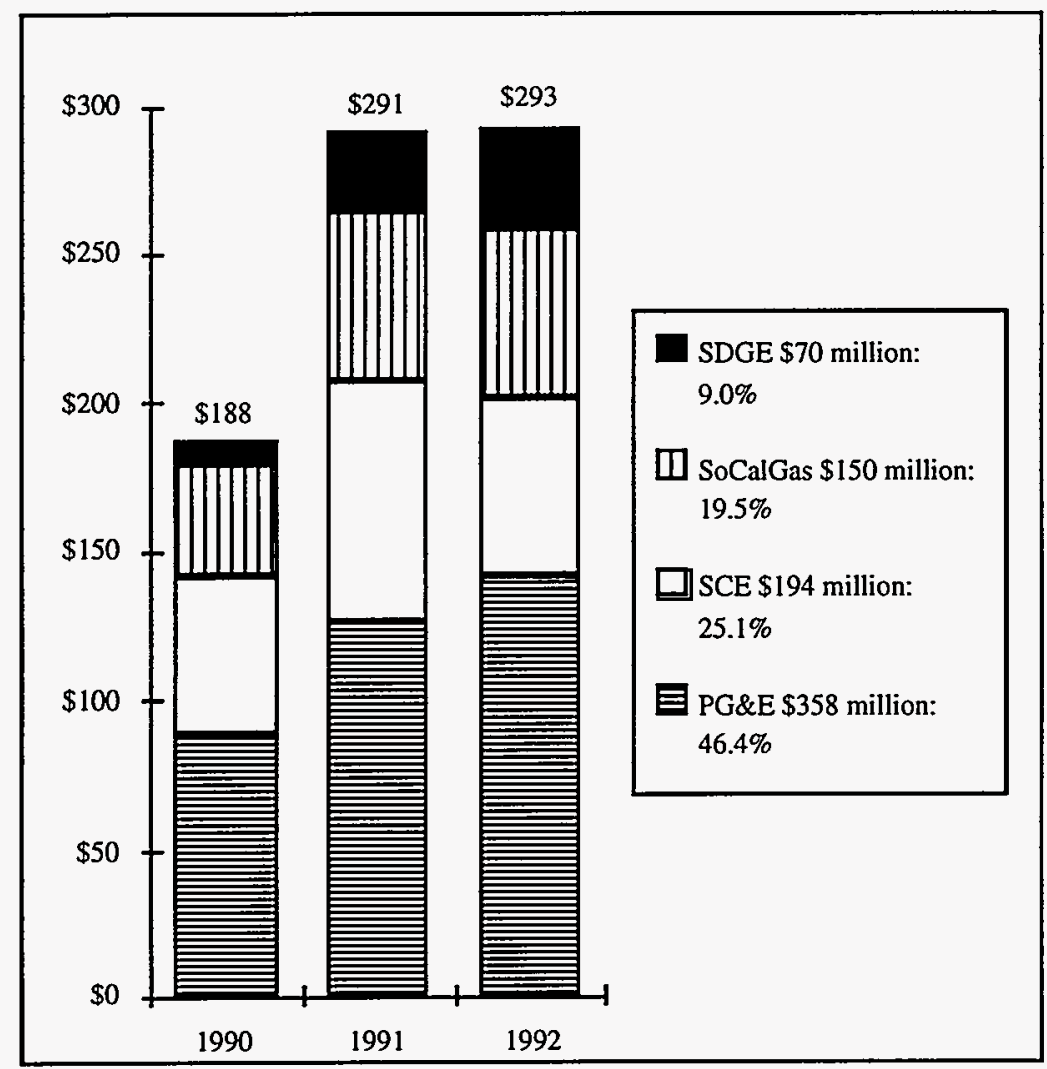

Source: Division of Ratepayer Advocates, California Public Utilities Commission, 1993

Figure 2.2 Total Energy-Efficiency/Conservation Expenditures (in Millions of Dollars): 1990-92

\subsection{DSM EXPENDITURES BY SECTOR AND PROGRAM TYPE}

The four investor-owned California utilities operate DSM programs that serve the residential, commercial, industrial, and agricultural sectors. These programs can be divided into two types: (1) resource programs that typically earn the utilities shared-savings incentives, and (2) equity/services programs that generally are operated for performance-adder incentives.

Resource programs include a variety of retrofit incentive and new construction programs. These programs are intended to be viable, cost-effective alternatives to supply-side options for which the utilities are eligible to earn shared-savings incentives.

Equity/services programs include residential direct assistance programs for low-income households, which are viewed as equity programs. Most of the utilities are eligible to earn performance-adder incentives for operating these programs. DSM programs that provide energy management services such as energy audits of buildings and industrial processes also fall into the equity/services category. The savings of these programs are difficult to measure, even though they may be significant. Utility incentives are therefore based on performance-adders and not shared- 
savings. Many of the equity and services programs are mandated by the CPUC, while the resource programs are not.

Reflecting these various programmatic differences, the CPUC employs the following classification scheme for DSM programs:

- retrofit energy-efficiency incentives (residential and commercial/industrial/ agricultural - C///A),

- residential direct assistance,

- new construction (residential and C/I/A), and

- energy management services (residential and $\mathrm{C} / \mathrm{I} / \mathrm{A}$ ).

Figure 2.3 indicates that retrofit energy-efficiency incentive programs account for the largest percentage of DSM expenditures of the four types of programs, totaling $\$ 313$ million or 41 percent of the total. Residential direct assistance programs account for the next largest percentage, with $\$ 225$ million (29 percent). Energy management services are a close third, with $\$ 157$ million (20 percent). Finally, new construction programs represent the smallest type, with only $\$ 77$ million, or $10 \%$ of the total expenditure.

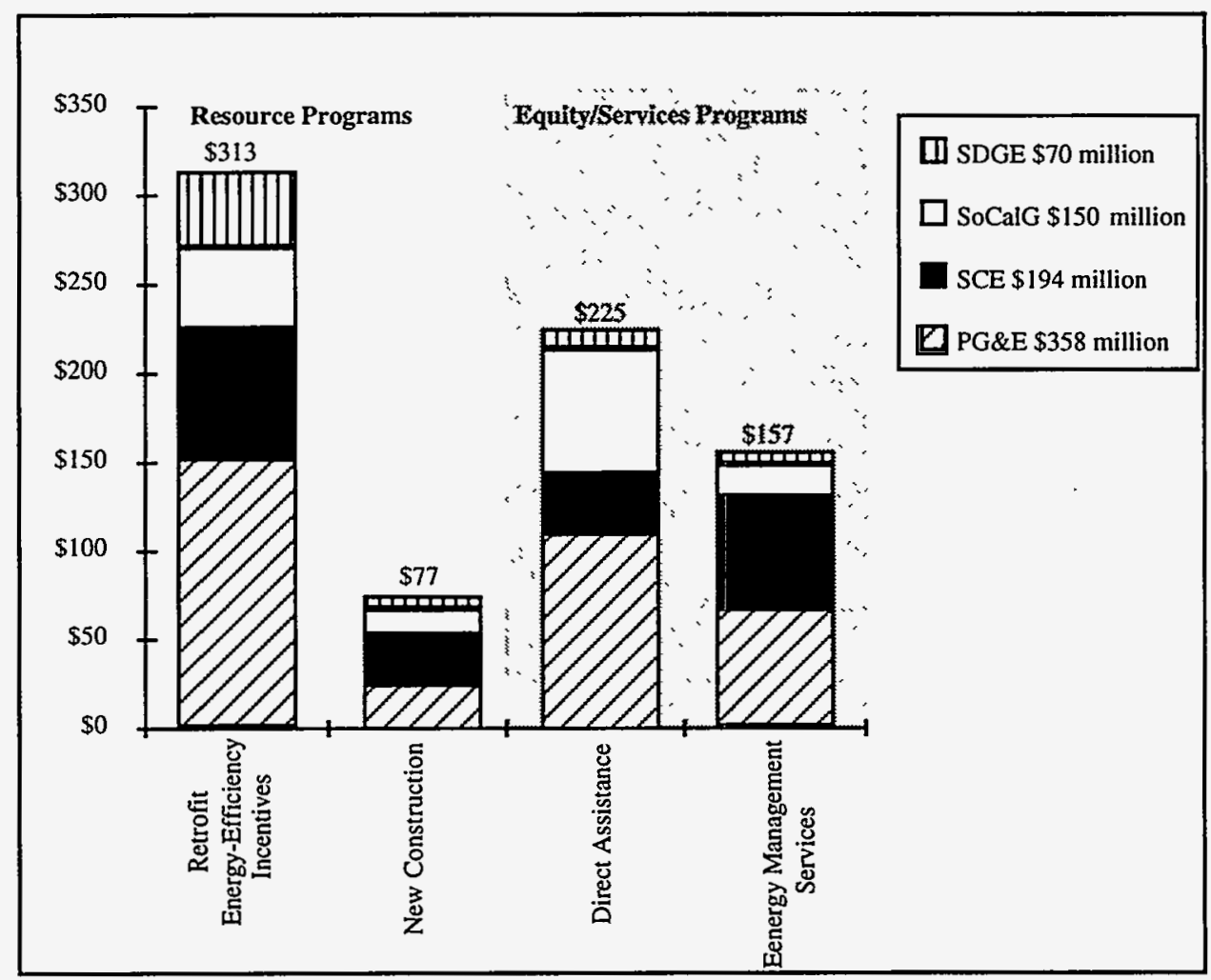

Source: Division of Ratepayer Advocates, California Public Utilities Commission, 1993

Figure 2.3 Total Energy-Efficiency/Conservation Expenditures by Program Type (in Millions of Dollars): 1990-92 
Figure 2.4 shows the allocation of each utility's DSM expenditures across the four types of programs. These expenditure profiles exhibit several noteworthy differences. In particular, PG\&E and SCE spent high proportions of their total DSM budgets on energy management services programs. SoCalGas, in turn, dedicated a large proportion of its total DSM expenditures to its residential direct assistance programs. All three of these utilities spent a sizable share of their DSM expenditures on equity/services programs, ranging from $48 \%$ for SCE to $60 \%$ for SoCalGas. SDG\&E provides a different profile, with 60 percent of its DSM expenditures going to retrofit energyefficiency incentive programs. Altogether, SDG\&E spent only $27 \%$ of its DSM expenditures on equity/services.

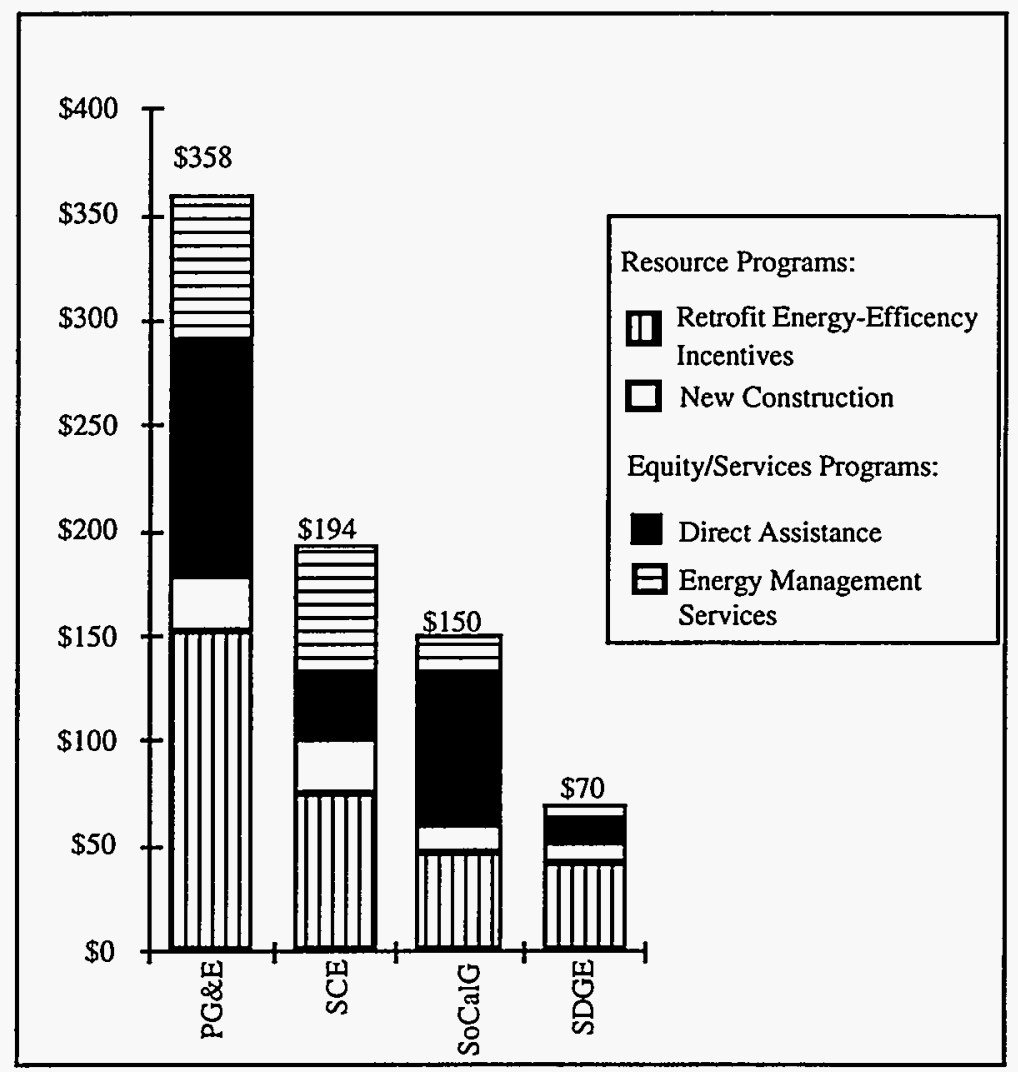

Source: Division of Ratepayer Advocates, California Public Utilities Commission, 1993

Figure 2.4 Total Energy-Efficiency/Conservation Expenditures by Utility (in Millions of Dollars): $1990-92$

\subsection{OVERVIEW OF PROGRAM PARTICIPATION LEVELS}

The impact studies shown in Table 1.1 provide a basis for describing the magnitude of the California DSM activities in terms of program participation levels (described in this section) and numbers of measures distributed (described in section 2.4). The impact studies do not report participant or measure penetration levels for every DSM program, nor do all the impact studies cover 
all three years. ${ }^{2}$ As a result, the data presented in the following figures should be viewed as illustrative and not as a complete inventory.

Altogether, the four types of residential DSM programs shown in Figure 2.5 for which evaluation studies were submitted served more than 800,000 households. Altogether, an estimated 2,400,000 customers benefited from California's DSM programs over the three-year period. Although there may be some duplication in these totals--as when a household first has an audit and then participates in a retrofit incentive program--the numbers are nevertheless impressive. Table C.1 in Appendix $\mathrm{C}$ lists the programs and annual numbers of participants that constitute the totals reported in Figure 2.5.

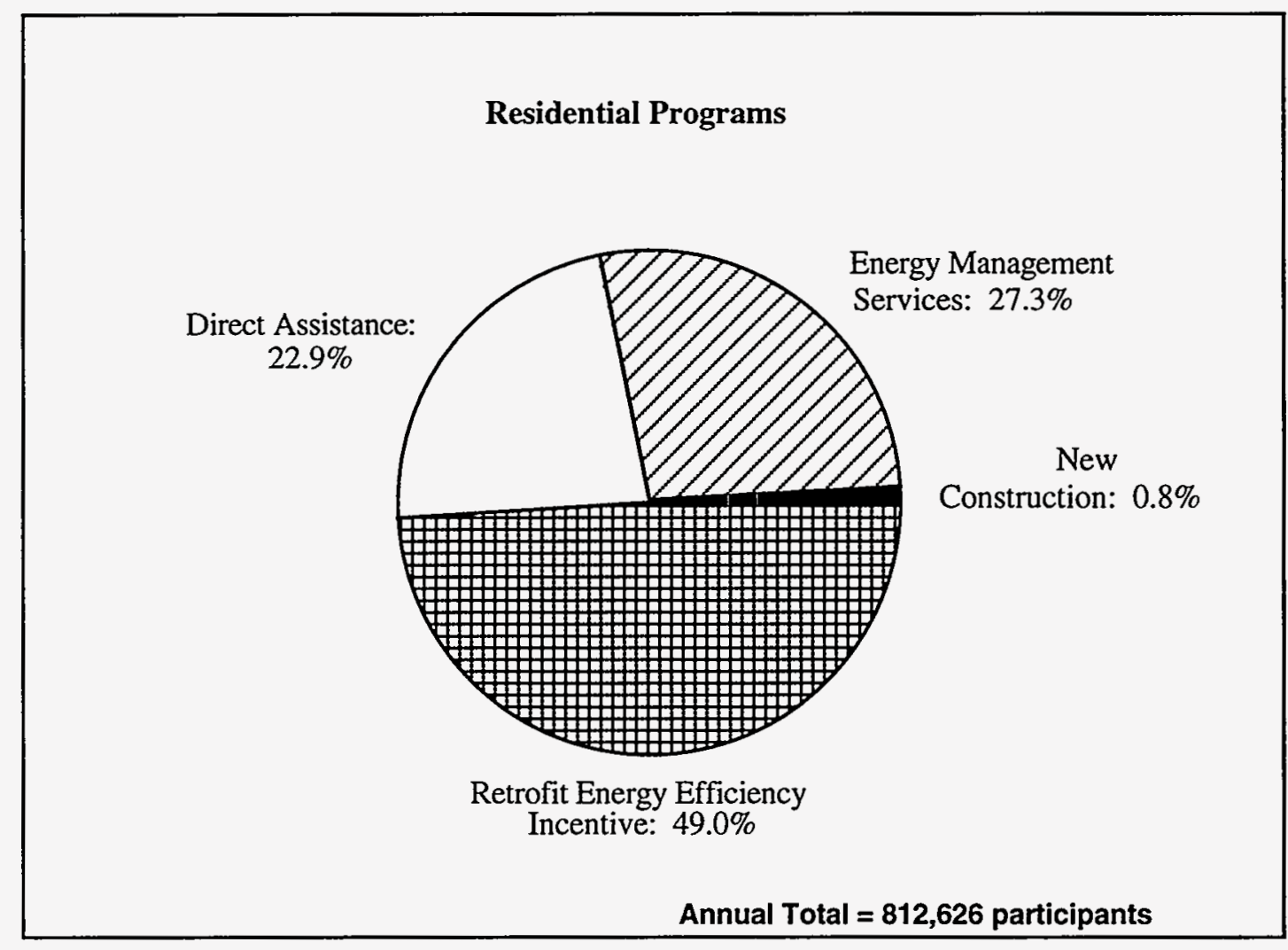

\section{Figure 2.5 Annual Number of Participants in Residential Programs Covered by Evaluation Studies}

Impact evaluations of 11 residential retrofit energy-efficiency incentive programs were conducted, spanning all four utilities. Included among these programs are residential weatherization, ceiling insulation, appliance efficiency, compact fluorescent, and low-flow showerhead programs.

2 The data on numbers of participants are annualized, so that comparisons can be made across impact studies that cover different time periods. For example, 21,976 households participated in PG\&E's Ceiling Insulation Rebate Program during 1991 and 1992. The annualized participation level reported in this chapter, therefore, is $10,988$. 
These eleven programs served almost 400,000 participants on an annual basis during the 1990-92 time frame (Figure 2.5). The compact fluorescent lighting programs account for approximately half of these participants. Programs offering incentives for the purchase of energy-efficient central airconditioning units and refrigerator replacements account for the largest share of the remaining participants.

Each of the four utilities operated a residential energy management services program between 1990 and 1992. Altogether, approximately 222,000 households participated in the programs covered by evaluation studies each year, receiving home audits, energy information, and/or low-cost measures such as low-flow showerheads or compact fluorescent lamps. The largest of these programs is operated by SCE, which accounts for nearly half of these participants.

As noted previously, residential direct assistance programs account for $29 \%$ of the total expenditures of the four utilities on energy-efficiency/conservation programs. Based on participation levels for seven of these programs, nearly 186,000 low-income households (representing 23\% of the number of residential participants) participated in these seven programs each year between 1990 and 1992. These programs range from relamping efforts (which accounted for 59,874 of SCE's participants each year) to more substantial home weatherization and appliance repair and replacement programs, which served most of the remaining participants.

Several of the utilities also operate residential new construction programs that provide financial incentives and technical assistance to builders to construct homes that exceed Title 24 standards. Participants in the three programs with impact studies served approximately 6,900 participants each year. These numbers are small, as are the expenditures on these DSM programs, partly because of the depressed home construction industry that characterized the national economy during this period.

Figure 2.6 summarizes the annual levels of participation in the C/I/A programs covered by the impact studies. The annual total is 61,000 participants, suggesting a three-year total of 183,000 . Table C.2 in Appendix C lists the levels of participation by program.

The definition of program "participants" is complicated for many C/I/A programs. For example, one customer may be responsible for many audits or several retrofit "projects" located at more than one site. At the other extreme, several customers may be part of a single commercial building new construction project. Since information was not always available on participation levels using identical units, Figure 2.6 is a compilation of different units. (See Table C.2 for further details.) The number of units have been annualized based on the reporting period, to give a mean number of units delivered per year. Some of these figures are derived by extrapolating sample results over a utility customer base.

C/I/A energy management services programs operated by the four utilities served approximately one-fourth as many participants annually (totaling 52,000) as their residential EMS 
program counterparts. As with the residential EMS programs, SCE delivered energy management services to the largest number of C/I/A participants -- accounting for approximately half of the total. At the other extreme, SDG\&E had fewer than 1,000 participants in their C/I/A EMS programs.

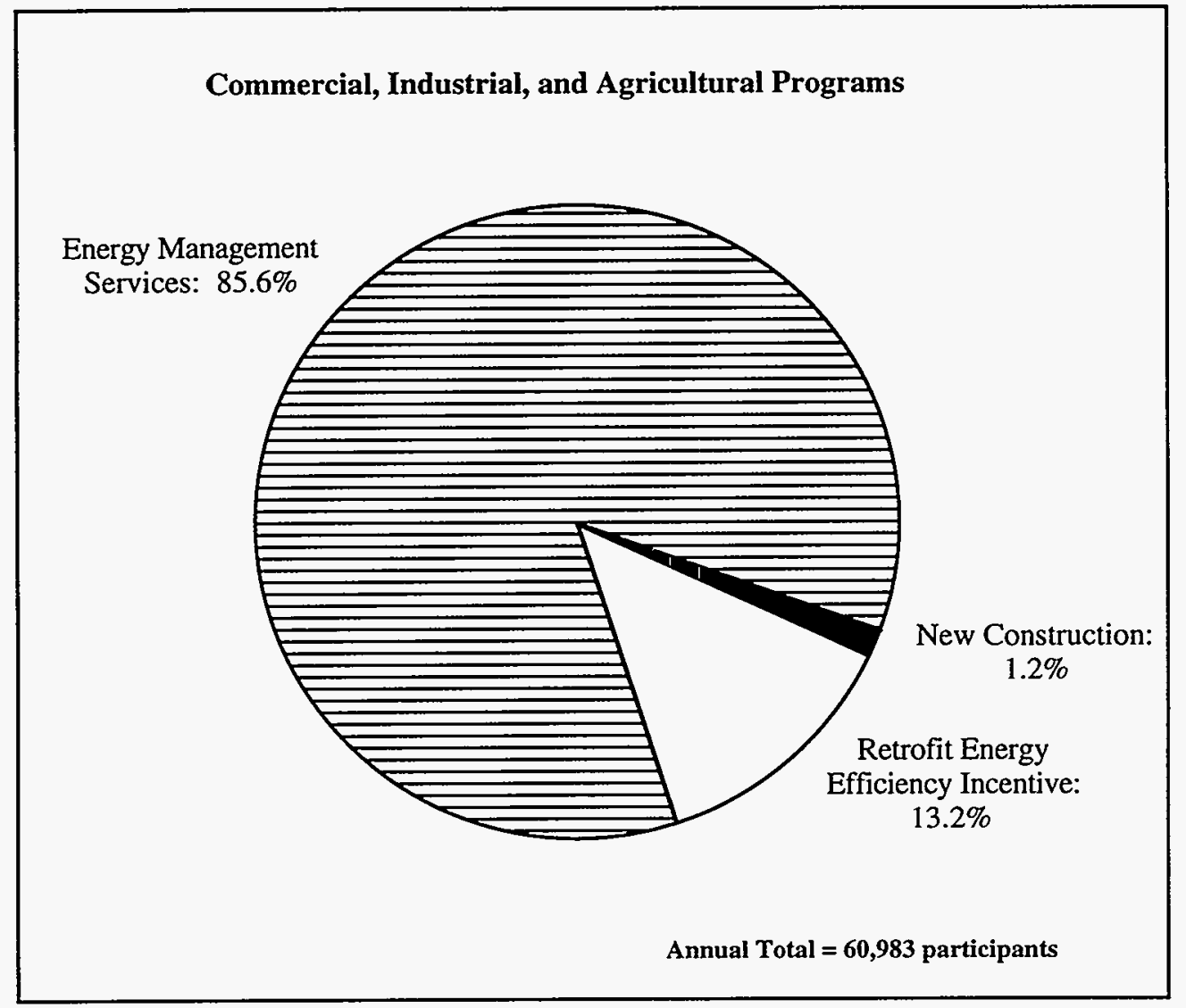

Figure 2.6 Annual Number of Participants in C/I/A Programs Covered by Evaluation Studies

Levels of participation in C/I/A new construction programs are much smaller than in C/I/A retrofit and energy management services programs, reflecting the lower level of utility expenditures dedicated to these programs. The number of participants in C/J/A new construction programs operated by three of the four utilities, per year, ranged from 57 in PG\&E's program to 584 in SCE's program. The energy-efficiency technologies promoted by these programs include high-efficiency lighting, glazing, daylighting controls, motors, adjustable speed drives, and high-efficiency cooling, refrigeration, and cooking equipment.

Based on the numbers of participants in programs covered by impact evaluation studies itemized in Figures 2.5 and 2.6, the four California utilities served nearly 900,000 participants annually between 1990 and 1992, or more than 2,600,000 participants over the three years. Since a participant may take advantage of two or more of a utility's programs, the unduplicated number of 
participants may be somewhat less. Nevertheless, these figures indicate that an impressive number of customers have benefited from California's DSM programs.

\subsection{INSTALLATION LEVELS FOR SELECTED MEASURES}

In addition to comparing the levels of DSM expenditures and the numbers of DSM program participants across utilities, it is possible to compare the numbers of DSM measures distributed for a small subset of residential measures: compact fluorescent lamps, low-flow showerheads, and refrigerator replacements.

Based on the impact evaluation studies reviewed, compact fluorescent lamps would appear to be the DSM measure that was distributed to the greatest number of customers between 1990 and 1992. In particular, the annualized numbers shown in Figure 2.7 indicate more than 775,000 lamps were distributed each year by the three utilities that deliver electric services: PG\&E, SCE, and SDG\&E. Between 200,000 and 300,000 lamps were distributed annually by each of these utilities under programs for which impact evaluation studies were submitted. The average number of compact fluorescent lamps delivered per household ranged across programs from 1.0 to 4.6 .

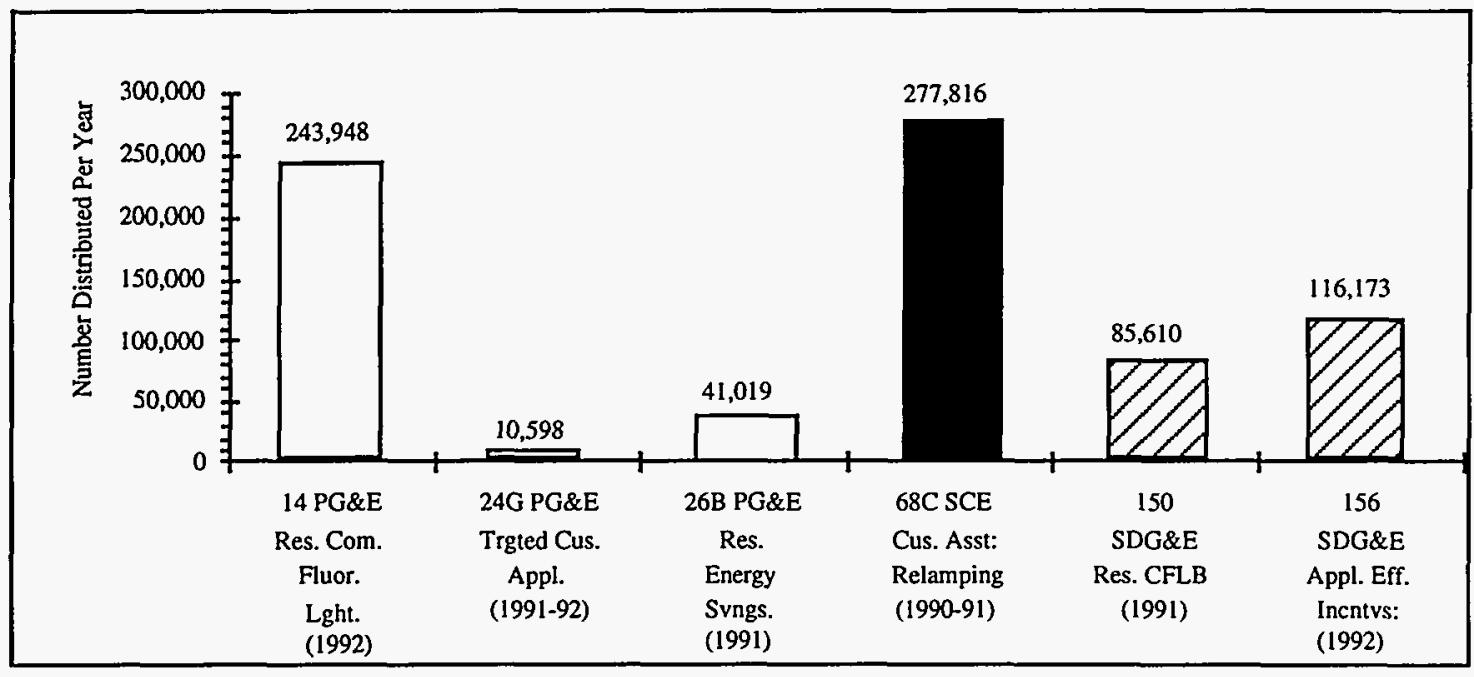

Figure 2.7 Number of Compact Fluorescent Lamps Distributed for Programs Covered by Evaluation Studies

All four utilities operated one or more programs that included the distribution of low-flow showerheads. However, data on numbers of measures installed are available for only two utilities: PG\&E and SDG\&E. The numbers reported in Figure 2.8 suggest that these utilities distributed more than 120,000 low-flow showerheads on an annual basis during the three-year study period under programs for which impact evaluation studies were submitted.

Refrigerator replacements are a feature of the DSM programs operated by three of the four utilities (specifically, those that provide electric services). The three programs listed in Figure 2.9 for 
which evaluation studies were submitted contributed to the purchase of nearly 123,000 energyefficient refrigerators each year between 1990 and 1992.

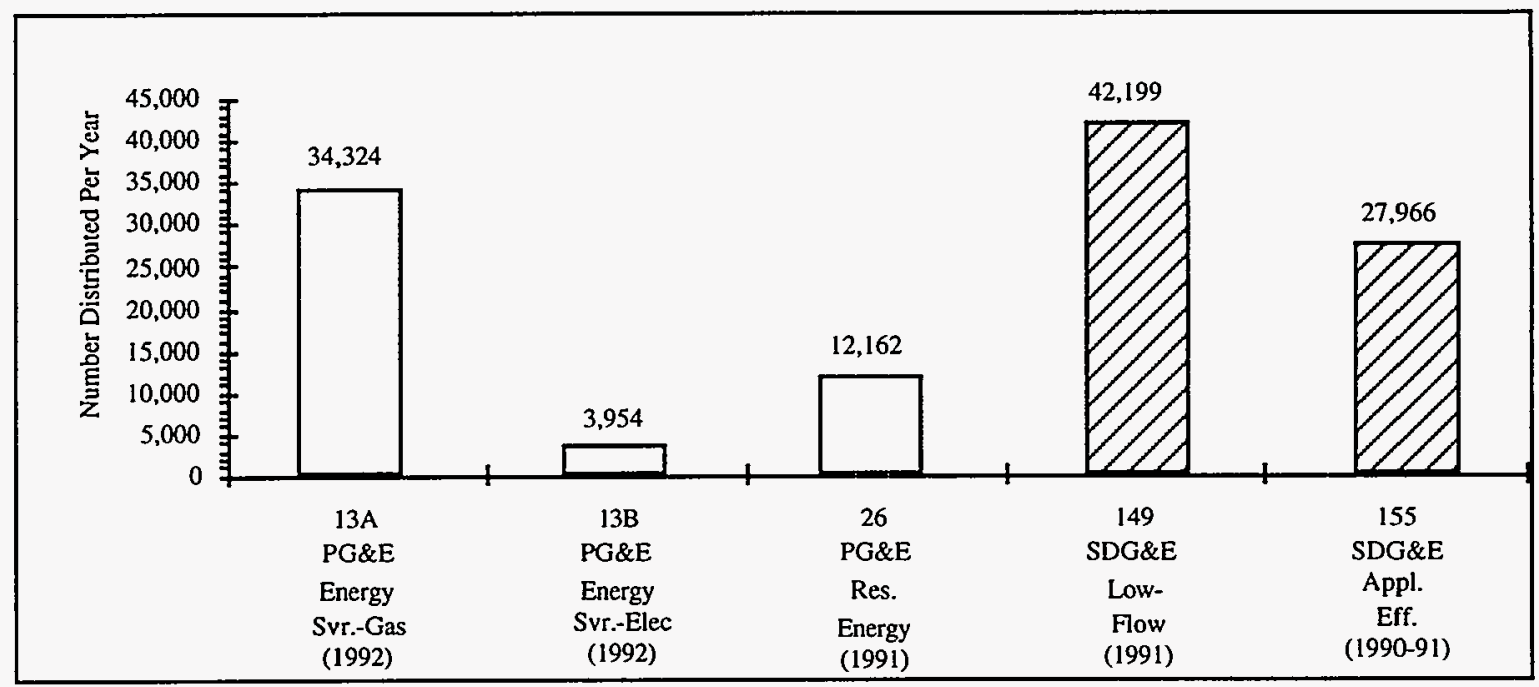

Figure 2.8 Number of Low-Flow Showerheads Distributed Under Programs Covered by Evaluation Studies

Based on the measure penetration rates itemized in Figures 2.7 through 2.9, the four California utilities have had a significant impact on the purchase and installation of energy-efficient equipment and materials in the State. Undoubtedly this has been responsible for generating regionwide consumer demand for DSM products and for strengthening the wholesale and retail infrastructures that promote their distribution beyond the immediate participants in DSM programs. None of the 50 impact evaluations reviewed here attempted to monetize these market transformation benefits.

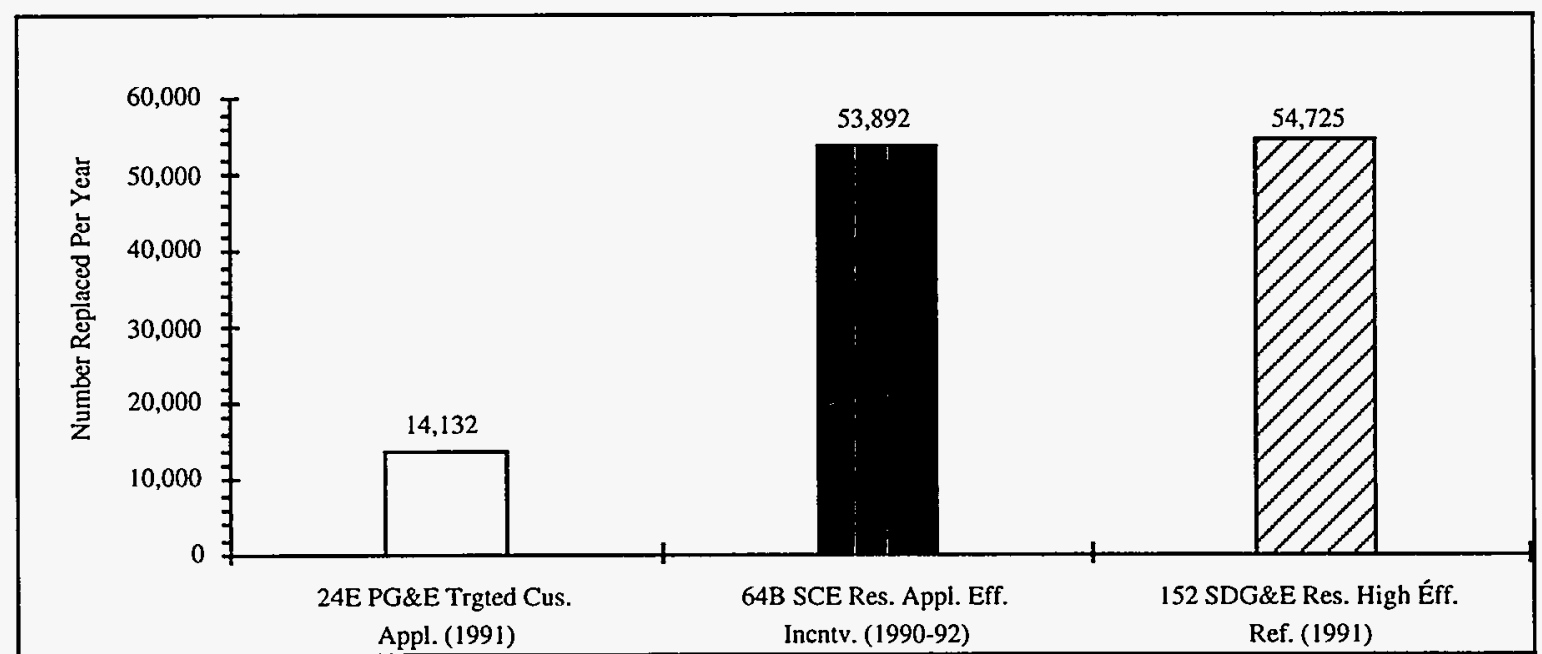

Figure 2.9 Number of Refrigerator Replacements Under Programs Covered by Evaluation Studies 
This chapter has documented the sizable investment made by California utilities in their 1990-92 energy-efficiency/conservation programs. It also highlights the variability in the magnitudes and types of DSM investments made by each utility.

- PG\&E invested $\$ 358$ million on DSM programs, with a higher-than-average percentage going to residential direct assistance programs $(42 \%)$, which served approximately 76,000 low-income households each year. Of the four utilities, PG\&E invested the lowest percentage of its DSM expenditures $(7 \%)$ in new construction programs.

- SCE spent a particularly high percentage (31\%) of its $\$ 194$ million DSM investment providing energy management services. These programs benefited 110,000 households and more than 25,000 commercial, industrial, and agricultural participants each year. .

- SoCalGas spent only $13 \%$ of its $\$ 150$ million DSM budget on energy management services. Its DSM emphasis was on residential direct assistance programs, which consumed $47 \%$ of its budget and provided appliance repair and replacement services to 31,000 low-income households each year.

- SDG\&E spent $60 \%$ of its $\$ 70$ million DSM expenditures on retrofit energyefficiency incentives. This investment contributed to the purchase of nearly 55,000 high-efficiency refrigerators and more than 70,000 low-flow showerheads each year.

The emphasis of each utility on different types of DSM programs and energy end uses can be explained in part by the type of energy distributed by each utility: natural gas only (SoCalGas), electricity only (SCE), or both fuels (PG\&E and SDG\&E). Two obvious examples are compact fluorescent and refrigerator replacement programs which are part of the DSM portfolios of the three utilities that offer electric services, but are not operated by SoCalGas. Other explanations for the diverse approaches must lie in characteristics of the customer base, climate, and perhaps the resource planning process. It is possible that by sharing the results of DSM impact evaluations, a trend toward greater convergence on the most successful types of programs and end uses will emerge. 


\section{SUMMARY OF EX-POST PROGRAM IMPACT ESTIMATES FOR SELECTED PROGRAMS}

\subsection{INTRODUCTION}

This chapter, along with Chapter 4, summarizes energy and demand savings as reported in the individual utility evaluations studied. This chapter summarizes estimated savings at the programmatic level (where available), while Chapter 4 summarizes savings reported at the participant or measure level. The focus is on net electrical energy savings ( $\mathrm{mWh}$ or $\mathrm{kWh}$ ), net electrical demand savings (MW or $\mathrm{kW}$ ), and net gas savings (therms).

Before describing our results, it is important to note the constraints of this analysis. Because of the significant variation in the ways savings were estimated and reported, it is difficult to systematically compare estimates of savings on the same dimensions or to aggregate savings. Some of the sources of this problem are described below.

- The savings reported vary by time frame. Some studies reported savings for a single year, while others reported savings for multiple years or parts of years. Where possible, the authors attempted to annualize the savings, if this could be done with a reasonable degree of confidence. If not, the savings are reported for the period covered by the study.

- Savings were reported at many different levels of aggregation. Some savings were reported for the program as a whole. In other cases, savings were reported on a per measure basis (e.g., per refrigerator replaced). In other cases, savings were reported on a per participant basis. In some cases, savings were reported by enduse measure class (e.g., lighting as a measure class category in commercial buildings as opposed to per fixture). Savings were also sometimes reported on a per building or per average building basis.

- Savings are reported in a variety of different units of measurement. Some studies reported savings on a megawatt hour per year basis. In other cases, average monthly kilowatt hours were reported. In yet another variant, watts per measure saved by a program were reported in one study, and a separate study then estimated the number of hours each measure was used. The combination of studies would thus provide estimated watt-hour savings.

- Consistent savings estimation approaches were not used across the four utilities, or even within single utilities. Evaluation methods also vary by sector and program type. For instance, significantly different approaches were employed to estimate savings for residential programs versus commercial, industrial, and agricultural programs. Although the use of different methods is often appropriate, it does complicate comparisons. These differences also may create systematic biases in the estimation of savings.

- Finally, the ways savings were reported tended to vary by the evaluation method employed. Conditional demand analysis, for example, often reported results in terms of units such as average monthly kilowatt hours, while building simulation modeling would report estimated savings per building, or per average building, disaggregated to measure classes. 
Wherever possible, the authors attempted to normalize the reported savings through simple calculations. In each case, the authors attempted to carefully label the savings as reported in the individual studies.

The programs themselves, even those that appear similar on the surface, are also highly diverse in design and delivery. This can account for significant variation in the reported savings. The fact that different program savings are reported on the same graphic is simply a presentational convenience, and is not meant to indicate the programs are comparable.

Since the completion of most of the studies summarized in this report, Protocols and Procedures for the Verification of Costs, Benefits, and Shareholder Earnings from Demand-Side Management Programs were developed by the four utilities, the California Energy Commission (CEC), the California Public Utilities Commission (CPUC) - Division of Ratepayer Advocates, and the Natural Resources Defense Council (NRDC). These Protocols (revised July 21, 1994) were adopted by CPUC Decision 93-05-063, and thus will govern all future DSM program evaluations beginning January 1, 1994.

The Protocols were designed to apply consistent and rigorous measurement and evaluation procedures to the DSM programs operated by the four utilities. They contain explicit and detailed guidelines for conducting impact evaluations and reporting impact evaluation results. Specifically, Tables 6 and 11 and Appendix E of the Protocols address reporting of impact measurement study results in a consistent manner. Adherence to these Protocols by the four utilities will greatly facilitate future comparison and aggregation efforts of the type attempted in this report, and may be expected to mitigate many of the aggregation problems encountered in this report. The evaluation studies summarized in this report were prepared prior to the adoption of the Protocols.

\subsection{RESIDENTIAL PROGRAMS}

This section summarizes savings where they were reported at the program level. Not all of the studies reported program level savings. Some studies only reported per measure savings. Therefore, the figures in this chapter do not present the total savings achieved, but only the portion of savings reported at the program level. Chapter 4 summarizes savings reported at the per measure level.

Figure 3.1 summarizes residential program level electricity savings as reported in the 50 studies. For those studies reporting program level savings, a total of $124.6 \mathrm{GWh}$ of savings were reported. Sixty-nine percent of these savings derived from retrofit incentive programs while $25 \%$ came from direct assistance programs. Table C.3 in Appendix C contains the study level details underlying the program level electricity savings reported in Figure 3.1. 


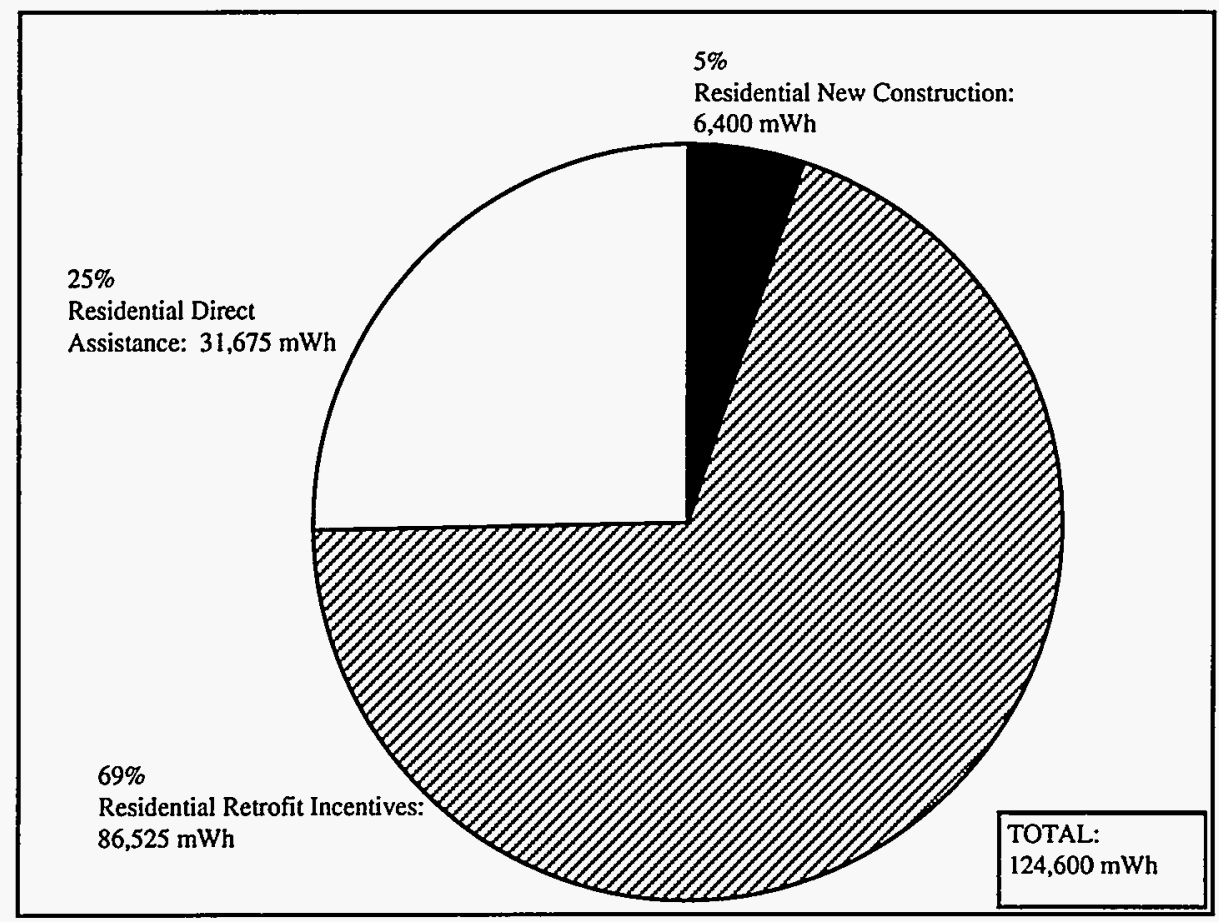

Figure 3.1 Summary of Residential Program Level mWh Savings Reported in Nine Evaluation Studies

Based on these impact studies of residential programs, Southern California Edison's Residential Appliance Efficiency Program (Study No.64) accounts for the largest program-wide electricity savings with a total of 53,341 megawatt hours of savings between 1990 and 1992. SCE also accounts for the program with the second largest electricity savings--24,381 megawatt hours-which resulted from the Customer Assistance Relamping Program in 1990-91 (Study No. 68). According to the impact studies, the third largest program in terms of electricity savings was PG\&E's Residential Compact Fluorescent Program (Study No. 13). It saved 13,807 megawatt hours in a single year (1992). Thus, two of the three programs that saved the most electricity according to the impact studies were compact fluorescent lighting programs.

Figure 3.2 shows the distribution of program-level $\mathrm{mWh}$ savings (exclusive of new construction) by end-use. Sixty one percent of these savings derive from appliance efficiency programs, while $36 \%$ came from lighting programs.

Figure 3.3 summarizes residential gas savings for those studies reporting savings at the program level. A total of 8,853 kilotherms of gas savings were reported. The largest portion, $65 \%$, came from retrofit incentive programs. The balance was split approximately equally between direct assistance and energy management services. Table C.4 in Appendix C provides supporting detail on the studies underlying Figure 3.3. 


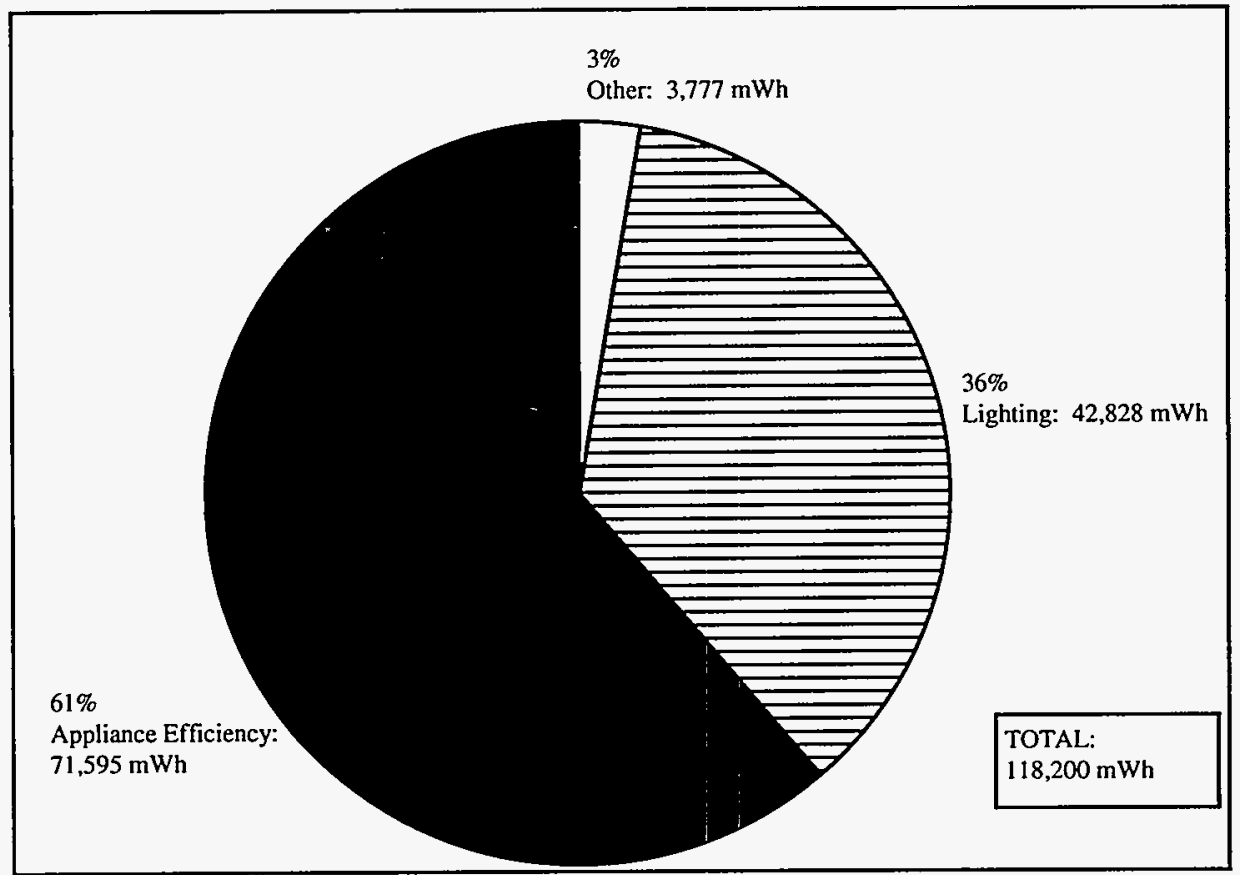

Figure 3.2 Summary of Residential Program Level $\mathrm{mWh}$ Savings By End-Use Category Reported in Nine Evaluation Studies (Excludes New Construction)

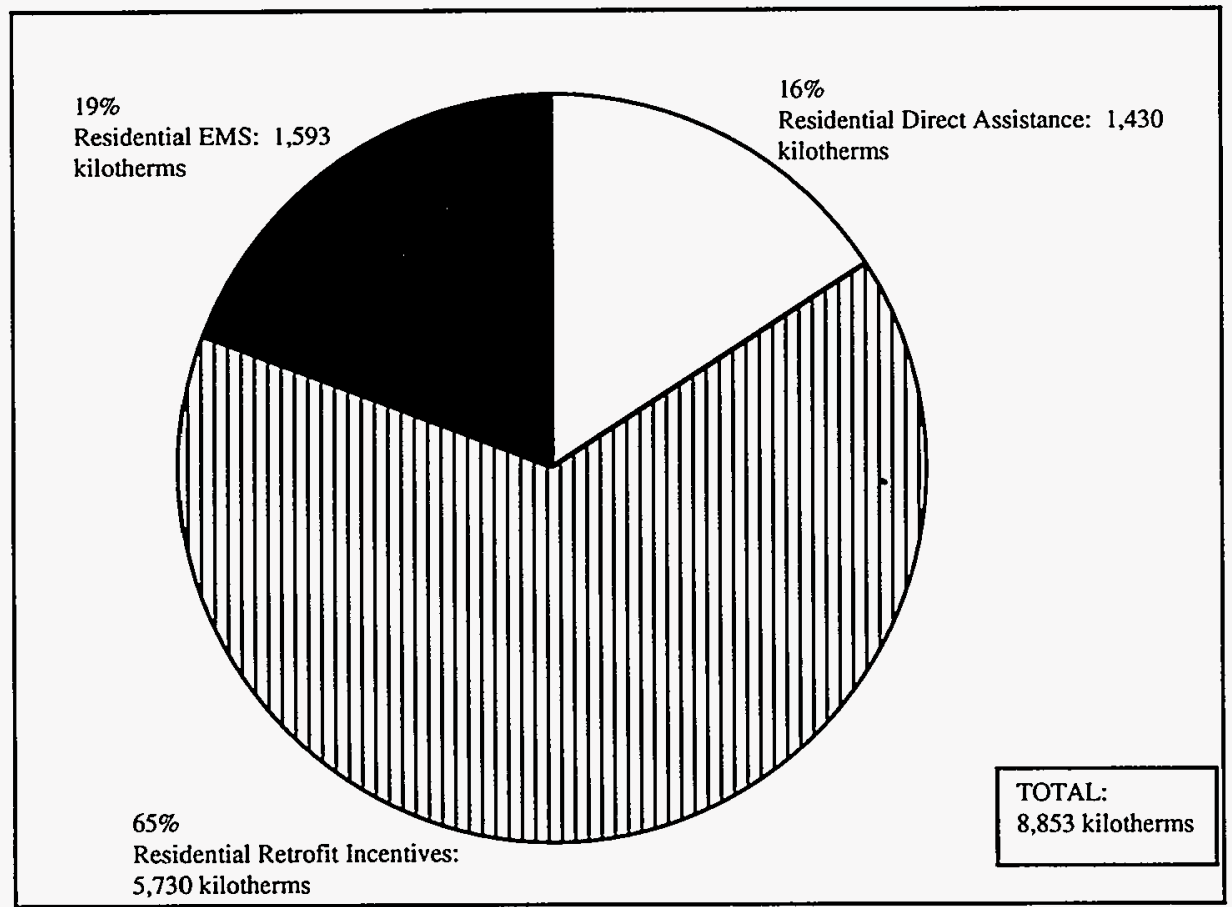

Figure 3.3 Summary of Residential Program Level Gas Savings Reported in Nine Evaluation Studies 
Southern California Gas' Residential Conservation Program (Study No. 129) reported the largest savings among these programs, totaling 2,559 kilotherms during 1990-92. This was followed closely by SoCalGas's Residential EMS Program with 1,693 kilotherms in 1990 (Study No. 195). The residential program with the largest estimated savings is PG\&E's Ceiling Insulation Rebate Program (Study No. 12), which produced an estimated savings of 714 kilotherms during the 1991-92 period.

\subsection{COMMERCIAL, INDUSTRIAL, AND AGRICULTURAL PROGRAMS}

This section summarizes the savings estimates for commercial, industrial, and agricultural (C/I/A) programs, where they were reported at the program level. Figure 3.4 summarizes net electrical energy savings. Compared to the residential programs reviewed above (Figure 3.1), the $\mathrm{C} / \mathrm{I} / \mathrm{A}$ programs saved an order of magnitude more electricity than the residential programs. (Seven non-residential evaluation studies reported program-wide energy savings as compared to nine residential evaluation studies.)

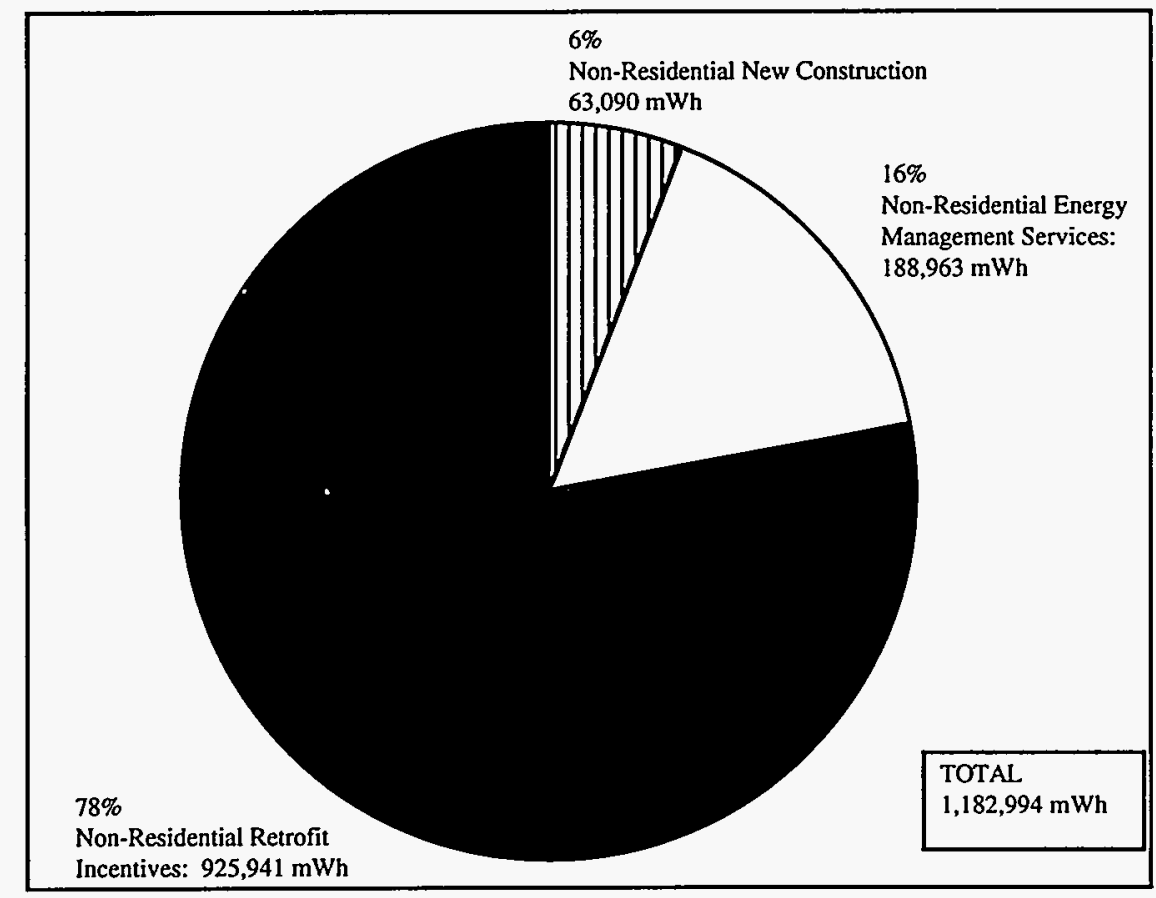

Figure 3.4 Summary of Program-Level Non-Residential mWh Savings Reported in Seven Evaluation Studies

A total of $1,182,994 \mathrm{mWh}$ of non-residential electricity savings were reported, with $78 \%$ of these savings deriving from non-residential retrofit incentive programs. Non-residential energy management services accounted for $16 \%$ of the savings while new construction accounted for $6 \%$ of the reported savings. 
PG\&E's Commercial, Industrial, and Agricultural Retrofit Rebate Program for the period 1991-92 (Study No. 43) reported over 663,000 megawatt hours of savings for the 1991-92 period. Its Commercial, Industrial, and Agricultural Customized Rebate Program saved over 208,000 megawatt hours between 1990 and 1991, and its Nonresidential Energy Management Services Program saved 177,000 megawatt hours over the same period. In contrast, recall that Southern California Edison's Residential Appliance Efficiency Program (Study No.64) is the residential program with the largest program-wide savings, totaling 53,341 megawatt hours of savings between 1990 and 1992.

Figure 3.5 summarizes non-residential electrical demand (MW) savings reported at the program level. (NOTE: Very few residential programs reported MW demand savings.) A total of 225.7 MW of demand savings were reported for non-residential programs at the program level. The largest share, 64\%, again derived from non-residential retrofit incentive programs. As with the estimates of energy savings, PG\&E's Commercial, Industrial, and Agricultural Retrofit Rebate Program accounts for the largest estimated demand savings among the impact studies, totaling 110.5 MW (Study No. 43) for the 1991-92 period. Table C.5 in Appendix C contains study details which underlie the values reported in Figures 3.4 and 3.5.

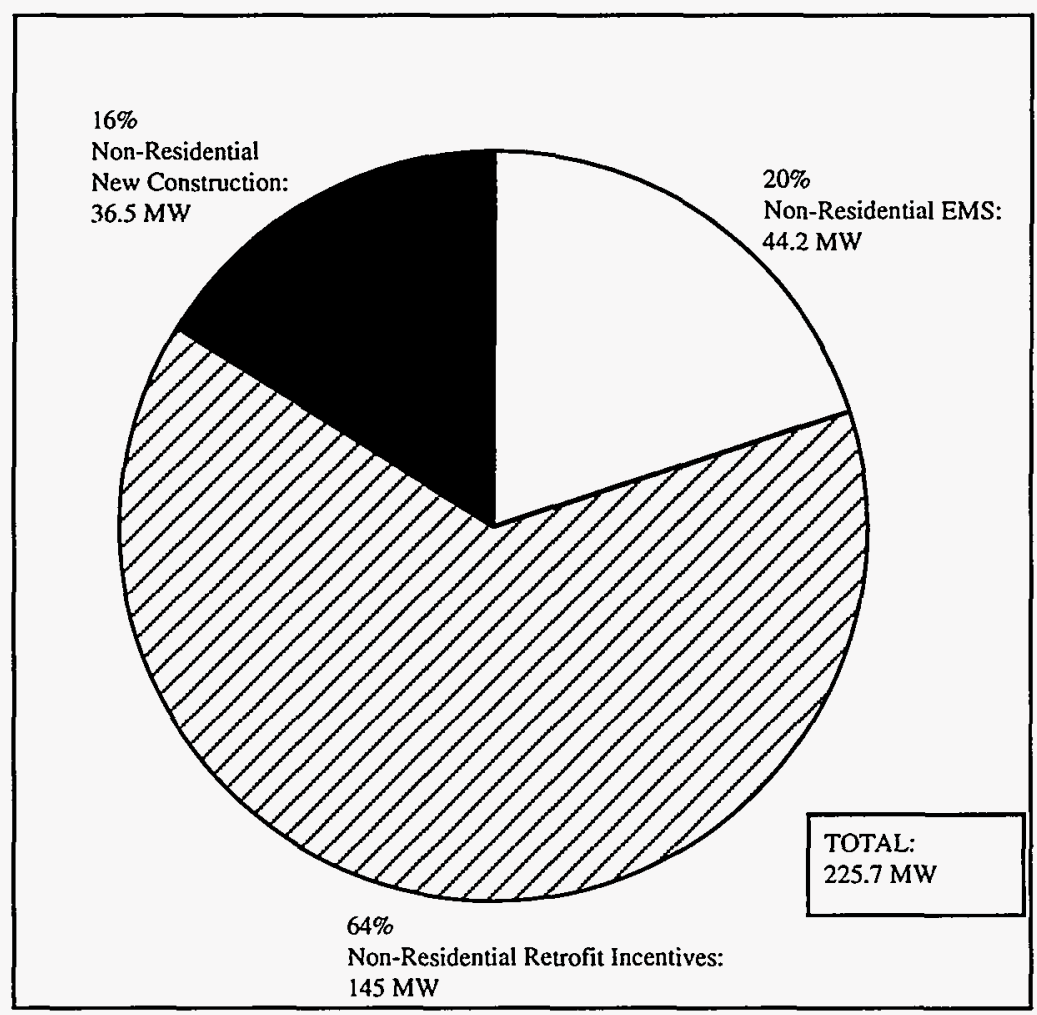

Figure 3.5 Summary of Program-Level Non-Residential MW Savings Reported in Six Evaluation Studies 
Only two studies reported non-residential program-level gas savings. A total of 2,712 kilotherms of gas savings were reported by these two studies. The largest of these programs, in terms of gas savings, was PG\&E's Nonresidential Energy Management Services Program, which reported 2,572 kilotherms of savings between 1990 and 1992. Details may be found in Table C.6 in Appendix C.

In summary, the aggregate program-level savings as reported by the impact studies are shown in Table 3.1 The table shows that electricity savings from $\mathrm{C} / \mathrm{V} / \mathrm{A}$ programs are an order of magnitude higher than electricity savings from the residential programs for those studies reporting programlevel savings. However, a majority of the estimated gas savings resulted from residential programs. In aggregate, over 1.3 million $\mathrm{mWh}$ of electricity savings were reported, and 11,565 kilotherms of gas energy savings. Chapter 4 will focus on summarizing evaluation studies which presented measurelevel savings estimates.

Table 3.1 Summary of Reported Program-Level Savings*

\begin{tabular}{|l|c|c|c|}
\hline & $\begin{array}{c}\text { Residential } \\
\text { Programs }\end{array}$ & $\begin{array}{c}\text { Commercial/Industrial/ } \\
\text { Agricultural Programs }\end{array}$ & Total \\
\hline mWh & 118,200 & $1,182,994$ & $1,301,194$ \\
\hline MW & --- & 225.6 & 225.6 \\
\hline Kilotherms & 8,853 & 2,712 & 11,565 \\
\hline
\end{tabular}

* Savings reflect only those reported at the program level in the studies reviewed. Many studies did not report program-level savings (e.g., only per measure savings were reported). These are not reflected in the above totals. 


\section{SUMMARY OF EX-POST PROGRAM IMPACT ESTIMATES FOR SELECTED MEASURES}

Chapter 3 summarized savings as reported at the programmatic level, that is, megawatt hour, megawatt, and kilotherm savings were aggregated to the whole program. Many of the evaluation studies also reported savings on a per measure or per participant basis, in addition to the aggregated programmatic savings. Other evaluation studies only reported savings at the measure or participant level. This chapter provides a summary of savings reported for selected measures or measure categories.

\subsection{RESIDENTIAL MEASURES}

As examples of measure savings reported in the residential sector, savings for refrigerator, residential lighting, and low-flow showerhead measures are summarized. In all cases, ex-post net savings are reported.

Figure 4.1 summarizes the net $\mathrm{kWh}$ savings of three programs that promoted energy-efficient refrigerators. As can be seen in Figure 4.1, the range of residential refrigerator-related annual savings vary widely, from $90 \mathrm{kWh}$ to $392 \mathrm{kWh}$ per refrigerator. (See Table C.7 in Appendix C for more details on the studies in Figure 4.1.) These wide ranges reflect some combination of differences in program design characteristics (e.g., refrigerator replacement versus early retirement programs) and evaluation methods. Readers are cautioned against direct comparison of these figures due to the large degree of variation in the program designs and time periods covered. For example, studies 152 and 64B cover programs which provided incentives to purchase refrigerators with greater energy efficiency. On the other hand, the PG\&E program (Study No. 24) offered early retirement of refrigerators and refrigerator repair.

Figure 4.2 provides similar comparisons for residential lighting measures. (See Table C.8 in Appendix $C$ for details on the studies in Figure 4.2.) Again, a wide variation of net kilowatt hour savings per lamp is reported (34 kilowatt hours to 128 kilowatt hours), reflecting some combination of differences in program design and implementation features (e.g., the number of lamps installed per home) and evaluation methods.

Further discussion of these two measures (energy-efficient refrigerators and compact fluorescent lamps) appears in chapter 5, where their varying realization rates are analyzed. 


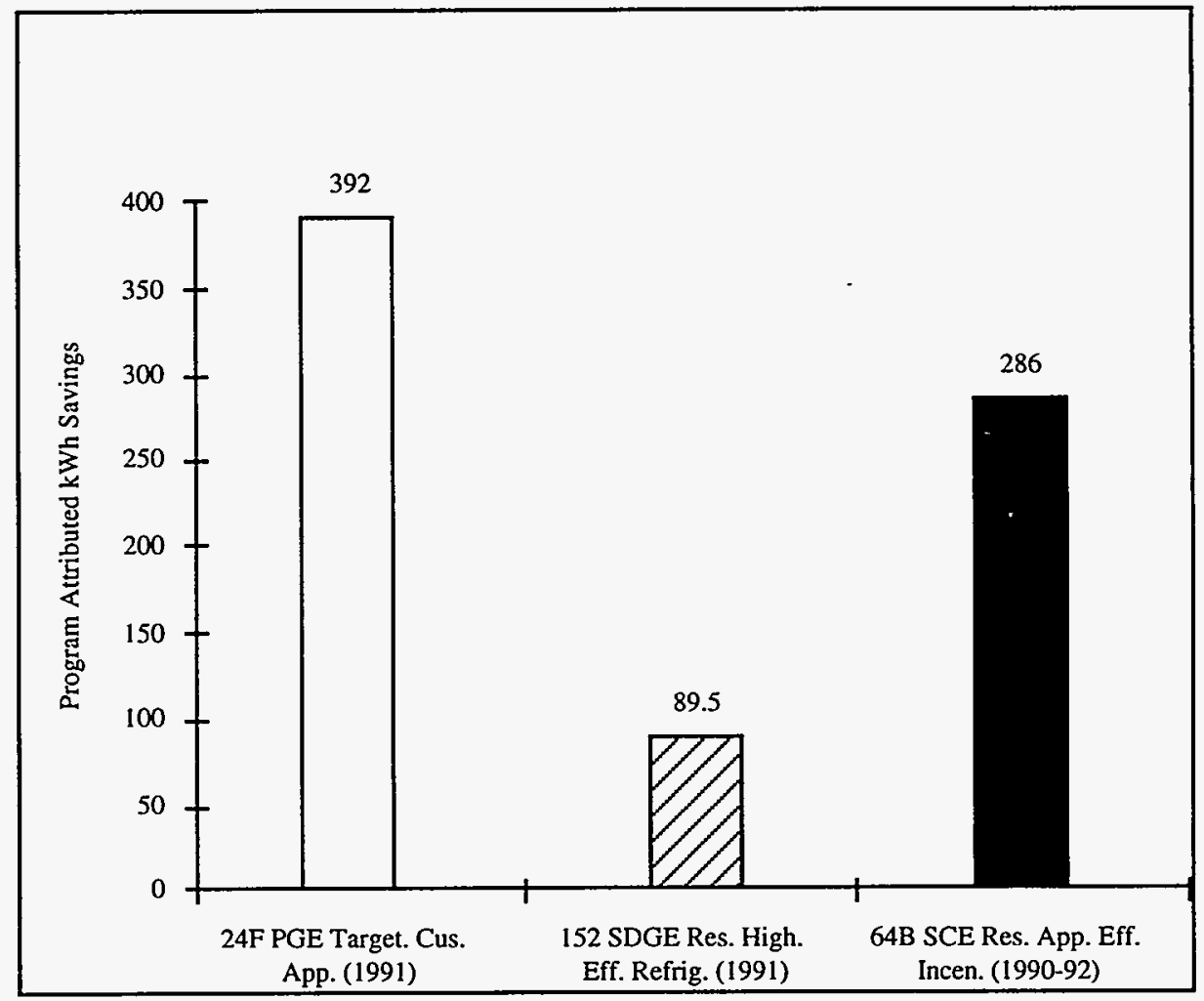

Figure 4.1 Savings Reported per Refrigerator Replaced

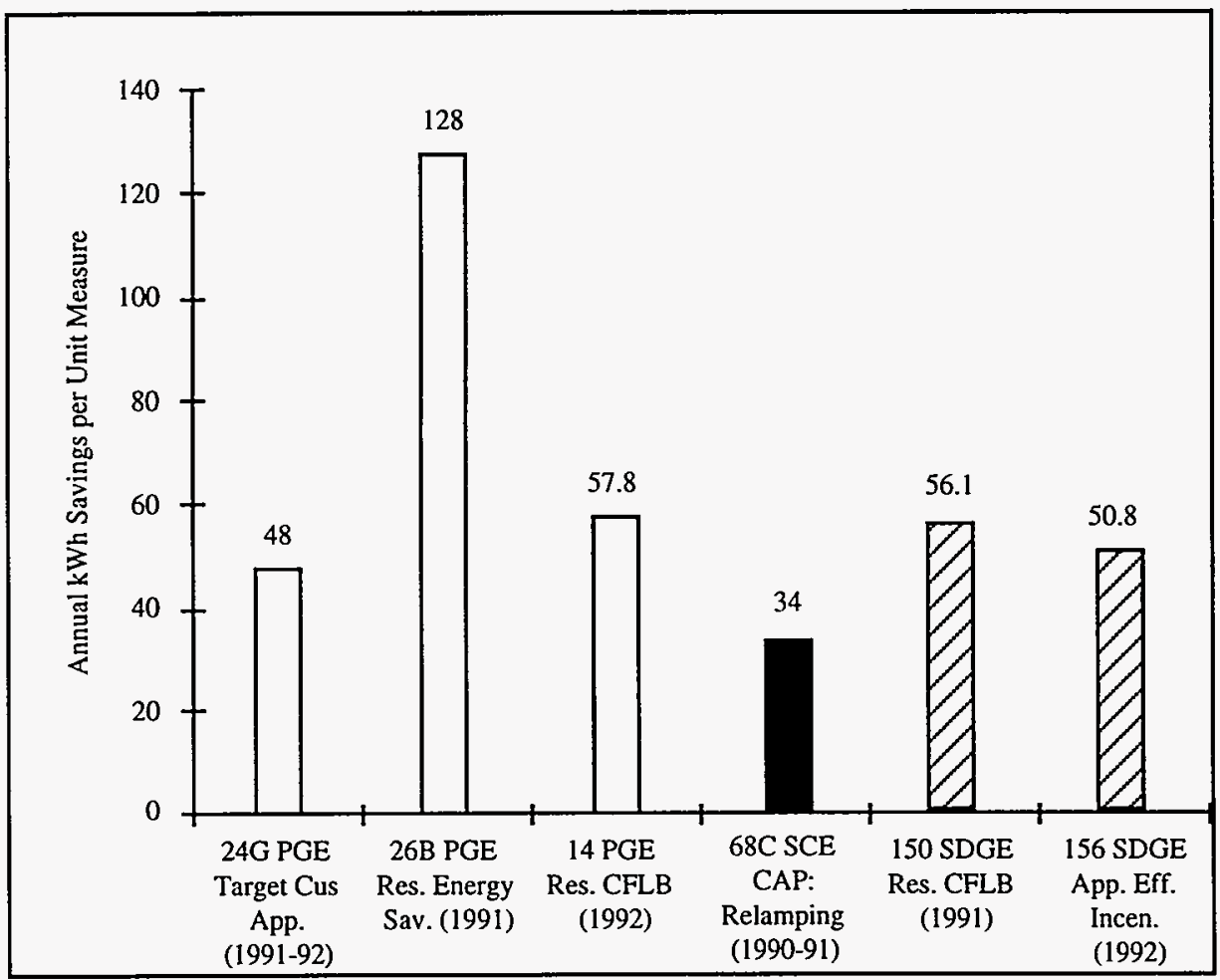

Figure 4.2 Savings Reported per Residential CFLB 


\subsection{COMMERCIAL, INDUSTRIAL, AND AGRICULTURAL MEASURES}

Ex-post estimates of impacts are available for only a few of the C/I/A measures covered by the evaluation reports studied here. These measure-specific estimates are discussed below.

The measure level savings reported by Southern California Edison for its 1990 Energy Management Services and Hardware Rebate Program are illustrated in Figures 4.3 and 4.4. (See Table C.9 in Appendix C for study details.) Figure 4.3 reports estimated annual gross kilowatt hour savings for the indicated measure category. ${ }^{1}$ Of the common measures selected for presentation in this report, lighting reflectors and HVAC energy management systems reported the largest gross annual savings at 96,960 kilowatt hours and 90,276 kilowatt hours respectively. Similarly, of the selected measures compared for demand savings, lighting reflectors again delivered the largest gross demand savings (19 $\mathrm{kW}$ ) followed by indoor lighting systems at $14.5 \mathrm{~kW}$ (see Figure 4.4).

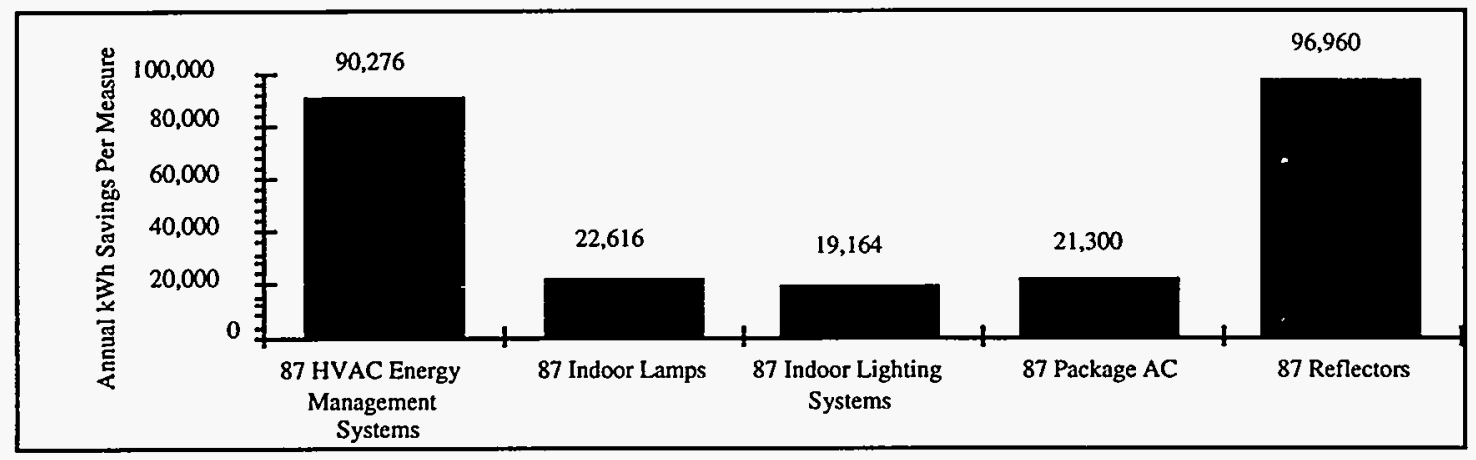

Figure 4.3 Annual kWh Savings Reported by C/I/A Measure Class

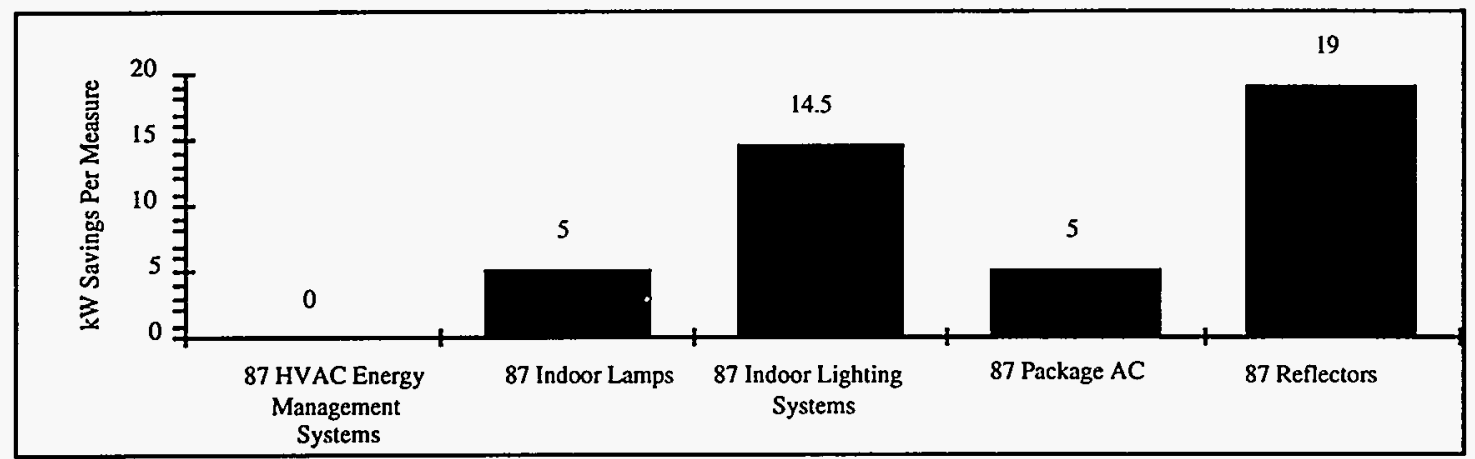

Figure 4.4 kW Savings Reported by C/L/A Measure Class

Figure 4.5 summarizes net annual gas savings per unit for selected measure types in the commercial, industrial, and agricultural sector. (See Table C.10 in Appendix C.) These results are

1 The study reports gross savings estimates for each measure category and then applies a blanket net-to-gross ratio to all per measure gross savings. The applicable net-to-gross ratios for combined rebate and energy management services programs are $93 \%$ for HVAC, $57 \%$ for lighting, and $63 \%$ for other hardware. 
reported by Southern California Gas across two studies (Study No. 137, High Efficiency Commercial Equipment and Study No. 139, Industrial Demand Side Management) for a full range of program measures. Only selected measures are illustrated in Figure 2.5. The figure demonstrates that the largest net gas savings among the commercial measures derived from high-efficiency air conditioning at 17,201 annual net therm savings per unit. (On a program-level basis, however, high efficiency boilers yielded the highest net savings at over 1.9 million therms per year.) In the industrial sector, Southern California Gas reports that of the selected measures analyzed in this report, industrial furnaces deliver the greatest net annual gas savings at 3,053 therms per unit followed by industrial boilers at 1,611 annual therms per unit. Savings covered the program years 1990-92.

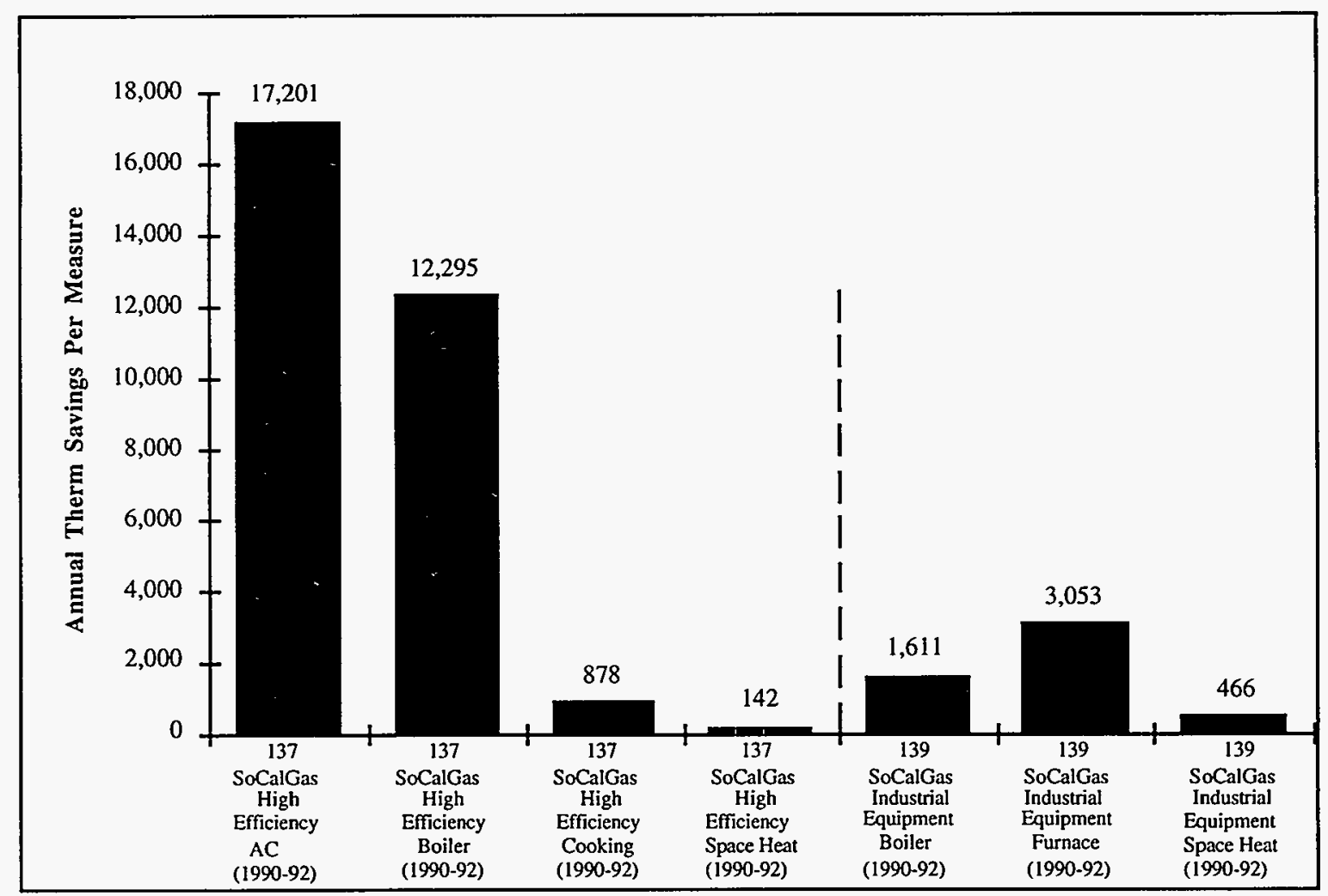

Figure 4.5 Annual Gas Savings Reported by C/I/A Measure Class (Therms) 


\section{COMPARISON OF EX-POST AND EX-ANTE IMPACT ESTIMATES}

This chapter assesses the relationship between ex-ante and ex-post estimates of energy savings. A primary purpose of the DSM impact evaluations described in this report is to determine whether or not any systematic biases exist in the ex-ante estimates of program savings. Do the anticipated savings tend to be larger or smaller than the savings subsequently achieved by the programs? Identification of systematic biases in the ex-ante estimates can lead to improvements in program design, more effective resource planning assumptions, and incentive payments that better reflect program benefits.

The realization rate is used as the main method of assessing bias. As a general rule, realization rates are calculated as the ex-post estimate of net savings divided by the ex-ante estimate of net savings. ${ }^{1}$ There are a few exceptions to this rule, however, as when the numerator of the realization rate is an ex-post estimate of gross savings because the impact study did not present net savings or because the net-to-gross ratio is assumed to be $100 \%$. In these cases, the denominator of the realization rate is usually an ex-ante estimate of gross savings. In still other exceptions the nature of the ex-ante estimate (i.e., net or gross) is unknown. Thus, the nature of all of the realization rates cannot be characterized with certainty.

Realization rates are influenced by numerous factors. First, external events such as economic conditions within a utility's service territory may cause a program to save more or less energy than planned. Economic growth, for instance, may increase the hours of operation of a commercial or industrial establishment, thereby increasing the energy saved by the installation of energy-efficient equipment. Alternatively, the demand for energy-efficient products could increase independent of the utility program. This could increase the percentage of free riders served by a program, thereby decreasing the energy savings attributable to the utility's DSM efforts.

Second, the methods used to predict the energy savings of a program (i.e., the ex-ante estimation procedure) may introduce biases in the calculation of realization rates. For instance, simple engineering calculations of ex-ante energy savings have often overestimated the energy savings generated by DSM programs (Keating and Nadel, 1991; Brown and White, 1992). An overestimation of the ex ante savings can cause the realization rate to fall below 1.0. Unfortunately, it

1 Net savings refer to the program impacts over-and-above naturally occurring conservation. They can be smaller than gross savings to the extent that some participants would have purchased and installed new energy conservation measures even without the program (i.e., free ridership). Net savings can also be larger than gross impacts to the extent that the program induces additional marketing by trade allies or additional customer investments in conservation measures outside of the program (i.e., market transformation). Many of the impact studies estimated the impacts of free ridership, but only a few of them attempted to estimate the market transformation impacts of California's DSM programs. As a result, in all of the impact studies reviewed, net savings never exceeded gross savings. 
was not possible to characterize the type of method used to produce ex-ante estimates of energy savings in order to explore this potential source of bias.

Finally, the methods used to estimate the energy savings of a program (e.g., the ex-post estimation procedure) may introduce biases in the calculation of realization rates. For instance, if the ex-post estimation procedure does not include an adjustment for free ridership, then the realization rate may be upwardly biased. Alternatively, if free drivers are counted as free riders, the bias is reversed. Similarly, ex-post estimation procedures that rely on engineering calculations can produce higher estimates than methods based on analysis of utility bills (Brown et al., 1991). The evaluation methods used to generate ex-post estimates of energy savings are examined in Section 5.5 as a potential source of bias.

We begin by describing the realization rates of all the programs and program segments studied, and compare these across utilities (Section 5.1) Attention then turns to an analysis of realization rates by sector (Section 5.2) and program type (Section 5.3). After describing the realization rates that resulted from different evaluation methods (Section 5.4), the chapter ends by focusing on the realization rates associated with three specific DSM measures (Section 5.5). As the chapter moves from an aggregate level of analysis to a focused assessment of specific measures, greater explanation of variations in realization rates is possible.

\subsection{REALIZATION RATES IN AGGREGATE}

The realization rates associated with 158 programs and program segments are examined in this section. PG\&E programs account for almost half of these rates (Table 5.1), which is consistent with the fact that they spent $46 \%$ of the DSM expenditures of these four utilities during the 1990-92 period. SDG\&E, on the other hand, accounts for $18 \%$ of the realization rates, while they spent only $9 \%$ of the DSM expenditures.

Table 5.1 Realization Rates by Utility

\begin{tabular}{|l|c|c|c|}
\hline & & & $\begin{array}{c}\text { Number of } \\
\text { Programs or } \\
\text { Segments }\end{array}$ \\
\hline All programs and program segments & 1.12 & 0.86 & 158 \\
\hline All programs/segments minus 4 highest outliers & 0.93 & 0.86 & 154 \\
\hline PG\&E & 0.99 & 0.83 & 73 \\
\hline SCE & 0.80 & 0.87 & 24 \\
\hline SoCalG & 1.78 & 0.66 & 32 \\
\hline SDG\&E & 0.99 & 0.95 & 29 \\
\hline
\end{tabular}


The lack of correspondence between each utility's percentage of DSM expenditures versus their percentage of realization rates underscores the fact that the 158 realization rates are not normalized in any sense. One value may represent a large program and may cover multiple years of program operation while another realization rate may represent a component of a smaller program and only a single year. Weighting of the realization rates by their ex-post estimates of net savings was beyond the scope of this study, but could represent a valuable addition to the analysis in future efforts of this type. ${ }^{2}$

The distribution of realization rates is shown in Figure 5.1. The median realization rate for all programs and program segments is 0.86 , and the mean is $1.12 .{ }^{3}$ Applying a statistical test for outliers, we note that the four highest realization rates are more than three standard deviations from the mean. If we do not include the four highest realization rates (ranging from 5.59 to 14.54), the median remains at 0.86 , but the mean realization rate drops to 0.93 .

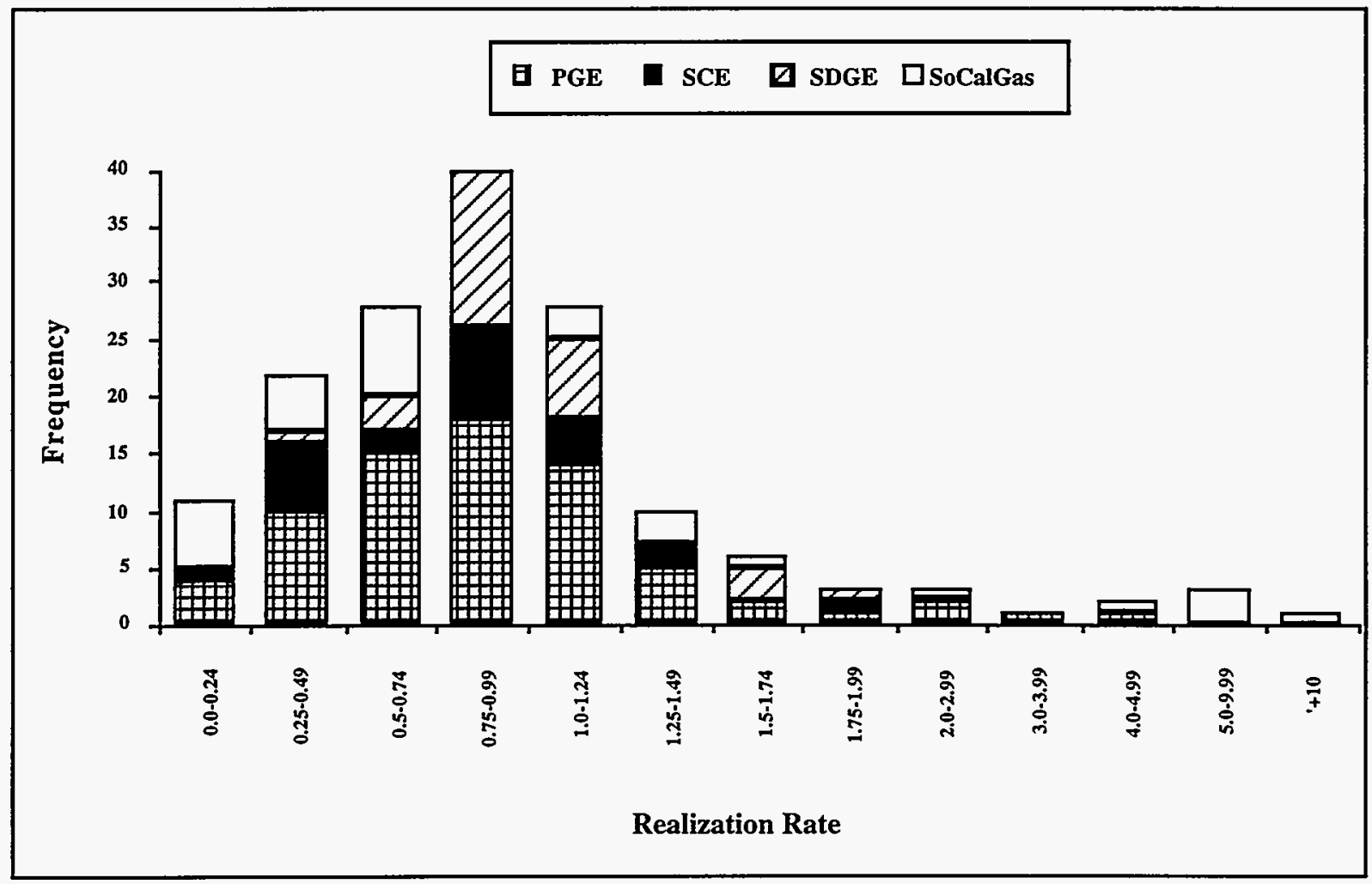

Figure 5.1 Distribution of Realization Rates (N=158)

2 For instance, if a realization rate is calculated by comparing the ex-post and ex-ante savings of a particular retrofit measure, then it would be necessary to know how many of these measures were installed to calculate the total energy savings associated with the realization rate. Alternatively, if a realization rate is calculated for a particular market segment, it would be necessary to know the number of participants in that segment to calculate the total energy savings and thereby weight the realization rate.

3 Both the mean and median values are unweighted measures of central tendency. Each realization rate is given an equal weighting in their calculation. 
If we assume that each realization rate is associated with a comparable level of energy savings, then the mean value of 1.12 for all programs and program segments suggests that in aggregate, these programs saved more energy than was anticipated by their ex-ante estimates. (Not including the four highest realization rates, the programs saved $93 \%$ of the energy anticipated by their ex-ante estimates.) A typical program, however, saved only $86 \%$ of the expected savings. This finding suggests that for a majority of the programs, the ex-ante estimates are upwardly biased, the ex-post estimates are downwardly biased, or both biases are operating simultaneously.

The realization rates range widely from the low values for a Showerhead Coupon Program of 0.03 (the electric component) and 0.05 (the gas component) to 14.54 for the boiler component of a High Efficiency Commercial Equipment Program (Figure 5.1). The difference between the mean and median values reflects the skewed distribution of realization rates. Nearly one quarter (22\%) of the programs delivered less than $50 \%$ of their ex-ante savings estimates, while $10 \%$ exceeded $150 \%$ of their ex-ante savings estimates and $3 \%$ exceeded $500 \%$ of their ex-ante savings estimates. This wide variation makes it difficult for resource planners to identify the optimum level of investment in DSM programs.

\subsection{REALIZATION RATES BY SECTOR}

The realization rates for commercial, industrial, and agricultural DSM programs tend to be higher than those for residential DSM programs (Table 5.2). The mean and median realization rates for C/I/A DSM programs are 1.26 and 0.91 , respectively, suggesting that these programs consistently produced the magnitude of savings that they were designed to deliver. (If the four highest C/I/A realization rates are removed, the mean is 0.96 and the median is 0.89.) In contrast, the mean and median realization rates for residential DSM programs are only 0.88 and 0.69 , respectively, suggesting that they consistently fell short of their projected energy savings. Some of these sectoral differences may be due to the fact that the impact studies of residential and $\mathrm{C} / \mathrm{J} / \mathrm{A}$ programs tended to rely on different ex-post estimation and evaluation methods. ${ }^{4}$ Further, a higher percentage of the commercial/industrial/agricultural programs (compared with the residential programs) were operated by the utilities on the basis of shared-savings incentives, which may motivate the utilities to produce or exceed the expected levels of energy savings, thus increasing the ex-post savings and, thereby, the realization rate.

4 For instance, 26 of the nonresidential realization rates resulted from ex-post estimates based on simplified engineering models, which had a median realization rate of 1.0. On the other hand, none of the residential realization rates used this method for ex-post estimation. 
Table 5.2 Mean and Median Realization Rates by Sector

\begin{tabular}{|l|c|c|c|}
\hline Sector: & Mean & Median & $\begin{array}{c}\text { Number of } \\
\text { Programs or } \\
\text { Segments }\end{array}$ \\
\hline Residential & 0.88 & 0.69 & 60 \\
\hline Commercial/Industrial/Agricultural & 1.26 & 0.91 & 98 \\
\hline
\end{tabular}

The commercial, industrial, and agricultural DSM programs account for the five highest realization rates (Figures 5.2 and 5.3). (Tables C.11 and C.12 in Appendix C provides details on the studies summarized in Figures 5.2 and 5.3.) All of these are associated with programs operated by SoCalGas and four of them relate to commercial programs. They include:

- the High Efficiency Commercial Equipment Program (boilers, dryers, and weatherization),

- the Industrial Equipment Replacement Program (space heat), and

- the High Efficiency New Commercial Building Program (water heating).

The C/I/A programs also have a cluster of low realization rates ranging from 0.1 to 0.3 . As with the high rates noted above, these low rates are also associated with programs operated by SoCalGas, but they are dominated by industrial programs. They are:

- the Industrial Equipment Replacement Program (boilers, dryers, and furnaces),

- the Industrial Heat Recovery Program, and

- the High Efficiency New Commercial Building Program (space heat and cooking).

In contrast to the $\mathrm{C} / \mathrm{I} / \mathrm{A}$ programs, none of the realization rates for residential programs exceed 3.8. (See Figure 5.2.) The two highest rates are associated with PG\&E programs:

- the Ceiling Insulation Rebate Program (demand component) and

- the Residential Energy Savings Program (wraps for electric domestic hot water heaters).

In addition to the two extremely low values noted earlier for PG\&E's Energy Saver Showerhead Coupon Program, eight additional residential programs or program segments have realization rates of 0.3 or less. All but one of these are associated with residential direct assistance programs, which are not promoted for resource acquisition purposes, including:

- PG\&E's Energy Partners Program (gas-heated single-family dwellings with air conditioning),

- PG\&E's Energy Partners Program (gas-heated single-family dwellings without air conditioning), 


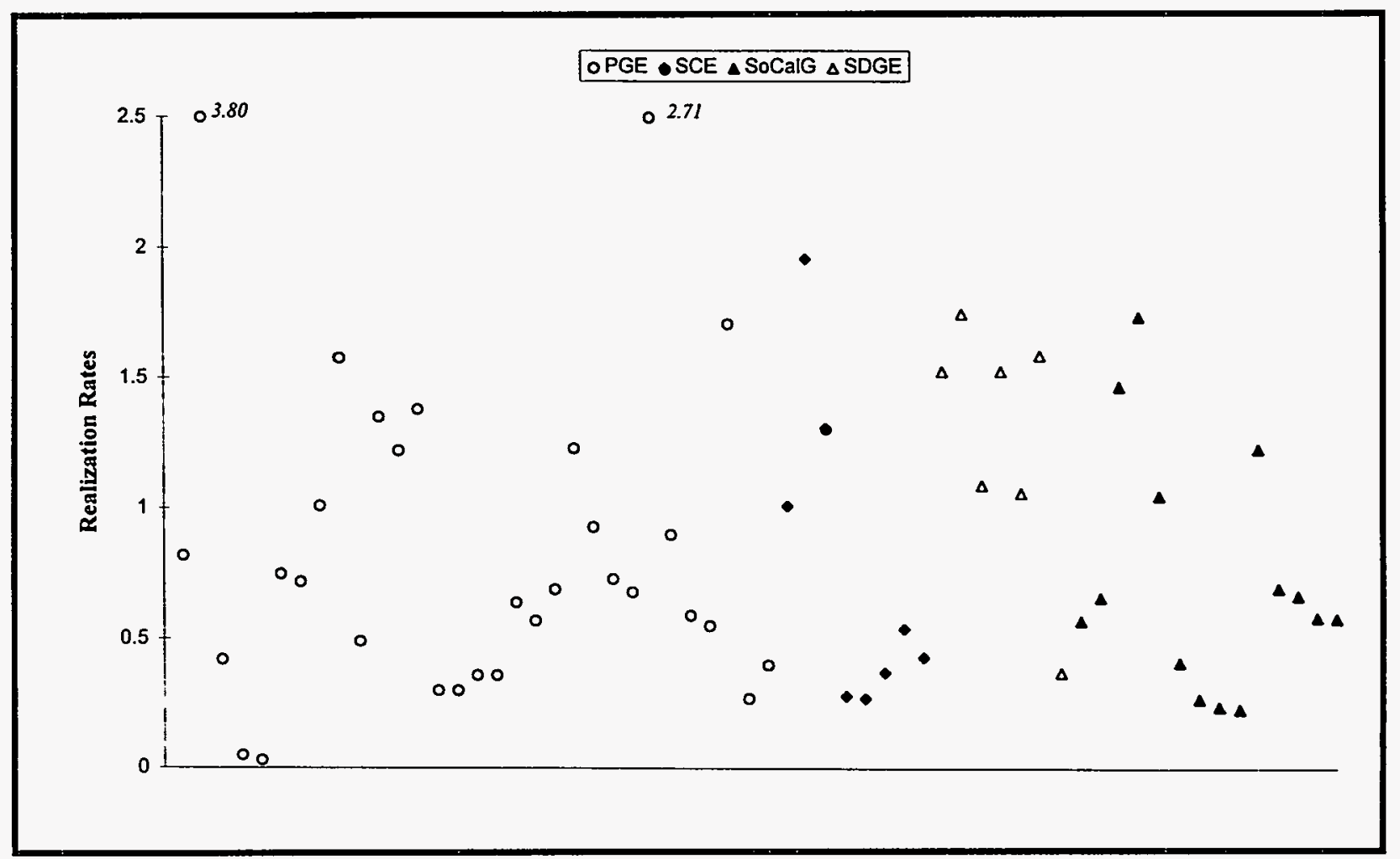

Figure 5.2 Realization Rates for all Residential Programs

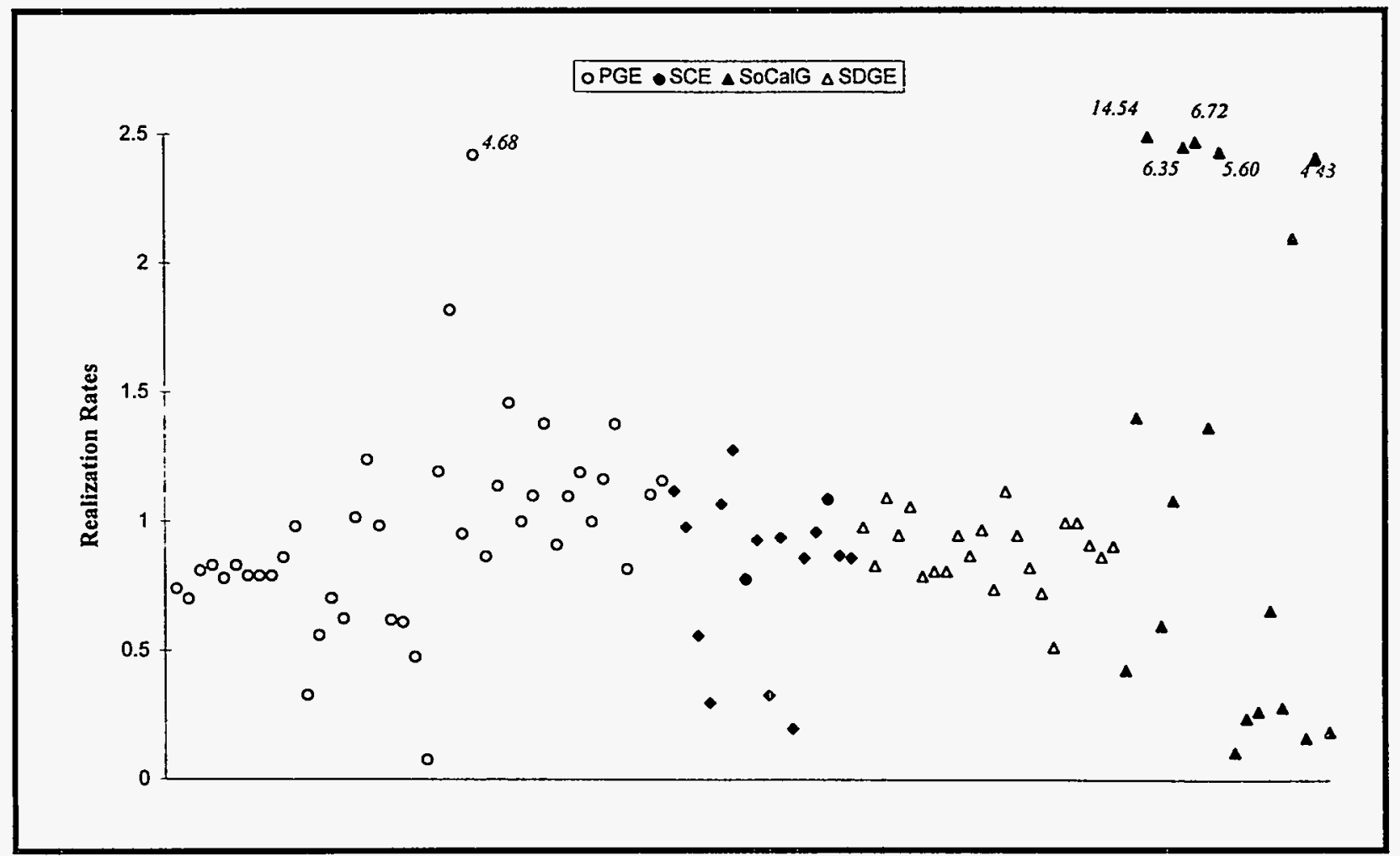

Figure 5.3 Realization Rates for all C/WA Programs 
- SCE's Customer Assistance Program (weatherization),

- SCE's Customer Assistance Program (evaporative coolers and heat pumps),

- SoCalGas's Weatherization/Conservation Program (attic insulation),

- SoCalGas's Weatherization/Conservation Program (water-heater blanket), and

- SoCalGas's Weatherization/Conservation Program (low-flow showerhead).

The other low realization rate pertains to the low-flow showerheads installed by PG\&E's Residential Energy Savings Program in dwellings with gas water heaters. Altogether, four of the lowest ten residential realization rates are associated with low-flow showerheads.

\subsection{REALIZATION RATES BY PROGRAM TYPE}

Of the seven types of DSM programs shown in Table 5.3, the lowest realization rates are experienced by residential direct assistance programs (with a mean of 0.68 and a median of 0.53 ). Recall that these programs account for a large share (29\%) of the total DSM expenditures of the four utilities during the three-year study period. The realization rates for the energy management services programs also tend to be less than 1.0. The residential energy management services programs tend to have particularly low realization rates, with a median of 0.59 but a mean of 1.0 , reflecting a few high-

Table 5.3 Realization Rates by Type of Program

\begin{tabular}{|c|c|c|c|}
\hline Type of Program & Mean & Median & $\begin{array}{l}\text { Number of } \\
\text { Programs or } \\
\text { Segments }\end{array}$ \\
\hline \multicolumn{4}{|l|}{ Resource Program: } \\
\hline TOTAL & 1.36 & 0.86 & 83 \\
\hline Residential retrofit incentives & 1.18 & 1.06 & 17 \\
\hline C/I/A retrofit incentives & 1.54 & 0.91 & 52 \\
\hline Residential new construction & 0.78 & 0.70 & 8 \\
\hline C/I/A new construction & 1.16 & 0.66 & 6 \\
\hline \multicolumn{4}{|l|}{ Equity/Service Program: } \\
\hline TOTAL & 0.85 & 0.86 & 75 \\
\hline Residential direct assistance & 0.68 & 0.53 & 26 \\
\hline $\begin{array}{l}\text { Residential energy management } \\
\text { services. }\end{array}$ & 1.00 & 0.59 & 9 \\
\hline C/I/A energy management services & 0.92 & 0.95 & 40 \\
\hline
\end{tabular}


performing programs. C//A energy management services programs have mean and median realization rates of 0.92 and 0.95 , respectively, indicating that they came close to generating the energy savings they were projected to deliver. All three of these types of programs earn performance-adder incentives for the utilities, and not shared savings incentives.

With the exception of residential new construction programs, the shared-savings incentive programs generally had higher-than-average realization rates. Residential retrofit incentive programs have the highest median realization rate (1.06 compared to 0.86 for all realization rates), and their commercial, industrial, and agricultural counterparts had the highest mean realization rate (1.54 compared to 1.12 for all realization rates). Recall that retrofit incentive programs account for the second largest share of total DSM expenditures (23\%) during the three-year study period. They also are the dominant DSM expenditure for which utilities earn shared savings incentives.

\subsection{REALIZATION RATES OF DIFFERENT EVALUATION METHODS}

In this section, a typology of seven evaluation methods is used to examine median realization rates. In Section 5.4 we look more closely at evaluation methods in conjunction with three selected DSM measures.

Tables 5.4 presents the mean and median realization rates for the seven evaluation methods, and for residential and C/I/A programs, separately.

Table 5.4 Realization Rates for Seven Evaluation Methods

\begin{tabular}{|l|c|c|c|c|c|c|}
\hline \multirow{2}{*}{ Evaluation Method: } & \multicolumn{3}{|c|}{ Residential Programs } & \multicolumn{3}{c|}{ C/I/A Programs } \\
\cline { 2 - 7 } & Mean & Median & $\begin{array}{c}\text { Number of } \\
\text { Programs or } \\
\text { Segments }\end{array}$ & Mean & Median & $\begin{array}{c}\text { Number of } \\
\text { Programs or } \\
\text { Segments }\end{array}$ \\
\hline Billing analysis & 0.81 & 0.64 & 23 & 0.95 & 0.87 & 33 \\
\hline $\begin{array}{l}\text { Conditional demand } \\
\text { analysis }\end{array}$ & 0.96 & 0.67 & 21 & 2.87 & 1.09 & 14 \\
\hline Metered data & 0.93 & 0.86 & 4 & NA & NA & NA \\
\hline $\begin{array}{l}\text { Simplified engineering } \\
\text { model }\end{array}$ & NA & NA & NA & 1.23 & 1.00 & 26 \\
\hline $\begin{array}{l}\text { Engineering simulation } \\
\text { model }\end{array}$ & 0.94 & 0.48 & 6 & 3.10 & 0.78 & 6 \\
\hline $\begin{array}{l}\text { Statistically adjusted } \\
\text { engineering approach }\end{array}$ & 0.75 & 0.69 & 13 & 0.86 & 0.87 & 20 \\
\hline $\begin{array}{l}\text { Calibrated engineering } \\
\text { model }\end{array}$ & 1.22 & 1.31 & 6 & 0.75 & 0.79 & 13 \\
\hline
\end{tabular}

a Total exceeds 158 observations due to multiple methodologies being applied in some cases. 
Billing analysis and statistically adjusted engineering approaches both produce similar results in that mean and median realization rates of less than one are observed for both residential and CI/A programs. The tendency for billing analysis to produce lower-than-average realization rates is highlighted by the fact that it accounts for four of the six lowest C/I/A realization rates (all four of which relate to industrial programs). In the residential sector, billing analysis appears to be the "methodology of choice" for evaluating residential direct assistance programs. Thus, the association of equity programs with low realization rates may be an artifact of the methodology used to estimate their ex-post energy savings.

Of the remaining evaluation methods, calibrated engineering models tended to produce high realization rates in the residential sector, and low rates in the C/V/A sector. In contrast, conditional demand analysis produced high realization rates in the C/L/A sector and average rates in the residential sector. Simplified engineering models are associated with 26 realization rates in the CII/A sector and produce a median realization rate of 1.0 and a mean value of 1.23 . In contrast, simplified engineering models -- with relatively high realization rates among $\mathrm{C} / \mathrm{T} / \mathrm{A}$ programs -- were not used at all in the residential sector, which may have contributed to this sector's relatively low realization rates.

\subsection{REALIZATION RATES FOR SELECTED MEASURES}

Realization rates for three residential DSM measures are examined in this section: compact fluorescent lamps, low-flow showerheads, and refrigerator replacements. Collectively, these three measures have median realization rates that span the spectrum from 0.27 for low-flow showerheads to 1.23 for refrigerator replacements (Table 5.5). In addition to the wide variation in realization rates across programs offering different measures, there is also considerable variation in realization rates among programs offering similar measures. Features of the DSM programs that offer these measures and their impact evaluations are described below in an attempt to explain why realization rates are so variable.

Table 5.5 Realization Rates by Selected Measure

\begin{tabular}{|l|c|c|c|}
\hline & Mean & Median & $\begin{array}{c}\text { Number of } \\
\text { Programs or } \\
\text { Segments }\end{array}$ \\
\hline Compact fluorescent lamps & 0.90 & 0.83 & 6 \\
\hline Low-flow showerheads & 0.57 & 0.27 & 7 \\
\hline Refrigerator replacements & 1.29 & 1.23 & 4 \\
\hline
\end{tabular}

Compact Fluorescent Lamps. The impact evaluations present six realization rates for compact fluorescents. These rates vary from 0.37 to 1.59 , with a mean of 0.90 and a median of 0.83 . Table 5.6 summarizes some of the key factors that help to explain this wide variation. 
Table 5.6 Realization Rates for Compact Fluorescent Lamps

\begin{tabular}{|l|r|r|r|r|r|r|}
\hline & \#68C & \#24G & $\# 14$ & \#26B & \#150 & $\# 156$ \\
\hline Realization Rate & 0.37 & 0.68 & 0.75 & 0.90 & 1.09 & 1.59 \\
\hline $\begin{array}{l}\text { Ex-ante Net Savings } \\
\text { (kWh/bulb) }\end{array}$ & 89 & 71 & 77 & 142 & 51 & 32 \\
\hline $\begin{array}{l}\text { Ex-post Net Savings } \\
\text { (kWh/bulb) }\end{array}$ & $33^{\mathrm{b}}$ & $48^{\mathrm{b}}$ & 58 & 128 & $56^{\mathrm{b}}$ & 51 \\
\hline Utility & $\mathrm{SCE}$ & PG\&E & PG\&E & PG\&E & SDG\&E & SDG\&E \\
\hline $\begin{array}{l}\text { Lamps Distributed Per } \\
\text { Participant }\end{array}$ & 4.6 & 1.0 & 2.8 & 2.0 & 1.5 & 1.9 \\
\hline $\begin{array}{l}\text { Evaluation Method in Ex- } \\
\text { post Analysis }\end{array}$ & $\mathrm{SAE}$ & $\mathrm{SAE}$ & $\mathrm{CEM}$ & $\mathrm{BA}$ & $\mathrm{CEM}$ & $\mathrm{CEM}$ \\
\hline $\begin{array}{l}\text { Measure Retention Rate } \\
\text { Used in Ex-post Analysis }\end{array}$ & $100 \%$ & $90 \%$ & $87 \%$ & $71 \%$ & $61 \%$ & $80 \%$ \\
\hline $\begin{array}{l}\text { Rebound Effect Used to } \\
\text { Adjust Savings in Ex-post } \\
\text { Analysis }\end{array}$ & No & No & Yes & No & No & No \\
\hline $\begin{array}{l}\text { Free Ridership Estimate in } \\
\text { Ex-post Analysis }\end{array}$ & No & No & $25 \%$ & $48 \%$ & No & $22 \%$ \\
\hline $\begin{array}{l}\text { Average Wattage Replace- } \\
\text { ment in Ex-post Analysis }\end{array}$ & 75 & 37 & 55 & NA & 61 & 60 \\
\hline $\begin{array}{l}\text { Average Hours of Use Per } \\
\text { Day in Ex-post Analysis }\end{array}$ & 1.8 & 3.2 & 3.2 & NA & 4.1 & 3.7 \\
\hline
\end{tabular}

a $\mathrm{SAE}=$ statistically adjusted engineering approach

$\mathrm{CEM}=$ calibrated engineering model

$\mathrm{BA}=$ billing analysis

$\mathrm{NA}=$ information not reported in impact study

b The net-to-gross ratio is assumed to be $100 \%$ in these studies.

The magnitude of the ex-ante estimates of energy savings appears to explain some of the wide variation in realization rates. The six programs varied significantly in the assumed energy savings of a compact fluorescent bulb, ranging from 32 to $142 \mathrm{kWh} / \mathrm{lamp}$, and the two programs with the largest realization rates have the lowest estimates of ex-ante savings. Uniformity is not to be expected, since energy savings depend upon hours of use, replaced wattages, and levels of free ridership, among other variables. However, the variability among these six programs is also a function of differences in what factors are included in the ex-ante estimates. For instance, the planning assumptions for several of these programs did not include the possibility of free riders and did not discount the estimated energy savings to reflect the non-installation, removal, burnout, or destruction of some lamps. Where the planning assumptions were reported in the impact studies, they 
tended to overstate the magnitude of likely savings. For instance, PG\&E assumed an average of 5.1 hours of use per lamp in its 1992 Residential Compact Fluorescent Lighting Program, while the impact study estimated 3.2 hours. Similarly, PG\&E assumed that the lamps replaced by its Targeted Customer Appliance Program averaged 100 watts, but the impact study indicated an average of 65 watts, leading to a low average wattage replacement of 37 .

Different evaluation methods appear to characterize higher versus lower realization rates. Calibrated engineering models were used for both of the SDG\&E programs where ex-post estimates exceeded ex-ante projections. In contrast, statistically adjusted engineering approaches were used to evaluate the two programs with the lowest realization rates. Further, as noted above, realization rates will be lower if measure installation rates, rebound effects, and free ridership are included in the $e x$ post estimation, but not in the ex-ante estimation.

Program features also appear to explain realization rates. For instance, the lowest realization rate and the lowest ex-post energy savings was experienced by SCE's Relamping Program, which installed 4.6 lamps per participating low-income participant. This rate of installation may exceed the cost-effective opportunities available in the average participant's home, given the need for a lamp to be used several hours a day so that its replacement is cost-effective. This program had the lowest average hours of use per day (1.8 hours), which is consistent with the finding in Impact Study \#156 that installation and persistence rates decline as the number of compact fluorescent lamps distributed to each participating household rises.

Finally, indicators of program performance can explain the wide-ranging realization rates. For instance, the three programs that estimated free ridership produced estimates that ranged from $22 \%$ to $46 \%$, differences which will dramatically affect ex-post savings estimates as well as realization rates if these estimates deviate from planning assumptions. Similarly, rates of measure retention ranged from $61 \%$ to $90 \%$, average daily usage ranged from 1.8 to 4.1 hours per day, and average wattage replacement ranged from 37 to 75 watts. In general, the lower these values are, the lower the realization rates.

Altogether, this analysis of realization rates for compact fluorescent lamps highlights the large complex of factors that can cause actual savings to fall short (or significantly exceed) anticipated savings.

Low-Flow Showerheads. The impact evaluations present seven realization rates for low-flow showerheads. These rates vary from 0.03 to 1.75 , and have a median value of 0.27 . Table 5.7 summarizes some of the key features of these programs and their impact evaluations. 
Table 5.7 Analysis of Realization Rates for Low-Flow Showerheads

\begin{tabular}{|c|c|c|c|c|c|c|c|}
\hline & \#13B & $\# 13 \mathrm{~A}$ & \#130G & $\# 26 \mathrm{~F}$ & $\# 26 \mathrm{C}$ & \#155 & $\# 149$ \\
\hline Realization Rate & 0.03 & 0.05 & 0.23 & 0.27 & 0.59 & 1.06 & 1.75 \\
\hline $\begin{array}{l}\text { Ex-ante Net Savings per } \\
\text { Showerhead }\end{array}$ & $418 \mathrm{kWh}$ & $\begin{array}{c}19 \\
\text { therms }\end{array}$ & $\begin{array}{c}43^{\mathrm{b}} \\
\text { therms }\end{array}$ & $\begin{array}{c}37 \\
\text { therms }\end{array}$ & $832 \mathrm{kWh}$ & $\begin{array}{c}26^{\mathbf{b}} \\
\text { therms }\end{array}$ & $\begin{array}{c}12^{\mathrm{b}} \\
\text { therms }\end{array}$ \\
\hline $\begin{array}{l}\text { Ex-post Net Savings per } \\
\text { Showerhead } \\
\end{array}$ & $20 \mathrm{kWh}$ & 1 therm & $\begin{array}{c}10 \\
\text { therms }\end{array}$ & $\begin{array}{c}10 \\
\text { therms }\end{array}$ & $495 \mathrm{kWh}$ & $\begin{array}{c}28 \\
\text { therms }\end{array}$ & $\begin{array}{c}21 \\
\text { therms }\end{array}$ \\
\hline Utility & PG\&E & PG\&E & SoCalGas & PG\&E & PG\&E & SDG\&E & SDG\&E \\
\hline $\begin{array}{l}\text { Evaluation Method in } \\
\text { Ex-post Analysis } \\
\end{array}$ & ESM & ESM & $\mathrm{CDA}$ & $\mathrm{BA}$ & $\mathrm{BA}$ & $\mathrm{BA}$ & CEM \\
\hline $\begin{array}{l}\text { Measure Retention Rate } \\
\text { Used in Ex-post Analysis }\end{array}$ & $94 \%$ & $94 \%$ & $100 \%$ & $83 \%$ & $83 \%$ & $100 \%$ & $97 \%$ \\
\hline $\begin{array}{l}\text { Free Riders Estimate in } \\
\text { Ex-post Analysis }\end{array}$ & $92 \%$ & $92 \%$ & $0 \%$ & $40 \%$ & $40 \%$ & $0 \%$ & $0 \%$ \\
\hline
\end{tabular}

a ESM=engineering simulation model

$\mathrm{CDA}=$ conditional demand analysis

$\mathrm{BA}=$ billing analysis

CEM=calibrated engineering model

b The net-to-gross ratio is assumed to be $100 \%$ in these studies.

As with the analysis of compact fluorescent lamps, the magnitude of ex-ante estimates of energy savings appears to explain some of the variation in realization rates. The ex-ante estimates of energy savings per low-flow showerhead vary widely, from 418 to $832 \mathrm{kWh} / \mathrm{year}$ and from 12 to 57 therms/year. The two programs with highest realization rates are both associated with relatively low ex-ante estimates of savings.

The use of different evaluation methods also helps to explain the magnitude of realization rates. In particular, the two highest realization rates resulted from evaluations that did not take into account the existence of free riders. In contrast, the two lowest realization rates (associated with PG\&E's 1992 Energy Saver Showerhead Coupon Program) were the result of impact evaluations with extremely high estimated free ridership rates $(92 \%)$ that were not anticipated when planning the program (when it was assumed that half of the participants would be free riders). Ex-post estimates of the retention of low-flow showerheads were fairly consistent across the impact studies, ranging from $83 \%$ to $97 \%$. Although the planning estimates for this factor were not reported, it is unlikely that measure persistence was a major source of variation between realization rates.

The extremely low realization rates for PG\&E's 1992 Energy Saver Showerhead Coupon Program also reflect the program's success during previous years. By 1992, the availability of highflow showerheads to be replaced with program showerheads had shrunk dramatically, and with it, 
realized savings. Because the showerheads being replaced often had moderate, rather than high, gallon-per-minute flow rates, the program's ex-post estimate of energy savings was less than one-third of its ex-ante estimates. The high free ridership level in 1992 may also reflect the market impacts of the program during previous years.

Refrigerator Replacements. The impact evaluations present four realization rates for refrigerator replacements. These rates vary from 0.73 to 1.96 , and have a median value of 1.23 (Table 5.8).

Table 5.8 Analysis of Realization Rates for Refrigerator Replacements

\begin{tabular}{|l|c|c|c|c|}
\hline & \#24F & $\# 24 E$ & $\# 152$ & \#64B \\
\hline Realization Rate & 0.73 & 0.93 & 1.53 & 1.96 \\
\hline Type of Program ${ }^{\mathrm{a}}$ & ER \& RR & ER \& RR & EER & EER \\
\hline $\begin{array}{l}\text { Ex-ante Net Savings } \\
\text { (kWh/Refrigerator) }\end{array}$ & 537 & 422 & 59 & 146 \\
\hline $\begin{array}{l}\text { Ex-post Net Savings } \\
\text { (kWh/Refrigerator) }\end{array}$ & 392 & 392 & 90 & 286 \\
\hline $\begin{array}{l}\text { Utility } \\
\begin{array}{l}\text { Evaluation Method in Ex- } \\
\text { post Analysis }\end{array}\end{array}$ & SG\&E & PG\&E & SDG\&E & SCE \\
\hline $\begin{array}{l}\text { Free Ridership Accounted } \\
\text { for in Ex-post Analysis }\end{array}$ & Yes & SAE & CEM & CDA \\
\hline
\end{tabular}

a ER=early retirement $R R=$ refrigerator repairs EER=incentives to buy more energy-efficient refrigerators b $\quad$ SAE=statistically adjusted engineering approach

$\mathrm{CDA}=$ conditional demand analysis CEM=calibrated engineering model

The four realization rates listed in Table 5.8 refer to two different types of refrigerator replacement programs. PG\&E's Targeted Customer Appliance Program is primarily an "early retirement" program designed to help low-income customers reduce their electricity bills by replacing their older less energy-efficient appliances with more efficient ones at no cost to the participant. ${ }^{5}$ One of the realization rates is for 1991 (Impact Study \#24E) and the second is for 1992 (Impact Study \#24F). The other two programs provided incentives for households to purchase more energyefficient refrigerators. ${ }^{6}$

5 In some cases the Program repairs broken refrigerators or provides new refrigerators to households that do not have working appliances, thereby increasing their electricity consumption.

6 SCE's Residential Appliance Efficiency Incentives Program gave $\$ 50$ to $\$ 100$ rebates to residential customers who bought refrigerators that were larger than 12 cubic feet and were more efficient than refrigerators conforming to the California Energy Efficiency Title 20 refrigerator efficiency standards. The SDG\&E Residential Appliance Efficiency Incentives Program for refrigerators was designed to provide financial incentives to encourage 
Realization rates differ by type of program. The highest ex-ante savings estimates and the lowest realization rates are associated with PG\&E's early retirement program. The difference between the 1991 and 1992 realization rates ( 0.93 and 0.73 , respectively) is a function of different ex-ante estimate of net savings. The ex-ante estimate for 1992 was increased based on the assumption that the 1992 program would replace more energy-inefficient refrigerators than in 1991. The lowest $e x$ ante savings estimates and the highest realization rates-both exceeding 1.5 -were associated with the two programs that offered incentives to promote the purchase of more energy-efficient refrigerators. Thus, the ex-ante net savings of the first type were overestimated, and for the second type they were underestimated.

A variety of different evaluation methods were used to estimate the energy saved by the program per replaced refrigerator. As with the previous DSM measures, statistically adjusted engineering approaches produced lower realization rates than calibrated engineering models. Each of the evaluations accounted for free ridership in their ex-post estimation of net savings, but different methods were used. The PG\&E program's evaluation user survey data to estimate a free ridership rate of about $30 \%$, the SDG\&E program's evaluation compared retail sales before vs. after the program to estimate net impacts, and the SCE program's evaluation used a nonparticipant group in its conditional demand analysis to adjust for free ridership. These different approaches may have had an impact on the resulting realization rates.

In sum, the impact studies reviewed here suggest that on average, California's DSM programs operating between 1990 and 1992 delivered $112 \%$ of the energy savings that were planned, and the typical program delivered approximately $86 \%$ of the energy savings it was designed to deliver. A majority of the programs $(62 \%)$ delivered between $50 \%$ and $125 \%$ of their ex-ante savings. The implementation of initiatives to narrow this range should be a major thrust of resource planners and program managers in the four California utilities. The impact of different ex-ante estimation procedures warrants further examination in this regard. The ex-ante estimates of savings for similar DSM measures, across utilities and across programs in the same utilities, were found to be extremely wide ranging and a possible source of systematic bias in the realization rates.

No single program feature or ex-post evaluation method appears to dictate a program's realization rate. However, by comparing the realization rates of similar DSM measures, it is possible to identify likely influences. In the residential sector, high realization rates are associated with calibrated engineering models, relatively low ex-ante estimates of savings, and evaluations that fail to discount savings for free riders, rebound effects, and imperfect measure retention. Among the CI/A

customers to purchase high efficiency refrigerators. High efficiency refrigerators are defined as units having a capacity of 12 cubic feet or more and exceeding the Title 20 efficiency standards by at least $10 \%$. Incentives ranged from $\$ 50$ to $\$ 400$, depending upon the level of efficiency improvement above current standards. 
programs, high realization rates are associated with commercial-sector programs and ex-post evaluation methods that involve simplified engineering models and conditional demand analysis. 


\section{CONCLUSIONS}

This report summarizes the results of more than 50 individual evaluation studies conducted by the four largest California investor-owned utilities. The effort involved the review of extensive amounts of material, including each utility's annual DSM activities reports and the individual evaluation studies themselves. It did not include (a) the collection of savings data sufficient for weighting realization rates; (b) analysis of the procedures used to generate ex-ante estimates of energy savings; or (c) the compilation of utility statistics, such as operating resources and the numbers of customers by sector, which would be necessary to compare and contrast the relative market penetration of each utility's DSM activities. Thus, the analysis involved the synthesis of a great deal of information, but did not include all of the data required to fully exploit the lessons to be learned by the compendium of impact studies.

Based on this review, the authors offer the following conclusions:

- The evaluation studies summarized in this report represented a monumental effort. Fifty evaluation studies, some multi-volume, were prepared at a cost of millions of dollars. Vast amounts of data were collected and analyzed. While the depth and rigor of the evaluations described in these 50 reports varied tremendously, state-ofthe-art methodologies generally were employed in an attempt to quantitatively estimate the energy and demand savings associated with the DSM programs of the four utilities. In some cases, multiple methodologies were employed in parallel to converge on the savings estimates (triangulation).

- The quantity of demand and energy savings documented in the evaluation studies is substantial. Over 1.3 million mWh of electricity savings, 11,500 kilotherms of gas savings and $225 \mathrm{MW}$ of demand savings, were reported across only those studies reporting at the program level. For example, PG\&E's Commercial, Industrial, and Agriculture Rebate Program produced in excess of 663,000 megawatt hours over a two-year period. In aggregate, C/I/A programs generated substantially more energy savings than residential programs.

- The transferability of savings estimates from DSM programs across utilities would be a desirable outcome so that utilities could learn from each other's evaluation experience. However, the transferability of savings estimates is impaired by the lack of common reporting formats and evaluation methods. The utilities employed a wide variety of evaluation methodologies and formats for reporting results. Particularly in the commercial, industrial, and agricultural studies, the utilities pursued four entirely different approaches to both the analysis and presentation of impact results. This made the job of consistent summarization and transferability extremely difficult. Future evaluation efforts, if they are to be compared consistently, should employ more consistent evaluation methods and adopt common reporting formats. The California Protocols and Procedures for the Verification of Costs, Benefits, and Shareholder Earnings from Demand-Side Management Programs, which took effect on January 1, 1994, should ensure such consistent reporting formats in the future. This will greatly facilitate future efforts to compile savings estimates across utilities and programs. The use of consistent evaluation methods for evaluating similar types of DSM programs (e.g., all four utilities' residential direct assistance programs) would be helpful. 
- The analysis of realization rates indicates that, on average, the 158 programs and program segments delivered $112 \%$ of their anticipated savings. However, this mean value is influenced by four very high realization rates, which are greater than 3 standard deviations from the mean. (This is illustrated by the median value of 0.86). If the four highest realization rates (ranging from 5.59 to 14.54) are removed from the analysis, the median remains at 0.86 , but the mean realization rate drops significantly to 0.93 . Overall, these results suggest that the forecasts of energy savings from the DSM programs were reasonably accurate. They also indicate that the California DSM programs operating between 1990 and 1992 have out-performed typical programs from the 1980's (both in California and nationwide), which often fell short of their expected savings by $30 \%$ to $70 \%$. However, it was not possible to discern how much the improved performance resulted from greater actual energy savings versus improved forecasting.

- The analysis of realization rates also indicated a high degree of variability in the ex-ante estimates. In some cases for similar technologies and measures, ex-ante savings estimates varied by as much as $300 \%$. This often had a strong impact on realization rates. Future evaluations might benefit from more consistent development and utilization of ex-ante approaches to narrow the range of variability. In addition, future attempts to compare and contrast realization rates would benefit from information on the methods used to produce ex-ante estimates of energy savings. It is recommended that the evaluation Protocols include such documentation of ex-ante estimation procedures in the reporting formats.

- One objective of evaluation is to enhance program performance. The lessons learned from evaluation may be factored back into program re-design to improve performance, reduce costs, and enhance savings and program efficiency. The wide degree of variation in ex-post savings estimates suggests that there are lessons to be learned about program design features that lead to higher or lower savings. It should be possible to identify what it is about some programs that make them generate greater savings than other programs serving the same sector and promoting similar DSM measures. The use of highly varying evaluation methods, however, makes it difficult to isolate program design effects. Future efforts may seek to evaluate similar programs using similar methods so as to identify the impacts of different program design features.

- For effective use in state-level DSM planning and forecasting, the ability must exist to aggregate savings estimates and evaluation results. The authors feel that the evaluation studies summarized in this report offer valuable information for statelevel planning. However, the structure of the studies did not permit consistent aggregation. The adoption of consistent reporting formats and structures in the future via adherence to the evaluation protocols should greatly facilitate the ability to aggregate the savings results.

The primary objective of this report was to summarize California's recent DSM evaluation studies. Additional analysis and review is recommended to assess particular components of the evaluations. For example, with some additional research, realization rates could be weighted by energy savings or expenditure levels to produce a more robust indication of overall program performance. 
In summary, the studies reviewed for this report provide a preliminary basis for (a) obtaining insights into the performance of California's DSM programs, (b) developing information which can be used to enhance program performance, and (c) guiding future evaluation work. The California monitoring and evaluation protocols should allow future evaluation efforts to build off this base and produce results which allow more complete summaries and comparisons across utilities. 


\section{REFERENCES}

Brown, Marilyn A., et al. 1991. The Impact of Bonneville's Model Conservation Standards on the Energy Efficiency of New Home Construction, Oak Ridge National Laboratory. ORNL/CON-310, August.

Brown, Marilyn A. and Dennis L. White. 1992. Evaluation of Bonneville's 1988 and 1989 Residential Weatherization Program: A Northwest Study of Program Dynamics, Oak Ridge National Laboratory, ORNL/CON-323, December.

California Public Utilities Commission, 1993. Protocols and Procedures for the Verification of Costs, Benefits, and Shareholder Earnings from Demand-Side Management Programs, November 30.

Division of Ratepayer Advocates, California Public Utilities Commission. 1993. Demand-Side Management Expenditures and Cost Effectiveness: Trends and Patterns, 1988-Current, August.

Hirst, Eric. 1994. Costs and Effects of Electric-Utility DSM Programs: 1989 Through 1997, Oak Ridge National Laboratory, ORNL/CON-392, June.

Hirst, E., R. Goeltz, and D. Trumble. 1989. "Effects of the Hood River Conservation Project on Electricity Use," Energy and Buildings 13(1).

1990-1992 Annual DSM Summary Reports of Pacific Gas \& Electric Company, Southern California Edison Company, Southern California Gas Company, and San Diego \& Electric Company.

Keating, K.N. and S. Nadel. 1991. "Engineering Estimates Versus Impact Evaluation Results: How Do They Compare and Why,".Proceedings of the International Energy Program Evaluation Conference, Chicago, IL, pp. 24-33.

Schlegel, Jeff, et al., 1993. Evaluation of DSM Shareholder Incentive Mechanisms, Madison, WI: Wisconsin Energy Conservation Corporation, January.

Sebold, F.D. and E.W. Fox. 1985. "Realized Savings from Residential Conservation Activity," The Energy Journal, 6(2). 


\section{APPENDIX A BIBLIOGRAPHY}

A. 1 
$-3$ 


\section{BIBLIOGRAPHY}

Pacific Gas \& Electric Company, 1992 Residential Compact Fluorescent Lighting Program Evaluation Survey Results, Study \#14, September 22, 1993.

Pacific Gas \& Electric Company, Annual Summary Report on Demand Side Management Programs in 1992 and 1993, March 1993

Pacific Gas \& Electric Company, Commercial, Industrial and Agricultural Direct Rebate Engineering Study-Phase I, CEC Report No. 31, December, 1991

Pacific Gas \& Electric Company, Commercial, Industrial and Agricultural Direct Rebate Engineering Study-Phase II, CEC Report No. 32, December, 1991

Pacific Gas \& Electric Company, Commercial, Industrial and Agricultural Direct Rebate Programs Hours of Operation Study, CEC Report No. 37, August, 1992

Pacific Gas \& Electric Company, Commercial New Construction Review of Engineering Assumptions, CEC Report No. 36, December, 1991

Pacific Gas \& Electric Company, Engineering Review of Energy Savings Estimates Underlying the Multifamily Property Direct Rebate Program, Study \#15, June 22, 1993.

Pacific Gas \& Electric Company, Evaluation of PG\&E's Energy Partners Program: Impact Evaluation Final, Study \#22, September 24, 1993.

Pacific Gas \& Electric Company, Evaluation of the CIA Retrofit Rebate Program Final Report, CEC Report No. 43, September, 1993

Pacific Gas \& Electric Company, Impact Evaluation of 1990-1992 Non-Residential Energy Management Services Programs, CEC Report No. 48, December, 1993

Pacific Gas \& Electric Company, Impact Evaluation of Pacific Gas \& Electric's Ceiling Insulation Rebate Program, Study \#12, September 21, 1993.

Pacific Gas \& Electric Company, Impact Evaluation of PG\&E's 1991 Residential Energy Savings Plan (ESP) Program, Study \#26, December, 1993.

Pacific Gas \& Electric Company, Impact Evaluation of the 1992 Energy Saver Showerhead Coupon Program, Study \#13, September 27, 1993.

Pacific Gas \& Electric Company, Impact Evaluation of the Targeted Customer Appliance Program, Study \#24, December 15, 1993.

Pacific Gas \& Electric Company, Non-Residential New Construction Impact Evaluation Study, CEC Report No. 44, October, 1993

Pacific Gas \& Electric Company, PG\&E Customized Rebate Program On-Site Validation Project, CEC Report No. 179, May, 1993

Pacific Gas \& Electric Company, Residential New Construction 1992 Impact Evaluation, Quantum Consulting Inc. and RCG/Hagler, Bailly, Inc., CEC Report No. 20, October, 1993

San Diego Gas \& Electric Company, Agricultural Energy Management Services Program: Analysis of: A Program Implementation Rate, Realization Rate, Net-to-Gross Rate, Participant Cost, \& Participant Satisfaction, MIAP-92-012, April, 1992 
San Diego Gas \& Electric Company, Annual Summary of Demand-Side Management Activities, March 1993

San Diego Gas \& Electric Company, Annual Summary of Demand-Side Management Activities, March 1991

San Diego Gas \& Electric Company, Annual Summary of Demand-Side Management Activities, March 1992

San Diego Gas \& Electric Company, Appliance Efficiency Incentives: Compact Fluorescents--1992 Lighting Process \& Impact Study, Study \#156, MIAP-92-P9-S1-R35, March, 1993.

San Diego Gas \& Electric Company, Appliance Efficiency Incentives: SDG\&Es 1991 Residential Compact Fluorescent Lighting Program--Impact and Cost-Effectiveness Analysis and Process Evaluation, Study \#150, September, 1992.

San Diego Gas \& Electric Company, Commercial \& Industrial Energy Efficiency Incentives: Lighting Retrofit, Using Metered Hours-of-Operation to Adjust Estimates of Demand and Energy Impacts, CEC Report No. 185, MIAP-91-P50-185-345, November, 1993

San Diego Gas \& Electric Company, Commercial/Industrial Energy Efficiency Incentives: Lighting Retrofit, Estimation of Gross Energy-Demand Impacts, CEC Report No. 174, MIAP-92-P50-S01R320, June, 1993

San Diego Gas \& Electric Company, Commercial/Industrial Lighting Retrofit Program: Analysis of Base Case Equipment by Measure, MIAP-91-049, CEC Report No. 165, October, 1991

San Diego Gas \& Electric Company, Low Flow Showerhead Program: Analysis of Persistence, Flow Rates, Energy Savings, and Customer Satisfaction, \#149, November, 1991.

San Diego Gas \& Electric Company, Residential Appliance Efficiency Incentives: Low-Flow Showerheads, Study \#155, June, 1993.

San Diego Gas \& Electric Company, Residential Direct Assistance: Estimates of the Gross Energy Impact, Study \#158, November, 1993.

San Diego Gas \& Electric Company, Residential Energy Management Services: Audits--Estimation of 1991/1992 Gross Energy Impacts, Study \#157, MIAP-93-P3-157-R335, September, 1993.

San Diego Gas \& Electric Company, Residential High Efficiency Refrigerator Program--Program Report, Study \#152, November, 1991.

San Diego Gas \& Electric Company, Residential High-Efficiency Central Air Conditioning Program, Study, \#144, November, 1991.

San Diego Gas \& Electric Company, Residential Load Management: Residential Time-of-Use Rate Program--Estimates of Demand and Energy Savings, Study \#159, MIAP-92-P23-S01-R321, April, 1993.

San Diego Gas \& Electric, SDG\&E Non-Residential Audit Evaluation Final Report, Regional Economic Research, Inc., CEC Report No. 162, February, 1991

Southern California Edison Company, 1990 Residential Appliance Efficiency Incentive Appliance Kilowatt Hour Usage and Savings by Time of Use, Study \#65, August 13, 1993.

Southern California Edison Company, 1990 Southern California Edison Energy Management Services and Hardware Rebate Program Evaluation Volume 3: The Application of the Results of 
Conditional Demand Analysis and Engineering Algorithms for Estimating Final Gross $\mathrm{kWh}$ and $\mathrm{kW}$ Impacts in the Commercial Sector, CEC Report No. 87, July, 1993

Southern California Edison Company, 1990 Southern California Edison Energy Management Services and Hardware Rebate Program Evaluation Volume 5: The Application of the Results of Conditional Demand Analysis, DOE2, and Engineering Algorithms for Estimating Revised Final Gross kWh and KW Impacts in the Commercial Sector, CEC Report No. 87 and 88, September, 1993

Southern California Edison Company, 1990 Southern California Edison Energy Management Services and Hardware Rebate Program Evaluation Volume 2: Estimating Gross kWh Impacts in the Commercial Sector Using Conditional Demand Analysis, CEC Report No. 87, July, 1993

Southern California Edison Company, 1990 Southern California Edison Energy Management Services and Hardware Rebate Program Evaluation Volume 4: Estimating Gross kWh Savings and KW Reductions Using DOE2 Engineering Simulation Modeling, CEC Report No. 88, September, 1993

Southern California Edison Company, 1990 Southern California Edison Energy Management Services and hardware Rebate Program Evaluation, Executive Summary, CEC Report No. $87,88,92,94,95$, November, 1993

Southern California Edison Company, 1990 Southern California Edison Energy Management Services and Hardware Rebate Program Evaluation Volume 8: A Review and Critique of Statistical Techniques for Estimating Net kWh and KW Impacts, CEC Report No. 93, 94, and 95, September, 1993

Southern California Edison Company, 1990 Southern California Edison Energy Management Services and Hardware Rebate Program Evaluation Volume 1 (Revised): Overview and Analysis Plan for Estimating Gross Impacts in the Commercial Sector, CEC Report No. 87, September, 1993

Southern California Edison Company, 1990 Southern California Edison Energy Management Services and Hardware Rebate Program Evaluation Volume 7: Estimating Gross and New kWh Savings and $K W$ Reductions in the Industrial and Agricultural Sectors Using Conditional Demand Analysis, CEC Report No. 94 and 95, October, 1993 (2 Volumes)

Southern California Edison Company, 1990 Southern California Edison Energy Management Services and Hardware Rebate Program Evaluation Volume 6: Estimating Net $\mathrm{kWh}$ Savings and $K W$ Reductions in the Commercial Sector Using Conditional Demand Analysis, CEC Report No. 92, September, 1993

Southern California Edison Company, 1991 Welcome Home Program Appliance Kilowatt Hour Usage and Savings by Time of Use for Southern California Edison, Final Report, Quantum Consulting Inc., CEC Report No. 77, November, 1993

Southern California Edison Company, Annual DSM Summary Report 1992 Results-1993 Plans, March, 1993

Southern California Edison Company, Annual Program Summary Report 1991 Results-1992 Plans, March 1992

Southern California Edison Company, Design for Excellence Commercial New Construction Incentive Program Impact Evaluation, ADM Associates, Inc., CEC Report No. 101, November, 1993 (2 volumes)

Southern California Edison Company, Impact Evaluation of Southern California Edisons Customer Assistance Programs, Study \#68, September 27, 1993. 
Southern California Edison Company, Impact Evaluation of Southern California Edisons Residential Energy Management Services Programs, Study \#66, February, 1993.

Southern California Edison Company, Residential Appliance Efficiency Incentives: A Conditional Demand Study of End Use kWh and Savings Estimates, Study \#64, June, 1993.

Southern California Edison Company, Southern California Edison Company's Filing of 1990/1991

Demand-Side Management Technical Appendix in Compliance with Decision No. 87-12-066 Ordering Paragraph 29, March, 1991

Southern California Edison Company, Southern California Edison Company's Filing of 1990/1991 Demand-Side Management Annual Report in Compliance with Decision No. 87-12-066 Ordering Paragraph 29, March, 1991

Southern California Edison Company, Southern California Edison Welcome Home Program Impact Analysis, Applied Econometrics, Inc., CEC Report No. 76, September, 1993

Southern California Edison Company, Technical Appendix, 1991 Results, March 1992

Southern California Edison Company, Technical Appendix, 1992 Results, March 1993

Southern California Gas Company, 1991 Demand-Side Management Report, March, 1992

Southern California Gas Company, 1991 Demand-Side Management Report, March 1992

Southern California Gas Company, 1991 Demand-Side Management Report Technical Appendix, March, 1992

Southern California Gas Company, 1991 DSM Report Technical Appendix, March, 1991 Revised

Southern California Gas Company, Annual Program Summary Report 1992 Results-1993 Plans, March, 1993 Revised

Southern California Gas Company, Demand-Side Management Report, March 1990

Southern California Gas Company, Demand-Side Management Report, March, 1991 Revised

Southern California Gas Company, First Year Load Impact Analysis of Southern California Gas Company's Industrial Demand-Side Management Programs for Years 1990, 1991, and 1992, Arthur D. Little, Inc., CEC Report No. 139, November, 1993

Southern California Gas Company, First Year Load Impact of Southern California Gas Company's Direct Assistance Program, Study \#13, July, 1993.

Southern California Gas Company, First Year Load Impacts of Southern California Gas Company's Residential New Construction Program, CEC Report No. 132, October, 1993

Southern California Gas Company, First Year Load Impacts of Southern California Gas Company's Commercial New Construction Program for Program Years 1990, 1991, and 1992, Analysis Group, Inc., CEC Report No. 140, November, 1993

Southern California Gas Company, First Year Load Impacts of Southern California Gas Company's Commercial Demand-Side Management Programs (Program Years 1990, 1991, and 1992), Analysis Group, Inc., CEC Report No. 137, November, 1993

Southern California Gas Company, Technical Appendix 1992 Results-1993 Plans, March, 1993 Revised 
Southern California Gas Company, The Consumption Impact of Southern California Gas Company's Residential Conservation Programs, Study \#129, February 8, 1993.

Southern California Gas Company, The First-Year Load Impacts of Southern California Gas Company's 199 Residential Energy Management Services Program, Study \#195, September, 1993. 
APPENDIX B OVERVIEW OF EVALUATION METHODOLOGIES 


\section{B. 2}




\section{OVERVIEW OF EVALUATION METHODOLOGIES}

This appendix provides a brief overview of evaluation methodologies employed to estimate energy and demand impacts in the evaluation studies. Greater detail on the methodological approaches can be found in the following sources, from which this summary was extracted:

Electric Power Research Institute, Impact Evaluation of Demand Side Management Programs: A Guide to Current Practice, CU 7179, Volume 1 Final Report, February, 1991

Oak Ridge National Laboratory, Handbook of Evaluation of Utility DSM Programs, ORNL/CON-336, December, 1991

The impact evaluation methods employed in the subject studies can basically be organized into four key categories (subcategories of evaluation methods used in the evaluation studies and assessed in this report are also indicated):

- Engineering methods,

-- Simplified engineering methods

-- Engineering simulation modeling

-- Calibrated engineering model

- Statistical methods,

-. Billing analysis

-- Conditional demand analysis

- Metering,

- Hybrid methods

-- Statistically adjusted engineering approach.

Each is briefly discussed in the following sections. The reader is referred to the above sources for greater detail.

Engineering Methods. Engineering estimation of savings typically involves equations which express energy use or demand in terms of a usage level divided by an efficiency for some period of time. There may also be terms in the equations that account for interactions with other end-uses or net gains or losses from previous time periods.

In many cases, engineering methods are concerned with unit impacts of a particular measure such as an energy efficient ballast. These simplified engineering methods rely on data on the number and type of different measures installed by program participants which is extracted from the program data base. An engineering analysis is applied to develop reliable estimates of unit impacts. These unit impacts may be derived from engineering simulations (see below) or from more simple engineering algorithms.

Simplified engineering algorithms have been developed for many common DSM measures, such as lighting, various types of HVAC, and water heating measures. 
Several of the evaluation studies summarized in this report included the use of engineering simulation modeling. The primary value of such models is in estimating savings in HVAC energy use through either HVAC or envelope modifications. The advantage that simulation tools provide is their ability to account for thermal mass effects, scheduling, interactive effects between different end uses, part load efficiencies, and system dynamics. Because simulation models explicitly account for such effects in the energy use of a building, they allow for estimation of relatively small effects. Also, the number of variables are explicitly accounted for making it possible to adjust for different conditions.

There are two general types of engineering simulation models, hourly and bin. Hourly models simulate every hour of the year in sequence. The bin method, on the other hand, corresponds to a five or ten degree range of ambient temperatures known as temperature bins. A common hourly engineering simulation tool used in the impact evaluations summarized in this report is DOE-2.

Calibrated engineering models involve calibrating simulation results to some other known measurement, such as billed energy or, if available, metered load data. This calibration provides some assurance that, for example, the sum of the disaggregated end-use loads totals the building load as measured (see section on Hybrid methods).

Engineering models typically rely on engineering judgment for virtually every input. They are applied to units such as individual measures (e.g., electronic ballasts). Engineering algorithms, for example, may be applied to estimate the impacts of individual DSM measures, whereas in the case of building simulation models, the unit is almost always a building. In consequence, the impact evaluation studies summarized in this report often estimate impacts for individual measures or for representative buildings.

Statistical Methods. There are a variety of statistical approaches which are used to estimate impacts of DSM programs. These statistical methods generally fall into two basic categories:

- Comparison approaches using data available in-house at the utility, and

- Multivariate regression approaches using customer specific survey data.

Simple comparison approaches such as billing analysis can be significantly less expensive in that they only require billing data and information on when the customer began participating in the DSM program. On a simplified basis, therefore, they can be applied without the need to collect external customer data. Billing analysis is a general catch phrase for these types of simplified approaches, since the data for these analyses is usually available directly from the utility's billing file and the program tracking data base. 
Such comparison approaches can be divided further:

- Time series comparison simply compares the participants energy use before the program to their energy use after the program. Any differences are then attributed to the DSM program.

- Cross sectional comparison. This approach compares the participant's post program energy use to the post program energy use of a control group of nonparticipants. Implicit in this approach is the assumption that the non participant control group is identical to the participant group in all respects except for program participation.

- Pre/post comparison. The pre/post comparison approach compares the change in the quantity of energy use over two time periods for two groups, the program participants and a control group of nonparticipants. This approach combines the features of the cross sectional and time series approaches.

These statistical comparison approaches can be augmented through weather normalization, because weather can have a large effect on energy use. The effect of such normalization is to remove the influences of weather, both over time and across participant and nonparticipant groups, thus allowing for more clear cut attribution of impacts to the DSM program. Other factors, such as underlying economic conditions, can also be similarly addressed.

Multivariate Regression. Multivariate regression approaches utilize a fuller data set than the more simple comparison approaches described above. They typically require survey data on individual customers. These multivariate statistical approaches all rely on the basic premise that changes in one variable can be explained by reference to changes in several other variables. In general, a multivariate regression model for an impact evaluation should include all measurable factors which influence energy consumption. The most commonly employed multivariate approach for energy and demand impact analysis involves using conditional demand analysis. Conditional demand frameworks are based on well defined engineering and economic principles. The conditional demand model is based on the identity that total energy consumption must be equal to the consumption of all of the energy consuming equipment in the building. There are many formulations of conditional demand models which can incorporate different levels of complexity. These models rely on external data collection, in that energy using equipment in the building must be known and incorporated in the model as well as billing data. Many of the DSM impact evaluation studies summarized in this report utilized the conditional demand analysis framework for estimating impacts.

Metering Approaches. A straight forward way of measuring the impact of a particular device is to instrument the device and collect metered data on its electricity consumption over selected time intervals. This is known in the utility industry as load research. Direct load research measures class or end-use demand $(\mathrm{kW})$, energy $(\mathrm{kWh})$, or reactive power (kVAR). 
Implementing metering as part of any study involves several interrelated steps. These include:

- Sample design,

- Sample selection,

- Recorder selection,

- Meter placement and replacement,

- Installation record keeping,

- Meter operation and maintenance,

- Data collection,

- Data validation and editing, and

- Data analysis.

Because of the costs of the metering hardware, installation labor, and data retrieval and analysis software and labor, metering is highly expensive. The hardware must be acquired, and must be installed by trained personnel. Metering at the end-use level often requires the use of qualified electricians and the infrastructure must be in place to collect and analyze massive amounts of data.

Because of its extensive cost, metering is not frequently used in DSM evaluation, though it is often used in support of other methodologies. However, such metering usually represents an accurate measurement of energy usage since, if properly installed, it represents direct measurement of the phenomenon as opposed to estimated impacts which are derived from engineering or statistical methods.

Metering can be performed at the whole building (premise) level. This involves recording load at the point where the power service enters the building. Metering can also be performed at the end-use level. This involves instrumenting individual end-uses, such as air conditioners, refrigerators, lighting circuits, etc.

Hybrid Approaches. In some cases hybrid approaches involving combinations of engineering, statistical, and metering methods are employed in DSM program impact evaluation. These hybrid approaches often seek to improve the quality and accuracy of the estimates available from any single approach. Another key objective of such hybrid approaches is to leverage the accuracy of high cost measurement approaches such as metering by combining them in small number with more general approaches.

An example of this type of approach is statistically adjusted engineering (SAE) estimates. SAE uses engineering estimates of savings as independent variables directly in a statistical model. An alternative use of the method is to disaggregate whole house or building metered loads into individual end-uses. Statistically adjusted engineering estimates are generated by using engineering estimates as 
independent variables in a regression equation instead of zero-one participation variables. This has the effect of combining an initial estimate of the savings of a particular measure with the statistically estimated savings so as to improve the overall precision of the statistical methods. This therefore, brings more information to bear on the estimation problem.

Another hybrid method which has recently evolved in the literature is the employment of double ratio estimation, which is based on the enhanced theoretical statistical performance of ratio estimators. In this approach, double sampling is typically employed, whereby a small sample of higher cost but presumably more accurate measurement (such as that derived from metering) is combined with a larger sample of lower cost data such as that available from a customer survey or billing information. The approach then seeks to analyze the ratios of the different estimates to produce an estimate of the impact of the DSM measure or program with increased precision. It should be noted that such methods were not typically employed (with one exception) in the evaluation studies reviewed as part of this report as they have only been developed in the literature in recent years.

Net to Gross Methods. Net to gross methods are those techniques used to adjust impact estimates on a gross level to account for free riders. Free riders are defined as customers who would have taken the identical action without the DSM program. There are also incremental free riders and deferred free riders, who may have been to some extent influenced by the program. Incremental free riders may have taken some but not all of the measures promoted by the program on their own. Deferred free riders may have taken all or some of the measures promoted by the program on their own, but at a later date.

Several methods to estimate free ridership, and thus adjust gross savings to reflect net savings, have been employed. Survey based approaches have frequently been used to measure free riders. Participants are surveyed and are asked several questions concerning what actions they may have taken if the program was not available. Based on the results of these surveys, proportions are estimated based on the respondents reporting of actions which would have been taken, and savings are adjusted accordingly based on these proportions. Survey based approaches to free ridership estimation have been known to have problems associated with self-reporting, particularly when such surveys are administered months or even years after the participant's decision to participate in the DSM program.

In some cases, market data is used to estimate free ridership. For example, data available from appliance dealers on general sales trends may be used to develop estimates of the underlying market in terms of the rated energy efficiency of products being sold, or dealer surveys may be employed in this context to determine what customers are purchasing in general without the existence of a particular incentive program. 
The use of a comparison group is also a typical evaluation technique to account for free ridership. The difference between the energy conservation actions of a sample of program participants and an appropriately selected comparison group provides an estimate of the net program impacts. However, this approach is made difficult by the challenge of finding a comparable comparison group that has not already been "contaminated" by knowledge of the existence of the program.

Statistical methods have also been used to estimate free ridership. Generally this method involves analysis of the energy related actions, characteristics, and attitudes for samples of participants and nonparticipants. Simulations are developed to predict the likelihood of the adoption of program sponsored measures with and without the program. The two estimates are then used to calculate the free rider ratio. A particular multivariate modeling approach is the discrete choice model. It uses discrete outcomes as a dependent variable. The dependent variable is 1 if the customer is a participant and 0 if the customer is a non participant. Independent variables include the factors that influence customer decisions to participate in the DSM program including: income, expected energy savings resulting from participation, and awareness of the program.

The DSM studies summarized in this report utilized several of these techniques to adjust gross estimates of savings for free ridership. 


\section{APPENDIX C}

\section{DETAILED EVALUATION TABLES}




\section{2}


Table C.1 Numbers of Participants in Residential Programs

\begin{tabular}{|c|c|c|c|c|}
\hline Study & Utility & Period & $\begin{array}{l}\text { Number of } \\
\text { Participants }\end{array}$ & Program \\
\hline \multicolumn{5}{|c|}{ Retrofit Energy Efficiency Incentive } \\
\hline 12 & PG\&E & $1991-92$ & 10,988 & Ceiling Insulation Rebate \\
\hline$\overline{14}$ & PG\&E & 1992 & 86,499 & Residential Compact Fluorescent Lighting \\
\hline $64 \mathrm{~A}$ & SCE & $1990-91$ & 4,941 & Res. Appliance Efficiency: AC \\
\hline 64B & SCE & $1990-91$ & 53,892 & Res. Appliance Efficiency: Refrigerators \\
\hline $129 \mathrm{~A}$ & SoCalGas & $1990-92$ & 15,552 & Residential Weatherization \\
\hline 129B & SoCalGas & $1990-92$ & 15,197 & Appliance Efficiency \\
\hline 144 & SDG\&E & 1991 & 54,725 & Res. High Eff. Central AC \\
\hline 149 & SCG\&E & 1991 & 29,637 & Low-Flow Showerheads \\
\hline 150 & SDG\&E & 1991 & 45,058 & Compact Fluorescent Light Bulbs \\
\hline 155 & SDG\&E & $1990-91$ & 20,317 & Efficiency Inc: Low-Flow Showerheads \\
\hline \multirow[t]{2}{*}{156} & SDG\&E & 1992 & 61,144 & Efficiency Inc: Compact Fluorescent Ltg. \\
\hline & Subtotal & & 397,950 & $48.97 \%$ \\
\hline \multicolumn{5}{|c|}{ Direct Assistance } \\
\hline 22 & PG\&E & 1991 & 66,000 & Energy Partners \\
\hline 24 & PG\&E & $1991-92$ & 10,598 & Targeted Customer Appliance \\
\hline $68 \mathrm{~A}$ & $\overline{S C E}$ & $1990-91$ & 1,449 & Customer Assistance: Weatherization \\
\hline $68 \mathrm{~B}$ & SCE & $1990-91$ & 4,800 & Customer Assistance: Hardware \\
\hline $68 \mathrm{C}$ & SCE & $1990-91$ & 59,874 & Customer Assistance: Relamping \\
\hline 130 & SoCalGas & $1990-92$ & 31,317 & Appliance Repair \& Replacement \\
\hline \multirow[t]{2}{*}{158} & SDG\&E & 1992 & 11,624 & Residential Direct Assistance \\
\hline & Subtotal & & 185,662 & $22.85 \%$ \\
\hline \multicolumn{5}{|c|}{ Energy Management Services } \\
\hline 26 & PG\&E & 1991 & 34,155 & Residential Energy Management Services \\
\hline 66 & SCE & 1990 & 110,043 & Residential Energy Management Services \\
\hline 195 & SoCalGas & 1990 & 55,398 & Residential Energy Management Services \\
\hline \multirow[t]{2}{*}{157} & SDG\&E & $1991-92$ & 22,500 & Residential Energy Management Services \\
\hline & Subtotal & & 222,096 & $27.33 \%$ \\
\hline \multicolumn{5}{|c|}{ New Construction } \\
\hline 20 & PG\&E & $1990-92$ & 3,178 & Welcome Home Res. New Construction \\
\hline 76,77 & SCE & $1990-92$ & 3,333 & Residential New Construction \\
\hline \multirow[t]{2}{*}{132} & SoCalGas & $1990-92$ & 407 & Residential New Construction \\
\hline & Subtotal & & 6,918 & $0.85 \%$ \\
\hline \multicolumn{3}{|c|}{ Total Participation } & 812,626 & \\
\hline
\end{tabular}


Table C.2 Numbers of Participants in C/I/A Programs

\begin{tabular}{|c|c|c|c|c|c|}
\hline Study & Utility & Period & No. of Units & Unit & Program \\
\hline \multicolumn{6}{|c|}{ Retrofit Energy Efficiency Incentive } \\
\hline 43 & PGE & $1991-1992$ & 3,401 & Projects & C/I \& Agri. Retrofit Rebate \\
\hline 137 & SoCalGas & $1990-1992$ & 2,017 & Equip Units & High Efficiency Com Equipment \\
\hline 139 & SoCalGas & $1990-1992$ & 1,327 & Participants & Industrial Equipment Replacemant \\
\hline 165 & SDGE & $11 / 90-8 / 91$ & 350 & Project Jobs & C/I Lighting Retrofit \\
\hline \multirow[t]{2}{*}{179} & PGE & $1990-1992$ & 928 & Applications & Customized Rebate \\
\hline & Subtotal & & 8,023 & & $13.16 \%$ \\
\hline \multicolumn{6}{|c|}{ Energy Management Services } \\
\hline 162 & SDGE & 1987-1989 & 151 & Participants & Non-Residential Audit Evaluation \\
\hline No Number & SDGE & 1991 & 400 & Tests (app.) & Agricultural EMS \\
\hline 48 & PGE & $1990-1992$ & 15,677 & Audits/Tests & Non-Residential EMS \\
\hline 87 , et al & SCE & $1990-1992$ & 23,983 & Audits & C/I \& Agri. EMS \& HDWR Rebate \\
\hline 87 , et al & SCE & 1990 & 1,943 & Customers & C/I \& Agri. EMS \& HDWR Rebate \\
\hline 137 & SoCalGas & $1990-1992$ & 4,947 & Audits & Com Energy Efficiency Analyses \\
\hline \multirow[t]{2}{*}{139} & SoCalGas & $1990-1992$ & 5,122 & Audits & Industrial Audit \\
\hline & Subtotal & & 52,223 & & $85.64 \%$ \\
\hline \multicolumn{6}{|c|}{ New Construction } \\
\hline 44 & PGE & $1990-1991$ & 57 & Buildings & Non-Residential New Construction \\
\hline 101 & SCE & $9 / 90$ thru $9 / 92$ & 584 & Cases & Com New Construction Incentive \\
\hline \multirow[t]{2}{*}{140} & SoCalGas & $1990-1992$ & 96 & Customers & High Efficiency New Com Building \\
\hline & Subtotal & & 737 & & $1.21 \%$ \\
\hline \multicolumn{3}{|c|}{ Nonresidential Program Units } & 60,983 & & \\
\hline
\end{tabular}

Table C.3 Residential Program Level mWh Savings

\begin{tabular}{|c|l|c|c|l|}
\hline $\begin{array}{c}\text { Study } \\
\text { No. }\end{array}$ & Utility & Year(s) & $\begin{array}{c}\text { Program Level } \\
\text { Reported Savings } \\
\text { (mWh) }\end{array}$ & \multicolumn{1}{|c|}{ Program } \\
\hline 12 & PG\&E & $1991-92$ & 3,699 & Ceiling Insulation Rebates \\
\hline 13 & PG\&E & 1992 & 78 & Energy Saver Showerhead \\
\hline 14 & PG\&E & 1992 & 13,807 & Residential Compact Fluorescent \\
\hline 24 & PG\&E & $1991-92$ & 7,294 & Targeted Customer Appliance \\
\hline 64 & SCE & $1990-92$ & 53,341 & Residential Appliance Efficiency \\
\hline 68 & SCE & $1990-91$ & 24,381 & Residential Direct Assistance \\
\hline 150 & SDG\&E & 1991 & 4,800 & Residential Compact Fluorescent \\
\hline 152 & SDG\&E & 1991 & 4,900 & Residential High Efficiency Refrigerator \\
\hline 156 & SDG\&E & 1992 & 5,900 & Residential Compact Fluorescent \\
\hline
\end{tabular}


Table C.4 Residential Program Level Kilotherm Savings

\begin{tabular}{|c|l|c|c|l|}
\hline $\begin{array}{c}\text { Study } \\
\text { No. }\end{array}$ & Utility & Year(s) & $\begin{array}{c}\text { Program Level } \\
\text { Reported Savings } \\
\text { (kilotherms) }\end{array}$ & \multicolumn{1}{|c|}{ Program } \\
\hline 12 & PG\&E & $1991-92$ & 714 & Ceiling Insulation Rebates \\
\hline 13 & PG\&E & 1992 & 30 & Energy Saver Showerhead \\
\hline 24 & PG\&E & $1991-92$ & 101 & Targeted Customer Appliance \\
\hline 129 & SoCalGas & $1990-92$ & 2,559 & Residential Conservation \\
\hline 130 & SoCalGas & $1990-92$ & 813 & Appliance Repair/Replacement \\
\hline 195 & SoCalGas & 1990 & 1,693 & Residential EMS \\
\hline 149 & SDG\&E & 1990 & 876 & Low-Flow Showerhead \\
\hline 155 & SDG\&E & $1990-91$ & 1,551 & Appliance Efficiency \\
\hline 158 & SDG\&E & 1992 & 516 & Residential Direct Assistance \\
\hline
\end{tabular}

Table C.5 Non-Residential Program Level $\mathrm{mWh}$ and MW Savings

\begin{tabular}{|c|l|l|c|c|l|}
\hline $\begin{array}{c}\text { Study } \\
\text { No. }\end{array}$ & Utility & Year(s) & $\begin{array}{c}\text { Program Level } \\
\text { Reported Savings } \\
\text { (mWh) }\end{array}$ & $\begin{array}{c}\text { Program Level } \\
\text { Reported Savings } \\
\text { (MW) }\end{array}$ & \multicolumn{1}{|c|}{ Program } \\
\hline 179 & PG\&E & $1990-91$ & 208,468 & 34.5 & Customized Rebate \\
\hline 48 & PG\&E & $1990-92$ & 176,963 & 40.6 & Non-Residential EMS \\
\hline 43 & PG\&E & $1991-92$ & 663,263 & 110.5 & Retrofit Rebate \\
\hline 44 & PG\&E & $1990-91$ & 20 & 4.8 & New Construction \\
\hline 101 & SCE & $1990-92$ & 68,070 & 31.7 & New Construction \\
\hline 174 & SDG\&E & 1992 & 54,210 & - & Energy Efficiency Incentives \\
\hline 162 & SDG\&E & $1985-89$ & 12,000 & 3.6 & Non-Residential Audit \\
\hline
\end{tabular}

Table C.6 Non-Residential Program Level Kilotherm Savings

\begin{tabular}{|c|l|c|c|l|}
\hline $\begin{array}{c}\text { Study } \\
\text { No. }\end{array}$ & Utility & Year(s) & $\begin{array}{c}\text { Program Level } \\
\text { Reported Savings } \\
\text { (kilotherms) }\end{array}$ & \multicolumn{1}{|c|}{ Program } \\
\hline 48 & PG\&E & $1990-92$ & 2,572 & Non-Residential EMS \\
\hline 162 & SDG\&E & $1985-89$ & 140 & Non-Residential Audit \\
\hline
\end{tabular}


Table C.7 Savings per Residential Refrigerator Replaced

\begin{tabular}{|c|l|c|c|l|}
\hline $\begin{array}{c}\text { Study } \\
\text { No. }\end{array}$ & Utility & Year(s) & $\begin{array}{c}\text { Program Attributed } \\
\text { Savings (kWh) }\end{array}$ & \multicolumn{1}{c|}{ Program Type } \\
\hline $24 \mathrm{~F}$ & PG\&E & 1991 & 392.0 & $\begin{array}{l}\text { Early Refrigerator Retirement and } \\
\text { Refrigerator Repair }\end{array}$ \\
\hline 152 & SDG\&E & 1991 & 89.5 & $\begin{array}{l}\text { Incentives to Purchase Energy Efficient } \\
\text { Refrigerators }\end{array}$ \\
\hline 64B & SCE & $1990-92$ & 286.0 & $\begin{array}{l}\text { Incentives to Purchase Energy Efficient } \\
\text { Refrigerators }\end{array}$ \\
\hline
\end{tabular}

Table C.8 Savings per Residential Compact Fluorescent Bulb

\begin{tabular}{|c|l|c|c|l|}
\hline $\begin{array}{c}\text { Study } \\
\text { No. }\end{array}$ & Utility & Year(s) & Annual Savings (kWh) & \multicolumn{1}{|c|}{ Program } \\
\hline 24G & PG\&E & $1991-92$ & 48 & Targeted Customer Appliance \\
\hline $26 \mathrm{~B}$ & PG\&E & 1991 & 128 & Residential Energy Savings \\
\hline 14 & PG\&E & 1992 & 57.8 & Residential Compact Fluorescent \\
\hline $68 C$ & SCE & $1990-91$ & 34 & CAP Relamping \\
\hline 150 & SDG\&E & 1991 & 56.1 & Residential Compact Fluorescent \\
\hline 156 & SDG\&E & 1992 & 50.79 & Appliance Efficiency Incentives \\
\hline
\end{tabular}

Table C.9 Electrical Savings for Selected Non-Residential Measures

\begin{tabular}{|c|c|c|c|c|c|c|}
\hline $\begin{array}{c}\text { Study } \\
\text { No. }\end{array}$ & Utility & Year & Measure Class & $\begin{array}{c}\text { Gross Annual } \\
\text { Savings Per } \\
\text { Unit (kWh) }\end{array}$ & $\begin{array}{c}\text { Demand } \\
\text { Savings } \\
\text { (kW) }\end{array}$ & Program Type \\
\hline \multirow{5}{*}{87} & \multirow{5}{*}{ SCE } & \multirow{5}{*}{1990} & HVAC Energy Mgt. Sys. & 90,276 & 0 & \multirow{5}{*}{$\begin{array}{l}\text { C/I/A Energy } \\
\text { Management and Hardware } \\
\text { Rebate Program }\end{array}$} \\
\hline & & & Indoor Lamps & 22,616 & 5 & \\
\hline & & & Indoor Lighting Sys. & 19,164 & 14.5 & \\
\hline & & & Package AC & 21,300 & 5 & \\
\hline & & & Reflectors & 96,960 & 19 & \\
\hline
\end{tabular}


Table C.10 Gas Savings for Selected Non-Residential Measures

\begin{tabular}{|c|c|c|c|c|c|c|}
\hline $\begin{array}{c}\text { Study } \\
\text { No. }\end{array}$ & Utility & Year & Measure Class & $\begin{array}{l}\text { Net } \\
\text { Annual } \\
\text { Savings } \\
\text { Per Unit } \\
\text { (Therms) }\end{array}$ & $\begin{array}{c}\text { Net Annual } \\
\text { Program- } \\
\text { Level } \\
\text { Savings } \\
\text { (kilotherm) }\end{array}$ & Program \\
\hline \multirow{4}{*}{137} & \multirow{4}{*}{ SoCalGas } & \multirow{4}{*}{ 1990-92 } & High Efficiency AC & 17,201 & 120 & \multirow{4}{*}{$\begin{array}{l}\text { High Efficiency } \\
\text { Commercial } \\
\text { Equipment }\end{array}$} \\
\hline & & & High Eff. Boiler & 12,295 & 1,979 & \\
\hline & & & High Eff. Cooking & 878 & 1,105 & \\
\hline & & & High Eff. Spc. Heat & 142 & 257 & \\
\hline \multirow{3}{*}{139} & \multirow{3}{*}{ SoCalGas } & \multirow{3}{*}{ 1990-92 } & Industrial Boiler & 1,611 & 89 & \multirow{3}{*}{$\begin{array}{l}\text { Industrial } \\
\text { Demand-Side } \\
\text { Management }\end{array}$} \\
\hline & & & Ind. Furnace & 3,053 & 183 & \\
\hline & & & Ind. Space Heat & 466 & 19 & \\
\hline
\end{tabular}


Table C.11 Realization Rates for all Residential Programs

\begin{tabular}{|c|c|c|c|c|c|}
\hline Obs. & Rpt. & Period & Program & Application & $\begin{array}{l}\text { RIz. } \\
\text { Rt. }\end{array}$ \\
\hline 1) & $12 \mathrm{~A}$ & 1991-1992 & Ceiling Insulation Rebate & Elec. Energy Savings & 0.82 \\
\hline 2) & $12 \mathrm{~B}$ & 1991-1992 & Ceiling Insulation Rebate & Capacity Savings & 3.80 \\
\hline 3) & $12 \mathrm{C}$ & 1991-1992 & Ceiling Insulation Rebate & Gas Savings & 0.42 \\
\hline 4) & $13 \mathrm{~A}$ & 1992 & Energy Saver Showerhead Coupon & Gas & 0.05 \\
\hline 5) & $13 \mathrm{~B}$ & 1992 & Energy Saver Showerhead Coupon & Electric & 0.03 \\
\hline 6) & 14 & 1992 & Residential CFLB & CFLB & 0.75 \\
\hline 7) & 20 & $3 / 91$ thru $12 / 92$ & Residential New Construction & & 0.72 \\
\hline 8) & 20 & $3 / 91$ thru $12 / 92$ & Residential New Construction & & 1.01 \\
\hline 9) & 20 & $3 / 91$ thru $12 / 92$ & Residential New Construction & & 1.58 \\
\hline 10) & $22 \mathrm{~A}$ & 1991 & Energy Partners & SF w/AC-electric & 0.49 \\
\hline 11) & $22 \mathrm{~B}$ & 1991 & Energy Partners & SF w/o AC-electric & 1.35 \\
\hline 12) & $22 \mathrm{C}$ & 1991 & Energy Partners & MF w/AC-electric & 1.22 \\
\hline 13) & $22 \mathrm{D}$ & 1991 & Energy Partners & MF w/o AC-electric & 1.38 \\
\hline 14) & $22 \mathrm{E}$ & 1991 & Energy Partners & SF w/AC-gas & 0.30 \\
\hline 15) & $22 \mathrm{~F}$ & 1991 & Energy Partners & SF w/o AC-gas & 0.30 \\
\hline 16) & $22 \mathrm{G}$ & 1991 & Energy Partners & MF w/AC-gas & 0.36 \\
\hline 17) & $22 \mathrm{H}$ & 1991 & Energy Partners & MF w/o AC-gas & 0.36 \\
\hline 19) & $24 \mathrm{~A}$ & 1991-1992 & Targeted Customer Appliance & 1991 electric (MWh) & 0.64 \\
\hline 19) & $24 \mathrm{~B}$ & 1991-1992 & Targeted Customer Appliance & 1991 electric (MWh) & 0.57 \\
\hline 20) & $24 \mathrm{C}$ & 1991-1992 & Targeted Customer Appliance & 1991 gas & 0.69 \\
\hline 21) & $24 \mathrm{D}$ & 1991-1992 & Targeted Customer Appliance & 1992 gas & 1.23 \\
\hline 22) & $24 \mathrm{E}$ & 1991 & Targeted Customer Appliance & Refrig. replacements & 0.93 \\
\hline 23) & $24 \mathrm{~F}$ & 1992 & Targeted Customer Appliance & Refrig. replacements & 0.73 \\
\hline 24) & $24 \mathrm{G}$ & $1991-1992$ & Targeted Customer Appliance & CFLB & 0.68 \\
\hline 25) & $26 \mathrm{~A}$ & 1991 & Residential Energy Savings & DHW wraps-electric & 2.71 \\
\hline 26) & $26 \mathrm{~B}$ & 1991 & Residential Energy Savings & CFLB-electric & 0.90 \\
\hline 27) & $26 \mathrm{C}$ & 1991 & Residential Energy Savings & Low-flow showerhead-electric & 0.59 \\
\hline 29) & $26 \mathrm{D}$ & 1991 & Residential Energy Savings & Indirect savings-electric & 0.55 \\
\hline 29) & $26 \mathrm{E}$ & 1991 & Residential Energy Savings & DHW wraps-gas & 1.71 \\
\hline 30) & $26 \mathrm{~F}$ & 1991 & Residential Energy Savings & Low-flow showerhead-gas & 0.27 \\
\hline 31) & $26 \mathrm{G}$ & 1991 & Residential Energy Savings & Indirect savings-gas & 0.40 \\
\hline 32) & $64 \mathrm{~A}$ & $1990-1992$ & Residential Appliance Efficiency Incen. & Air conditioners & 1.01 \\
\hline 33) & $64 \mathrm{~B}$ & $1990-1992$ & Residential Appliance Efficiency Incen. & Refrigerators & 1.96 \\
\hline 34) & 66 & 1990 & Residential Energy Management Service & & 1.31 \\
\hline 35) & $68 \mathrm{~A}$ & $1990-1991$ & CAP: Weatherization & Refrigerator replacements & 0.28 \\
\hline 36) & $68 \mathrm{~B}$ & $1990-1991$ & CAP: Hardware & E.-Eff Hdwr Install/Evap Cool & 0.27 \\
\hline 37) & $68 \mathrm{C}$ & $1990-1991$ & CAP: Relamping & Relamping & 0.37 \\
\hline 38) & 76 & 1990 & "Welcome Home" Res. New Const. & & 0.54 \\
\hline 39) & 77 & 1991 & "Welcome Home" Res. New Const. & & 0.43 \\
\hline 40) & 144 & 1991 & Central AC Program & & 1.53 \\
\hline 41) & 149 & 1991 & Low-Flow Shoerhead & & 1.75 \\
\hline 42) & 150 & 1991 & Residential CFLB & & 1.09 \\
\hline 43) & 152 & 1991 & Residential High Efficiency Refrigerator & & 1.53 \\
\hline 44) & 155 & $1990-1991$ & $\begin{array}{l}\text { Appliance Efficiency Incentives: Low- } \\
\text { Flow Showerhead }\end{array}$ & & 1.06 \\
\hline
\end{tabular}


Table C.11 Realization Rates for all Residential Programs (cont'd)

\begin{tabular}{|c|c|c|c|c|c|}
\hline Obs. & Rpt. & Period & Program & Application & $\begin{array}{l}\text { Rlz. } \\
\text { Rt. }\end{array}$ \\
\hline 45) & 156 & 1992 & Appliance Efficiency Incentives: CFLB & & 1.59 \\
\hline 46) & 158 & 1992 & Residential Direct Assistance & & 0.37 \\
\hline 47) & $129 \mathrm{~A}$ & 1990-1992 & Residential Weatherization & Water Heater Wrap & 0.57 \\
\hline 48) & $129 \mathrm{~B}$ & $1990-1992$ & Appliance Efficiency & High-efficiency DWH & 0.66 \\
\hline 49) & $129 \mathrm{C}$ & 1990-1992 & Appliance Efficiency & High-efficiency space heaters & 1.47 \\
\hline 50) & $130 \mathrm{~A}$ & $1990-1992$ & Appliance Repair \& Replace & Furnaces & 1.74 \\
\hline 51) & 130B & $1990-1992$ & Appliance Repair \& Replace & Water Heaters & 1.05 \\
\hline 52) & $130 \mathrm{C}$ & 1990-1992 & Appliance Repair \& Replace & Rantes & 0.41 \\
\hline 53) & $130 \mathrm{D}$ & $1990-1992$ & Weatherization/Conservation & Attic insulation & 0.27 \\
\hline 54) & $130 \mathrm{~F}$ & 1990-1992 & Weatherization/Conservation & DHW blanket & 0.24 \\
\hline 55) & $130 \mathrm{G}$ & $1990-1992$ & Weatherization/Conservation & LF showerhead & 0.23 \\
\hline 56) & 1301 & $1990-1992$ & Appliance Repair \& Replace & Program-wide statistics & 1.23 \\
\hline 57) & $132 \mathrm{~A}$ & 1990-1991 & Residential New Construction known as & High-efficiency space heat & 0.70 \\
\hline 58) & $132 \mathrm{~B}$ & 1990-1991 & Five Star Energy Saver & High-efficiency water heat & 0.67 \\
\hline 59) & $132 \mathrm{C}$ & 1990-1991 & Five Star Energy Saver & Wall Insulation & 0.58 \\
\hline 60) & 195 & 1990 & Residential EMS & & 0.58 \\
\hline
\end{tabular}


Table C.12 Realization Rates for all C/I/A Programs

\begin{tabular}{|c|c|c|c|c|c|}
\hline Obs. & Rpt. & Period & Program & Application & $\begin{array}{l}\text { Rlz. } \\
\text { Rt. }\end{array}$ \\
\hline 1) & 43 & 1991-1992 & C/I \& Agri. Retrofit Rebate & Net Demand Savings (Total) & 0.74 \\
\hline 2) & 43 & 1991-1992 & C/I \& Agri. Retrofit Rebate & Agricultural (Gross) & 0.70 \\
\hline 3) & 43 & 1991-1992 & C/I \& Agri. Retrofit Rebate & Commercial (Gross) & 0.81 \\
\hline 4) & 43 & 1991-1992 & C/I \& Agri. Retrofit Rebate & & 0.83 \\
\hline 5) & 43 & 1991-1992 & C/I \& Agri. Retrofit Rebate & Gross Savings (Total) & 0.78 \\
\hline 6) & 43 & 1991-1992 & C/I \& Agri. Retrofit Rebate & Net Savings ((Total) & 0.83 \\
\hline 7) & 43 & 1991-1992 & C/I \& Agri. Retrofit Rebate & Industrial (Gross) & 0.79 \\
\hline 8) & $43 \mathrm{~A}$ & 1991-1992 & C/I \& Agri. Retrofit Rebate & Agricultural (Net Demand) & 0.79 \\
\hline 9) & $43 \mathrm{~A}$ & 1991-1992 & C/I \& Agri. Retrofit Rebate & Agricultrual (Net) & 0.79 \\
\hline 10) & $43 \mathrm{~B}$ & 1991-1992 & C/I \& Agri. Retrofit Rebate & Lighting (Net Demand) & 0.86 \\
\hline 11) & $43 \mathrm{~B}$ & 1991-1992 & C/I \& Agri. Retrofit Rebate & Lighting (Net) & 0.98 \\
\hline 12) & $43 \mathrm{C}$ & 1991-1992 & C/I \& Agri. Retrofit Rebate & HVAC (Net Demand) & 0.33 \\
\hline 13) & $43 \mathrm{C}$ & $1991-1992$ & C/I \& Agri. Retrofit Rebate & HVAC (Net) & 0.56 \\
\hline 14) & 44 & $1990-1991$ & Non-Residential New Construction & KWH & 0.70 \\
\hline 15) & 44 & 1990-1991 & Non-Residential New Construction & KW & 0.62 \\
\hline 16) & 48 & 1990-1992 & Non-Residential EMS & MWH/AII & 1.01 \\
\hline 17) & $48 \mathrm{~A}$ & 1990-1992 & Non-Residential EMS & Commercial & 1.24 \\
\hline 19) & $48 \mathrm{~A}$ & $1990-1992$ & Non-Residential EMS & Commercial & 0.98 \\
\hline 19) & $48 \mathrm{~A}$ & $1990-1992$ & Non-Residential EMS & Commercial & 0.62 \\
\hline 20) & 48B & $1990-1992$ & Non-Residential EMS & Industrial & 0.61 \\
\hline 21) & $48 \mathrm{~B}$ & $1990-1992$ & Non-Residential EMS & Industrial & 0.48 \\
\hline 22) & $48 \mathrm{~B}$ & $1990-1992$ & Non-Residential EMS & Industrial & 0.08 \\
\hline 23) & $48 \mathrm{C}$ & 1990-1992 & Non-Residential EMS & AG Pump Tests & 1.19 \\
\hline 24) & $48 \mathrm{C}$ & $1990-1992$ & Non-Residential EMS & AG Pump Tests & 1.82 \\
\hline 25) & 179 & 1990-1991 & Customized Rebate & Agricultural & 0.95 \\
\hline 26) & 179 & 1990-1991 & Customized Rebate & Agricultural & 4.68 \\
\hline 27) & 179 & $1990-1991$ & Customized Rebate & Agricultural & 0.86 \\
\hline 29) & 179 & $1990-1991$ & Customized Rebate & Commercial & 1.14 \\
\hline 29) & 179 & $1990-1991$ & Customized Rebate & Commercial & 1.46 \\
\hline 30) & 179 & 1990-1991 & Customized Rebate & Commercial & 1.00 \\
\hline 31) & 179 & $1990-1991$ & Customized Rebate & & 1.10 \\
\hline 32) & 179 & $1990-1991$ & Customized Rebate & & 1.38 \\
\hline 33) & 179 & 1990-1991 & Customized Rebate & & 0.91 \\
\hline 34) & 179 & $1990-1991$ & Customized Rebate & Industrial & 1.10 \\
\hline 35) & 179 & $1990-1991$ & Customized Rebate & Industrial & 1.19 \\
\hline 36) & 179 & $1990-1991$ & Customized Rebate & Industrial & 1.00 \\
\hline 37) & $179 \mathrm{~A}$ & 1990-1991 & Customized Rebate & Lighting, sample $(n=73)$ & 1.17 \\
\hline 38) & $179 \mathrm{~A}$ & $1990-1991$ & Customized Rebate & Lighting, sample $(n=73)$ & 1.38 \\
\hline 39) & 179B & $1990-1991$ & Customized Rebate & Refrigeration, sample ( $n=73$ ) & 0.82 \\
\hline 40) & 179B & 1990-1991 & Customized Rebate & Refrigeration, sample ( $n=73$ ) & 2.71 \\
\hline 41) & $179 \mathrm{C}$ & $1990-1991$ & Customized Rebate & Miscellaneous, sample $(\mathrm{n}=73)$ & 1.11 \\
\hline 42) & $179 \mathrm{C}$ & 1990-1991 & Customized Rebate & Miscellaneous, sample (n=73) & 1.60 \\
\hline 43) & $87 \mathrm{~B}$ & 1990 & C/I \& Agri. EMS \& HDWR Rebate & HVAC EMS & 1.12 \\
\hline 44) & $87 \mathrm{~A}$ & 1990 & C/I \& Agri. EMS \& HDWR Rebate & Packaged A/C & 0.98 \\
\hline 45) & $87 \mathrm{C}$ & 1990 & C/I \& Agri. EMS \& HDWR Rebate & Clock Thermostate & 0.56 \\
\hline 46) & 87D & 1990 & C/I \& Agri. EMS \& HDWR Rebate & Indoor Lighting System & 0.30 \\
\hline 47) & $87 \mathrm{E}$ & 1990 & C/I \& Agri. EMS \& HDWR Rebate & Reflectors & 1.07 \\
\hline 48) & $87 \mathrm{~F}$ & 1990 & C/I \& Agri. EMS \& HDWR Rebate & Insulation & 1.28 \\
\hline 49) & $87 \mathrm{G}$ & 1990 & C/I \& Agri. EMS \& HDWR Rebate & Outdoor Lights & 0.78 \\
\hline
\end{tabular}


Table C.12 Realization Rates for all C/I/A Programs (cont'd)

\begin{tabular}{|c|c|c|c|c|c|}
\hline Obs. & Rpt. & Period & Program & Application & $\begin{array}{l}\text { RIz. } \\
\text { Rt. }\end{array}$ \\
\hline 50$)$ & $87 \mathrm{H}$ & 1990 & C/I \& Agri. EMS \& HDWR Rebate & Time Clocks & 0.93 \\
\hline 51) & $87 \mathrm{I}$ & 1990 & C/I \& Agri. EMS \& HDWR Rebate & Chemical Dishwasher & 0.33 \\
\hline 52) & $87 \mathrm{~J}$ & 1990 & C/I \& Agri. EMS \& HDWR Rebate & Flexible Barriers & 0.94 \\
\hline 53) & $87 \mathrm{~K}$ & 1990 & C/I \& Agri. EMS \& HDWR Rebate & Grouped HVAC & 0.20 \\
\hline 54) & $87 \mathrm{~L}$ & 1990 & C/I \& Agri. EMS \& HDWR Rebate & Grouped Lighting & 0.86 \\
\hline 55) & $87 \mathrm{M}$ & 1990 & C/I \& Agri. EMS \& HDWR Rebate & Grouped Process Hardware & 0.96 \\
\hline 56) & $87 \mathrm{~N}$ & 1990 & C/I \& Agri. EMS \& HDWR Rebate & Window Treatment & 1.09 \\
\hline 57) & 870 & 1990 & C/I \& Agri. EMS \& HDWR Rebate & Indoor Lamps & 0.87 \\
\hline 58) & 101 & 9/90 thru $9 / 92$ & Commercial New Construction Incen. & & 0.86 \\
\hline 59) & 162 & 1985-1989 & Non-Residential Audit Evaluation & $\mathrm{kW}$ (Total) & 0.98 \\
\hline 60) & 162 & $1985-1989$ & Non-Residential Audit Evaluation & $\mathrm{kWh}$ (Total) & 0.83 \\
\hline 61) & N/A & 1991 & Agricultrual EMS & Agricultural EMS (Therms) & 1.09 \\
\hline 62) & 0 & $1985-1989$ & Non-Residential Audit Evaluation & Therms (Total) & 0.95 \\
\hline 63) & $162 \mathrm{~A}$ & $1985-1989$ & Non-Residential Audit Evaluation & Space Cooling (kW) & 1.06 \\
\hline 64) & $162 \mathrm{~A}$ & $1985-1989$ & Non-Residential Audit Evaluation & Space Cooling (kWh) & 0.79 \\
\hline 65) & $162 \mathrm{~B}$ & $1985-1989$ & Non-Residential Audit Evaluation & Space Heating $(\mathrm{kW})$ & 0.81 \\
\hline 66) & $162 \mathrm{~B}$ & $1985-1989$ & Non-Residential Audit Evaluation & Space Heating (kWh) & 0.81 \\
\hline 67) & $162 \mathrm{~B}$ & $1985-1989$ & Non-Residential Audit Evaluation & Space Heating (Therms) & 0.95 \\
\hline 68) & $162 \mathrm{C}$ & $1985-1989$ & Non-Residential Audit Evaluation & Lighting (kWh) & 0.87 \\
\hline 69) & $162 \mathrm{C}$ & $1985-1989$ & Non-Residential Audit Evaluation & Lighting (kW) & 0.97 \\
\hline 70) & $162 \mathrm{D}$ & $1985-1989$ & Non-Residential Audit Evaluation & Motor Loand (kWh) & 0.74 \\
\hline 71$)$ & $162 \mathrm{D}$ & $1985-1989$ & Non-Residential Audit Evaluation & Motor Load (kW) & 1.12 \\
\hline 72) & $162 \mathrm{E}$ & $11 / 90-8 / 91$ & Non-Residential Audit Evaluation & Process Heating (Therms) & 0.95 \\
\hline 73) & $165 \mathrm{~A}$ & $11 / 90-8 / 91$ & C/I Lighting Retrofit & Ballast: Hybrid & 0.82 \\
\hline 74) & $165 \mathrm{~B}$ & $11 / 90-8 / 91$ & C/I Lighting Retrofit & Ballast: Electronic & 0.73 \\
\hline 75) & $165 \mathrm{C}$ & $11 / 90-8 / 91$ & C/I Lighting Retrofit & Ballast: $\mathrm{T}-8$ Electronic & 0.52 \\
\hline 76) & $165 \mathrm{D}$ & $11 / 90-8 / 91$ & C/I Lighting Retrofit & Lamp: F34 & 1.00 \\
\hline 77) & $165 \mathrm{E}$ & $11 / 90-8 / 91$ & C/I Lighting Retrofit & Lamp: F32 & 1.00 \\
\hline 78) & $165 \mathrm{~F}$ & $11 / 90-8 / 91$ & C/I Lighting Retrofit & Lamp: Delamping & 0.91 \\
\hline 79) & $165 \mathrm{G}$ & $11 / 90-8 / 91$ & C/I Lighting Retrofit & Delamp 1 + Opt. Reflectors & 0.87 \\
\hline 80) & $165 \mathrm{H}$ & $11 / 90-8 / 91$ & C/I Lighting Retrofit & Delamp 2+ Opt. Reflectors & 0.91 \\
\hline 81) & $137 \mathrm{~A}$ & 1990-1992 & High Efficiency Commercial Equipment & Cooking & 0.43 \\
\hline 82) & 137B & 1990-1992 & High Efficiency Commercial Equipment & Space Heat & 1.41 \\
\hline 83) & $137 \mathrm{C}$ & 1990-1992 & High Efficiency Commercial Equipment & Boiler & 14.54 \\
\hline 84) & 137D & $1990-1992$ & High Efficiency Commercial Equipment & Air Conditioner & 0.60 \\
\hline 85) & $137 \mathrm{E}$ & $1990-1992$ & High Efficiency Commercial Equipment & Water Heater & 1.09 \\
\hline 86) & $137 \mathrm{~F}$ & $1990-1992$ & High Efficiency Commercial Equipment & Dryer & 6.35 \\
\hline 87) & $137 \mathrm{G}$ & $1990-1992$ & High Efficiency Commercial Equipment & Weatherization & 6.72 \\
\hline 88) & $137 \mathrm{H}$ & 1990-1992 & Commercial Energy Efficiency Analyses & Audits & 1.37 \\
\hline 89) & $139 \mathrm{~A}$ & 1990-1992 & Industrial Equipment Replacement & Space Heat & 5.60 \\
\hline 90) & 139B & 1990-1992 & Industrial Equipment Replacement & Boiler & 0.11 \\
\hline 91) & $139 \mathrm{C}$ & $1990-1992$ & Industrial Equipment Replacement & Dryer & 0.24 \\
\hline 92) & 139D & $1990-1992$ & Industrial Equipment Replacement & Furnace & 0.27 \\
\hline 93) & $139 \mathrm{E}$ & $1990-1992$ & Industrial Equipment Replacement & Process Cooking & 0.66 \\
\hline 94) & 139F & $1990-1992$ & Industrial Audit & Not Applicable & 0.29 \\
\hline 95) & $139 \mathrm{G}$ & $1990-1992$ & High Efficiency New Commercial Bldg. & Not Applicable & 2.11 \\
\hline 96) & $140 \mathrm{~A}$ & $1990-1992$ & High Efficiency New Commercial Bldg. & Space Heat & 0.17 \\
\hline 97) & 140B & $1990-1992$ & High Efficiency New Commercial Bldg. & Water Heating & 4.43 \\
\hline 98) & $140 \mathrm{C}$ & $1990-1992$ & High Efficiency New Commercial Bldg. & Cooking & 0.19 \\
\hline
\end{tabular}

